System-Wide Water Resources Program

\title{
User's Guide to Linking the CE-QUAL-ICM and Ecopath Models
}

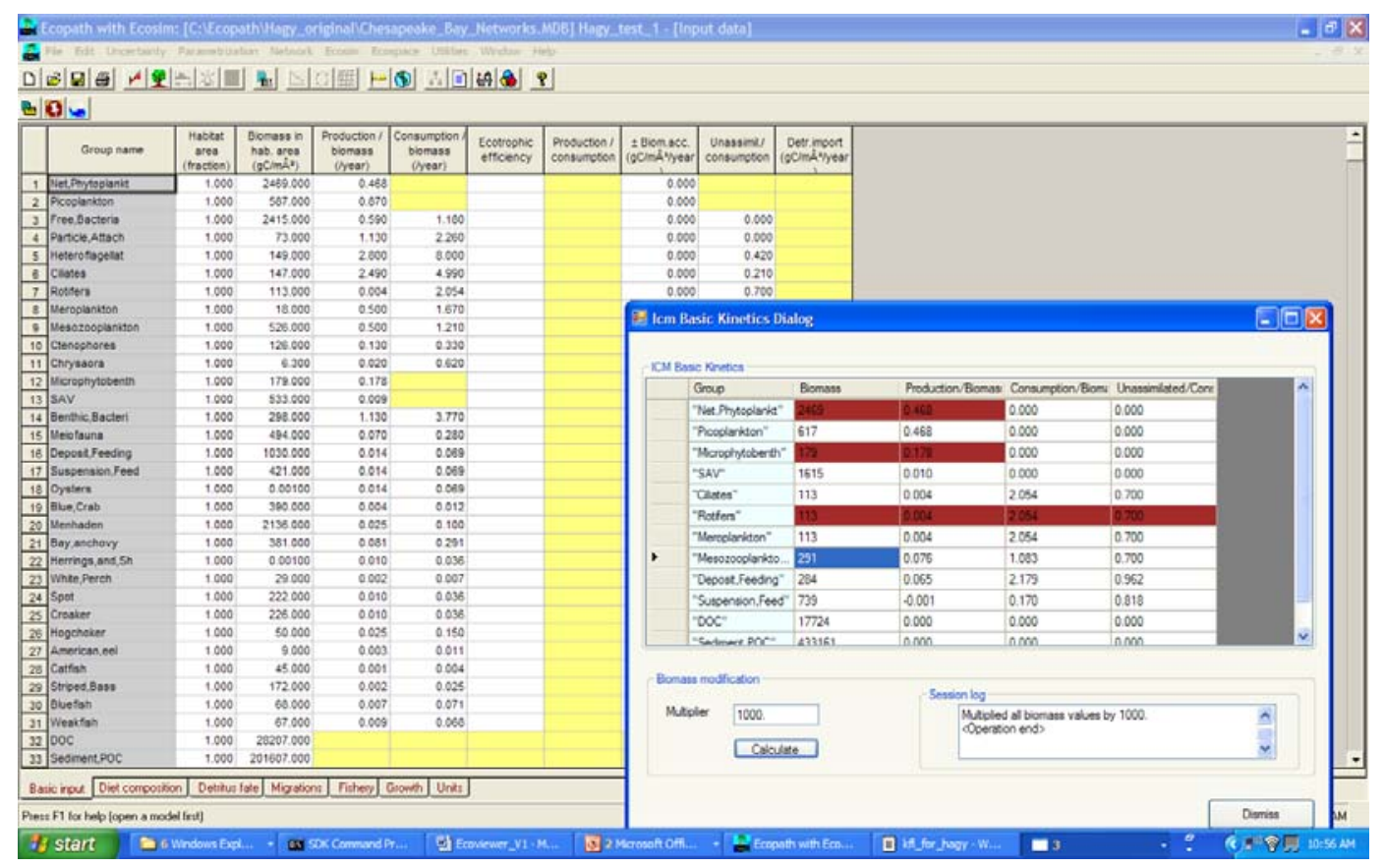




\section{User's Guide to Linking the CE-QUAL-ICM and Ecopath Models}

Carl F. Cerco, Dorothy H. Tillman, and Terry K. Gerald

Environmental Laboratory

U.S. Army Engineer Research and Development Center

3909 Halls Ferry Road

Vicksburg MS 39180-6199

Final report

Approved for public release; distribution is unlimited.

Prepared for U.S. Army Corps of Engineers

Washington, DC 20314-1000

Under System-Wide Water Resources Program 


\begin{abstract}
The present report is one of a series that documents research relating the coupling of spatially and temporally detailed eutrophication models with ecosystem models that lack spatial and temporal resolution. Specifically, the Corps of Engineers Integrated Compartment Water Quality Model (CE-QUAL-ICM) is coupled to the Ecopath with Ecosim (EWE) fisheries model. Previous reports in this series introduced the concepts necessary for communication between the two models and detailed the linkage. The previous linkage relied on a "human interface" between the two models. That is, information from CE-QUAL-ICM was printed and entered into the EWE input screen by hand. This process has been replaced by a graphical user interface (GUI), which is documented herein.
\end{abstract}

DISCLAIMER: The contents of this report are not to be used for advertising, publication, or promotional purposes. Citation of trade names does not constitute an official endorsement or approval of the use of such commercial products. All product names and trademarks cited are the property of their respective owners. The findings of this report are not to be construed as an official Department of the Army position unless so designated by other authorized documents. 


\section{Contents}

Figures and Tables..........................................................................................................................

Preface

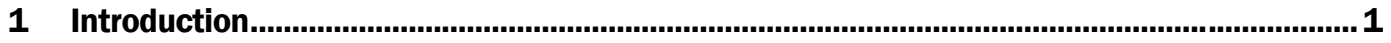

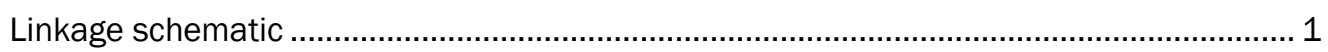

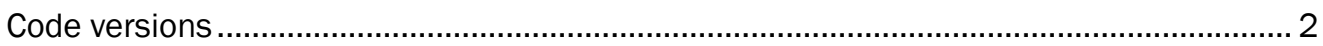

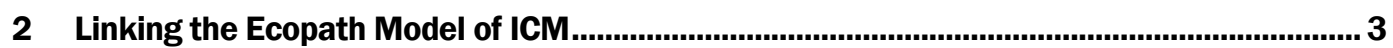

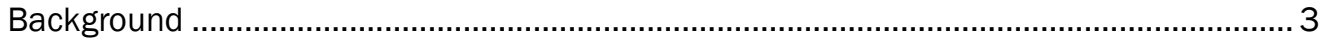

Step-by-step instructions ....................................................................................... 3

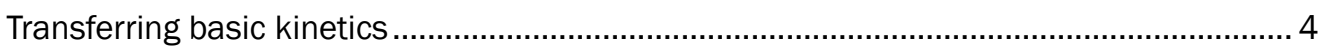

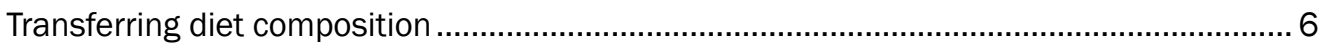

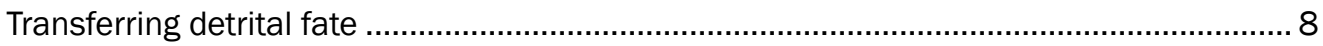

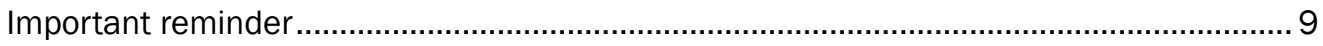

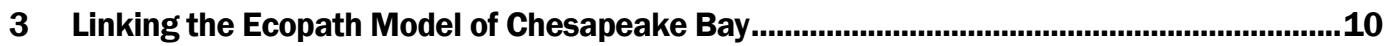

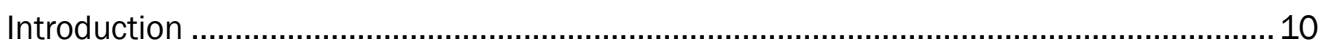

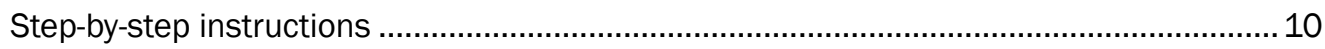

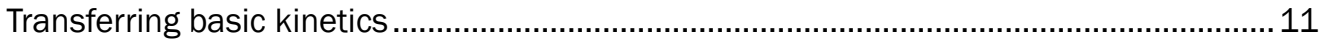

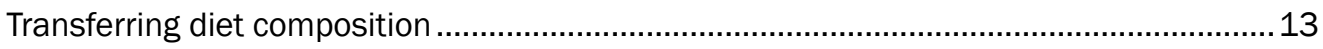

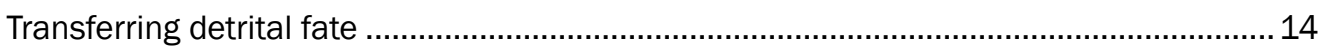

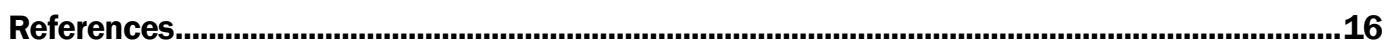

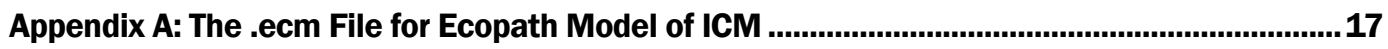

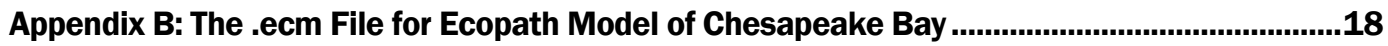

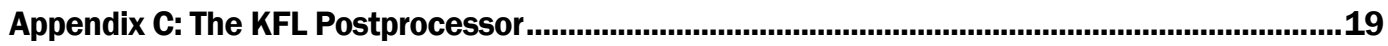

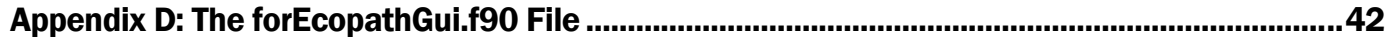

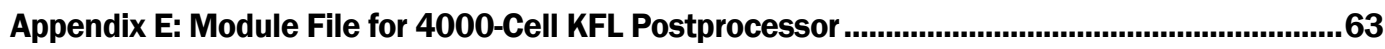

Report Documentation Page 


\section{Figures and Tables}

\section{Figures}

Figure 1. Flow chart for exchanging information between ICM and Ecopath..................................... 2

Figure 2. Linux shell to compile the KFL postprocessor. ...................................................................... 4

Figure 3. Opening the .eco and .eii files in the IcmEcoViewer GUI. .................................................. 4

Figure 4. Selecting "Basic Kinetics" information to be transferred from ICM to Ecopath................... 5

Figure 5. Ecopath after importing "Basic Kinetics" information from the "ICM Basic

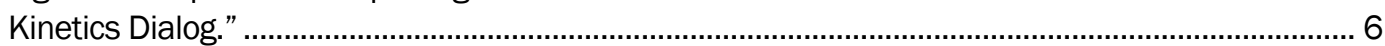

Figure 6. Selecting "Diet Composition" information to be transferred from ICM to Ecopath. ............ 7

Figure 7. Ecopath after importing "Diet Composition" information from the "ICM Diet

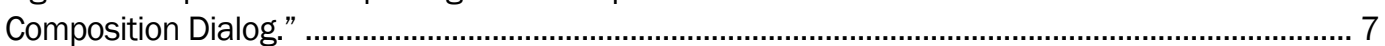

Figure 8. Selecting "Detritus Fate" information to be transferred from ICM to Ecopath..................... 8

Figure 9. Ecopath after importing "Detritus Fate" information from the "ICM Detritus Fate

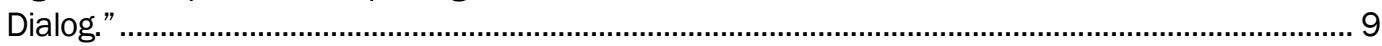

Figure 10. The "ICM Basic Kinetics Dialog" including a biomass conversion. .................................. 12

Figure 11. Ecopath model of Chesapeake Bay after importing "Basic Kinetics" information from the "ICM Basic Kinetics Dialog."

Figure 12. Selecting "Diet Composition" information to be transferred from ICM to the Ecopath model of Chesapeake Bay..

Figure 13. Ecopath model of Chesapeake Bay after importing "Diet Composition" information from the "ICM Diet Composition Dialog."

Figure 14. "Detritus Fate" information to be transferred from ICM to Ecopath model of Chesapeake Bay.

Figure 15. Ecopath model of Chesapeake Bay after importing "Detritus Fate" information from the "ICM Detritus Fate Dialog." 


\section{Preface}

This work was conducted under funding from the System Wide Water Resources Program (SWWRP). Dr. Steven L. Ashby is Program Manager of SWWRP. The work was conducted under the direction supervision of Dr. Barry W. Bunch, Chief, Water Quality and Contaminant Modeling Branch, Environmental Laboratory (EL), U. S. Army Engineer Research and Development Center (ERDC), Vicksburg, MS.

This report was prepared by Carl F. Cerco, Dorothy H. Tillman, and Terry K. Gerald of the Water Quality and Contaminant Modeling Branch, EL, ERDC. At the time of publication of this report, Dr. Beth Fleming was Director of EL.

COL Gary E. Johnston was Commander and Executive Director of ERDC. Dr. James R. Houston was Director. 


\section{Introduction}

The present report is one of a series that documents research relating the coupling of spatially and temporally detailed eutrophication models with ecosystem models that lack spatial and temporal resolution. Specifically, the Corps of Engineers Integrated Compartment Water Quality Model (CE-QUAL-ICM, Cerco and Meyers 2000) is coupled to the Ecopath with Ecosim (EWE) fisheries model (Christensen et al. 2000). Previous reports in this series introduced the concepts necessary for communication between the two models (Tillman et al. 2006) and detailed the linkage (Cerco and Tillman 2008). The previous linkage relied on a "human interface" between the two models. That is, information from CE-QUAL-ICM was printed and entered into the EWE input screen by hand. This process has been replaced by a graphical user interface (GUI), which is documented herein.

\section{Linkage schematic}

The linkage (Figure 1) relies on a number of computer executable, input, and output files. The ICM Executable is the compiled version of CEQUAL-ICM as applied to the subject water body. Ecopath is the basic steady-state, spatially averaged foundation of EWE. The ICM Executable produces a KFL Output file. The KFL Output file is a binary file that contains the information to be passed to EWE. The KFL Output file is read by a KFL Postprocessor, which is assembled from several components including the main routines, routines which relate specific versions of ICM and EWE, and modules that define variables and array sizes. The .ecm file is an ASCII file, prepared by the user, which associates variable names between ICM and Ecopath. The .eco file is produced by the KFL postprocessor and conveys information from ICM into the graphical user interface. The .eii file is an Ecopath file used for importing and exporting information. The .eco and eii files are input to the GUI, which manages the exchange of information between the two models. The GUI creates a new .eii file, which contains selected information from ICM and is read back into Ecopath. 


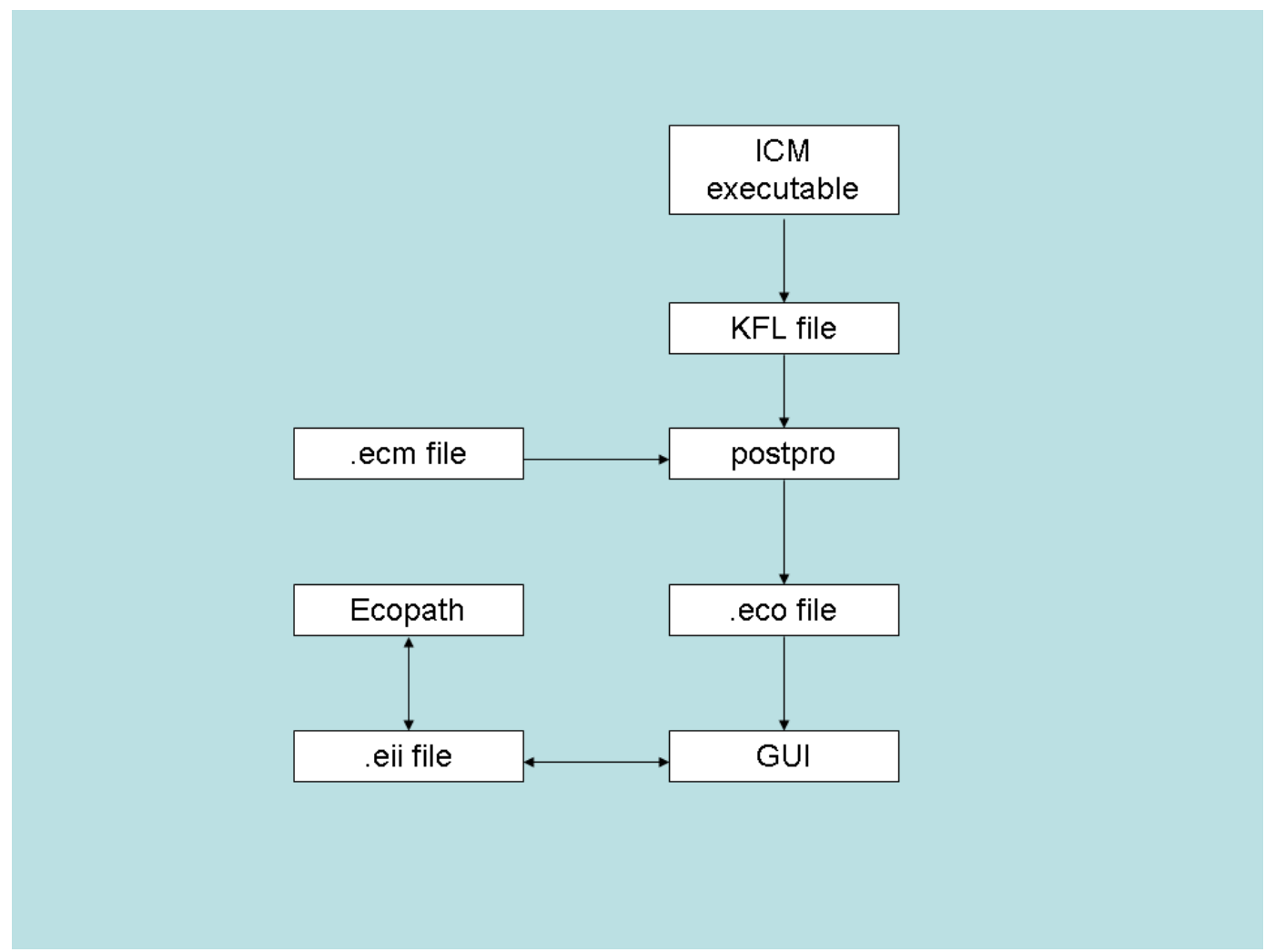

Figure 1. Flow chart for exchanging information between ICM and Ecopath.

\section{Code versions}

The version of ICM described here contains the features developed for the 2002 application to Chesapeake Bay (Cerco and Noel 2004). For development purposes, the code is applied on the 4,00o-cell grid employed in the original Chesapeake Bay application (Cerco and Cole 1994). The KFL file is a binary file that must be compatible (format, array dimensions) with the KFL postprocessor, which is coded in FORTRAN 90. EWE is version 5.1 (Christensen et al. 2000), downloaded as a Windows PC executable from the Ecopath with Ecosim web site (www.ecopath.org). The Ecopath application to Chesapeake Bay was developed by Hagy (2002) and was provided by the author. The GUI is coded in C\# and operates in the Windows PC environment. 


\section{Linking the Ecopath Model of ICM}

\section{Background}

For development and debugging purposes, an Ecopath model of the ICM carbon cycle was created. This simplified Ecopath model also provides a good introduction to the GUI.

\section{Step-by-step instructions}

1. Execute the ICM model and create a KFL file.

2. Start EWE and export an .eii file based on the model of the ICM carbon cycle.

3. The names of the .ecm and .eco files are hardwired in the KFL postprocessor. Edit file kfl_cfcs_400ocell.f and ensure the correct files are specified (ecm_input_file = 'fort.gui_400oV2.ecm', eco_output_file = 'fort.gui_400oV2.eco').

4. Compile the postprocessor (Figure 2).

5. The postprocessor opens file 'wqm_kfl.opt'. Link the KFL output file to wqm_kfl.opt. (ln -s wqm_kfl.sav_fix wqm_kfl.opt).

6. Execute the postprocessor (./postpro_400o). The postprocessor uses two auxiliary input files. File KFL_postpro_area.npt lists the surface cells in the ICM grid that are to be averaged into a single Ecopath domain. File sbox_col.dat lists the cells that underlie the surface cells listed in KFL_postpro_area.npt. The postprocessor creates two output files. File KFL_postpro_area_400o.opt is an ASCII listing of postprocessed information. This material was previously entered into Ecopath by hand. File fort.gui_400oV2.eco is the information input directly to the GUI.

7. Postprocessing is conducted on the same machine on which ICM is executed. If this machine is not the $\mathrm{PC}$ on which Ecopath is operated, the .eco file should be transferred to the PC.

8. Start the GUI by double-clicking on the IcmEcoViewer icon. Go to the "File" heading and open the ICM file (Figure 3). Go to the "File" heading again and open the EcoPath eii file. 


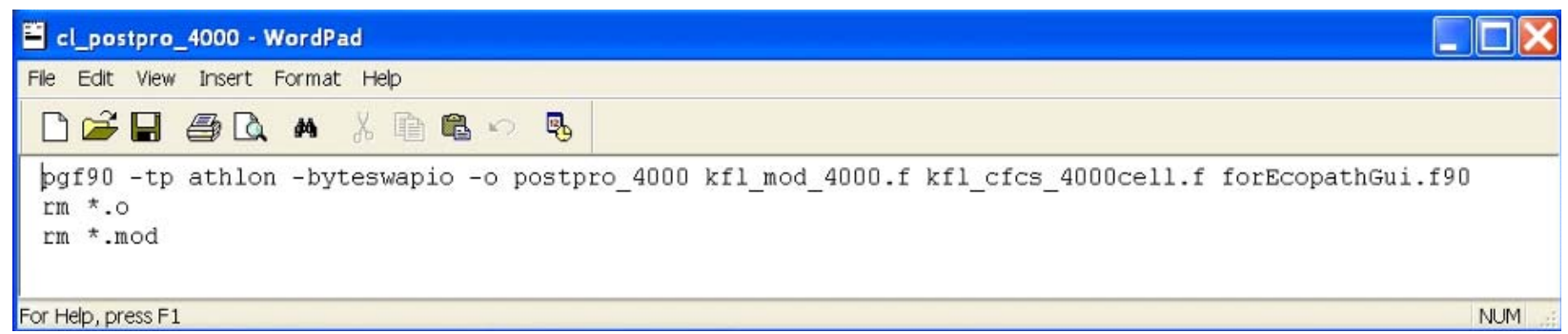

Figure 2. Linux shell to compile the KFL postprocessor.

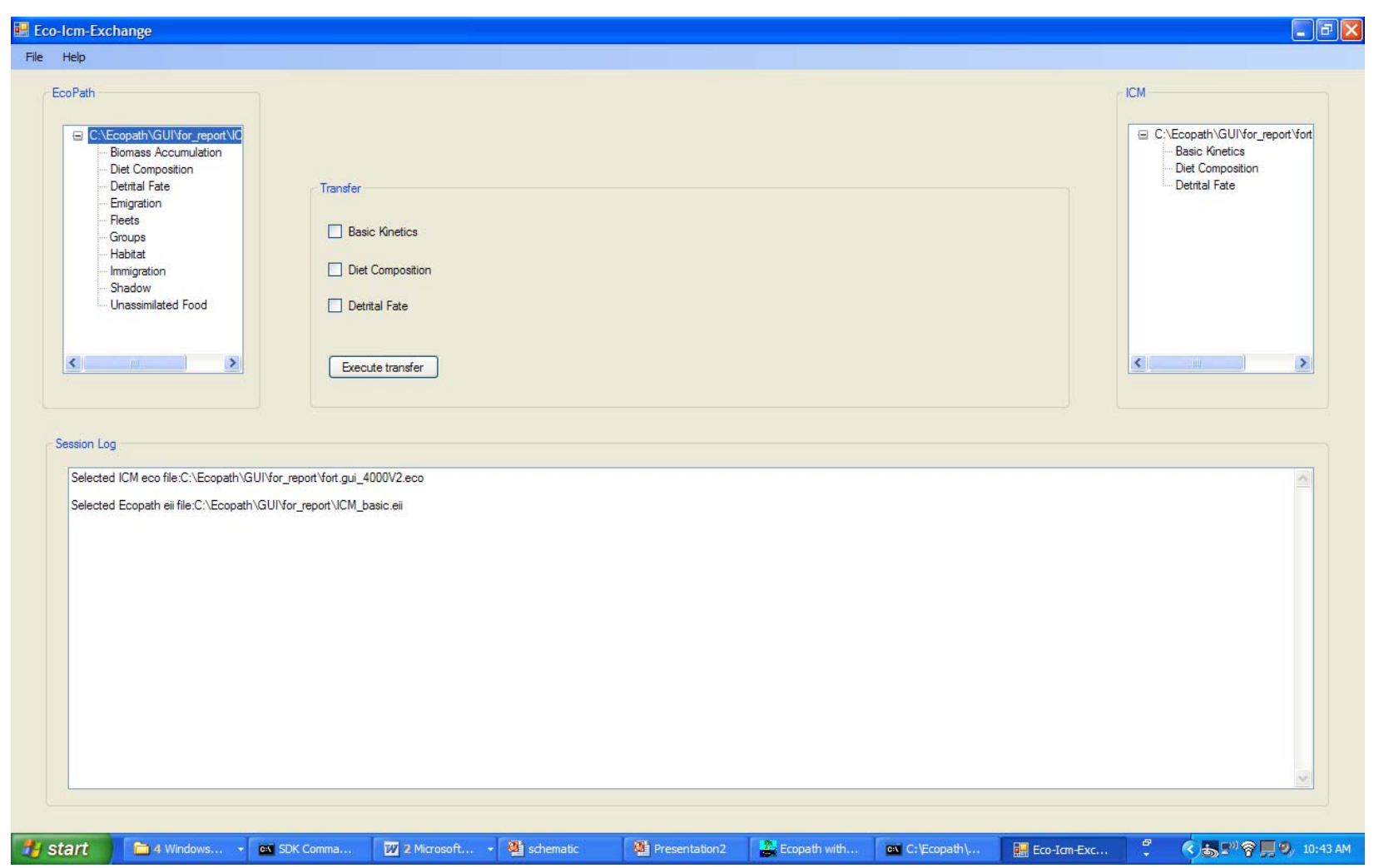

Figure 3. Opening the .eco and .eii files in the IcmEcoViewer GUI.

\section{Transferring basic kinetics}

Information may be transferred from ICM into three Ecopath screens, the Basic Kinetics screen, the Diet Composition screen, and the Detrital Fate screen. Proceed as follows to transfer information to the Ecopath Basic Kinetics screen.

1. Double-click on "Basic Kinetics" in the upper right-hand list. A screen entitled "ICM Basic Kinetics Dialog" will appear. (If not visible, look under the "Eco-Icm Exchange" window.) Double-click on the information to transfer to Ecopath. These entries will be highlighted in red (Figure 4). 
2. Click in the "Basic Kinetics" box under the "Transfer" heading.

3. Click the "Execute Transfer" bar. A "Transfer Summary Report" will appear. This report can be dismissed.

4. Click the file header and then click the "Save EcoPath eii file" option. Provide a name (such as Test_1) and click the "Save" bar.

5. Activate Ecopath and click the "File" header. Click on the "Import Text (.eii)" option and navigate to the folder where the output from the GUI is stored.

6. Open the .eii file produced by the GUI. The items selected in Step 1 should appear in the Ecopath "Basic Kinetics" screen (Figure 5).

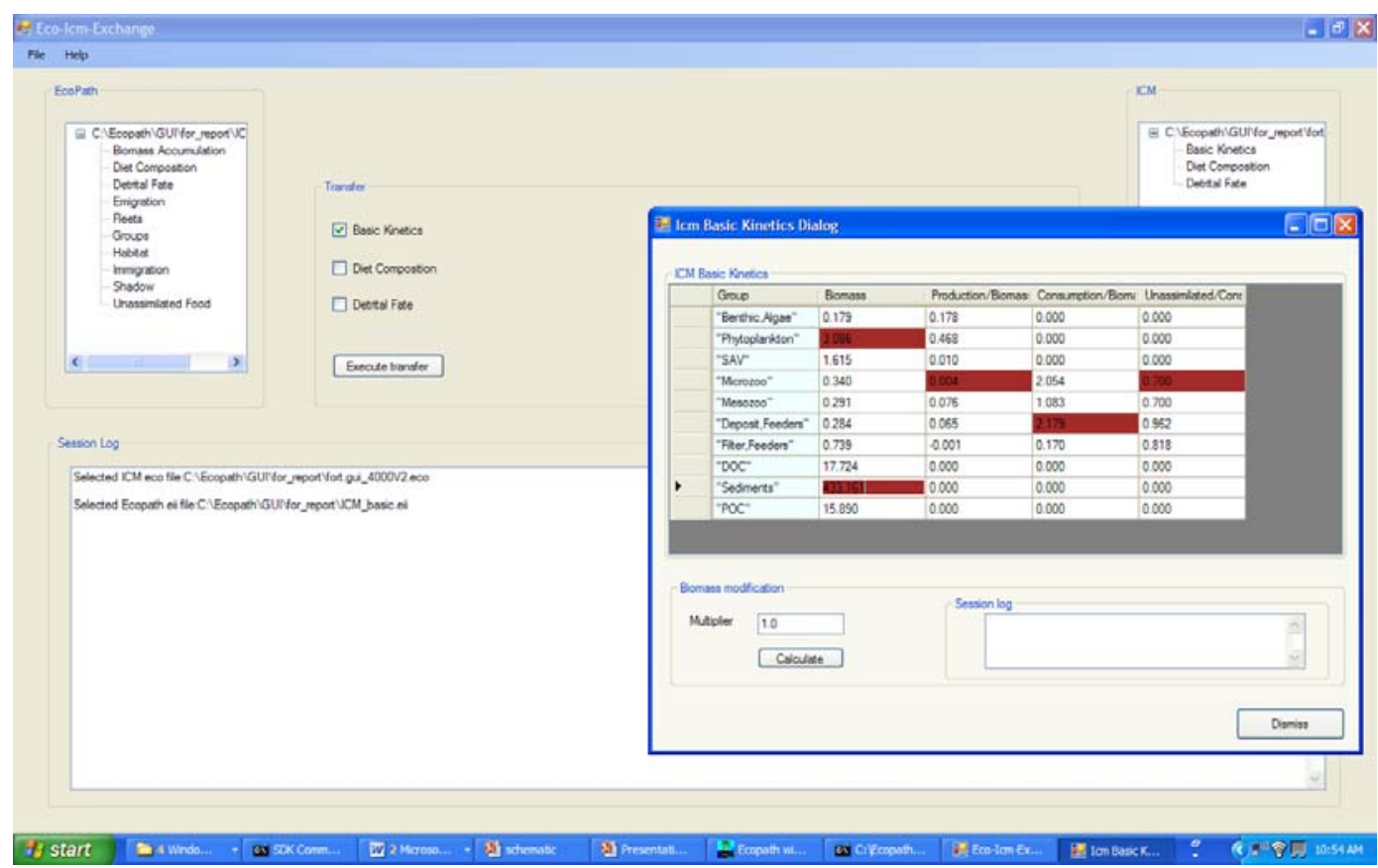

Figure 4. Selecting "Basic Kinetics" information to be transferred from ICM to Ecopath. 


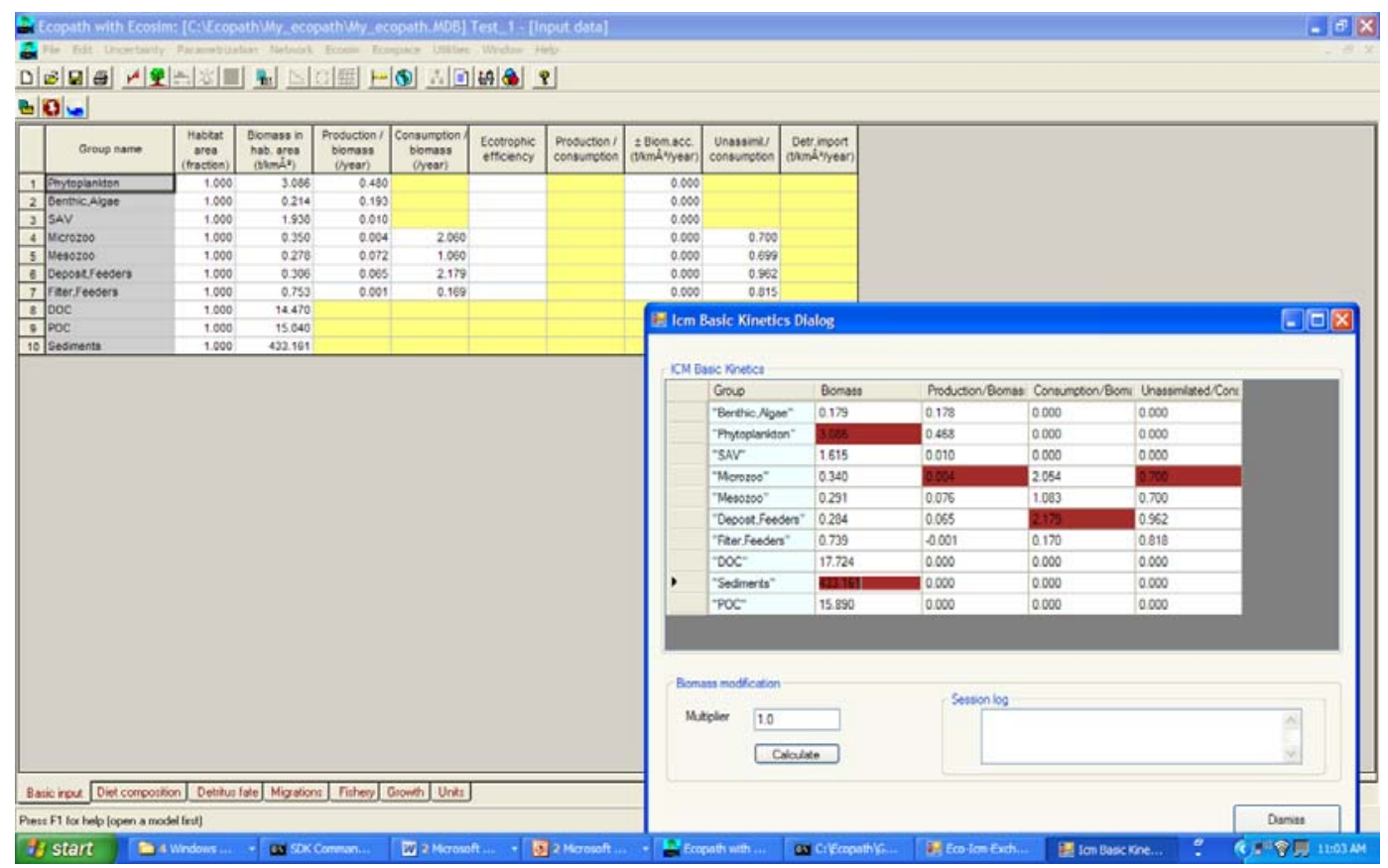

Figure 5. Ecopath after importing "Basic Kinetics" information from the "ICM Basic Kinetics Dialog."

\section{Transferring diet composition}

1. Double-click on "Diet Composition" in the upper right-hand list. A screen entitled "ICM Diet Composition Dialog" will appear. (If not visible, look under the "Eco-Icm Exchange" window.) Double-click on the information to transfer to Ecopath. These entries will be highlighted in red (Figure 6).

2. Click in the "Diet Composition" box under the "Transfer" heading.

3. Click the "Execute Transfer" bar. A "Transfer Summary Report" will appear. This report can be dismissed.

4. Click the file header and then click the "Save EcoPath eii file" option. Provide a name (such as Test_2) and click the "Save" bar.

5. Activate Ecopath and click the "File" header. Click on the "Import Text (.eii)" option and navigate to the folder where the output from the GUI is stored.

6. Open the .eii file produced by the GUI. The items selected in Step 1 should appear in the Ecopath "Diet Composition" screen (Figure 7). (Note that the screens are transposed between the GUI and Ecopath.) 


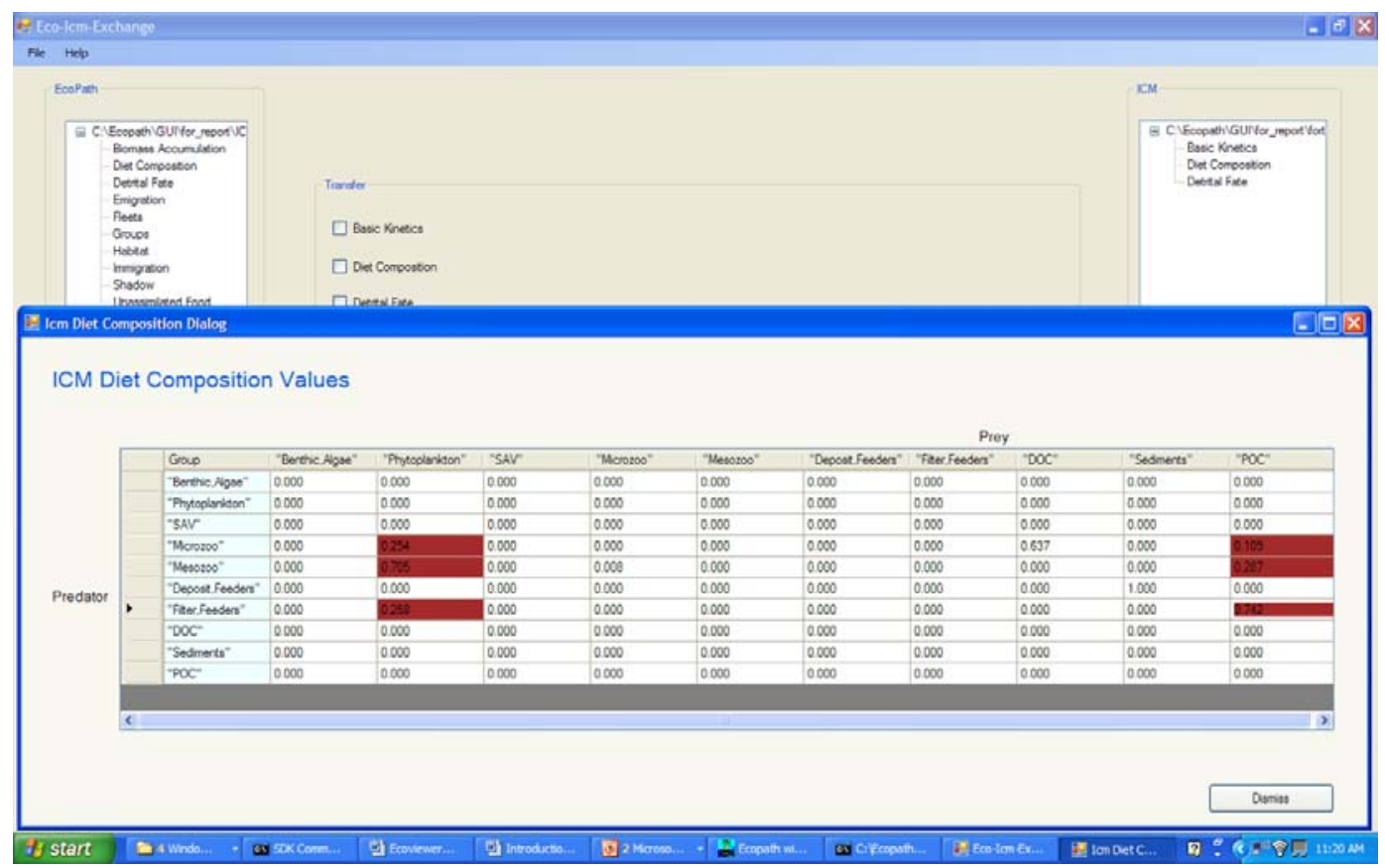

Figure 6. Selecting “Diet Composition” information to be transferred from ICM to Ecopath.

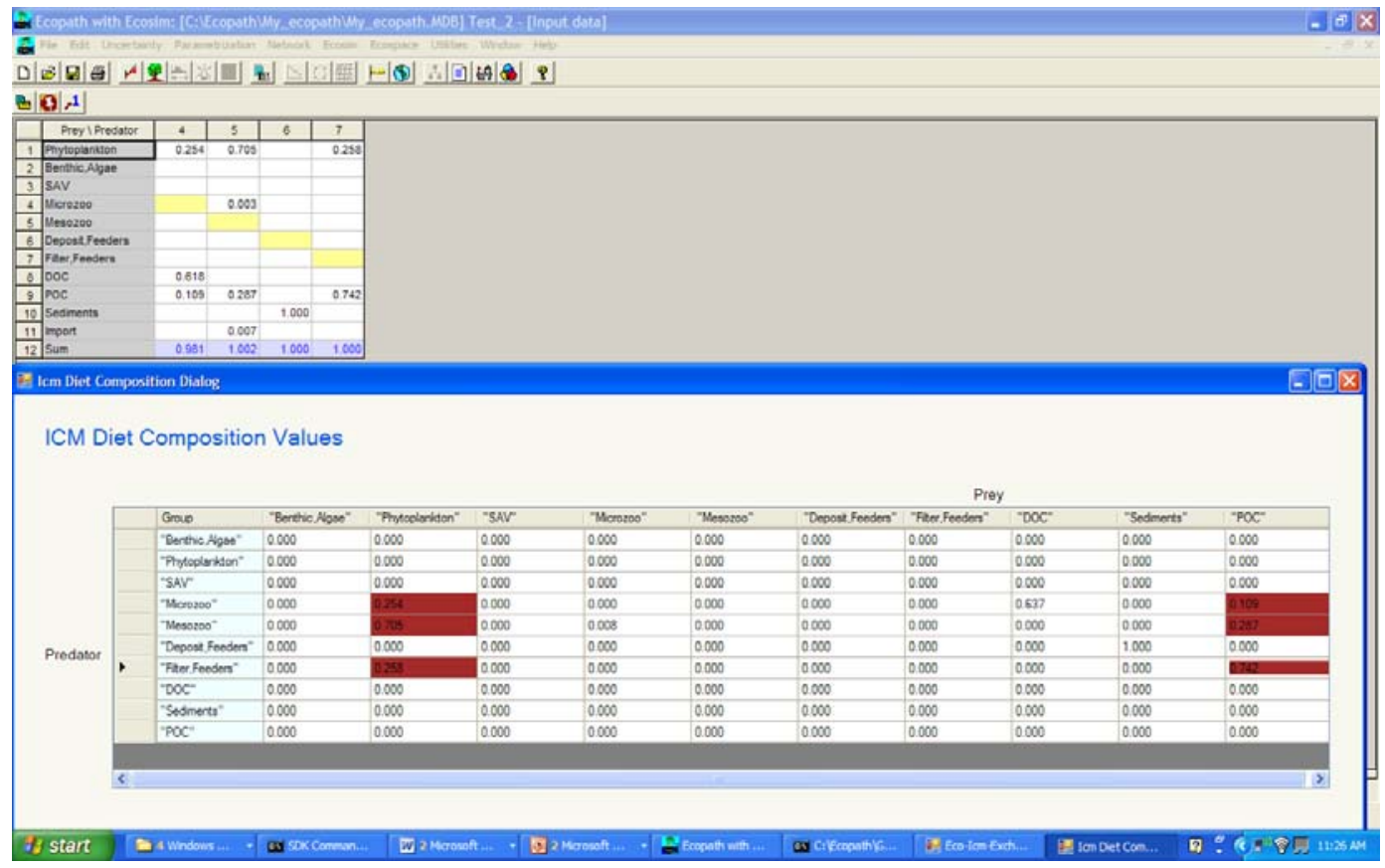

Figure 7. Ecopath after importing "Diet Composition" information from the "ICM Diet Composition Dialog." 


\section{Transferring detrital fate}

1. Double-click on "Detrital Fate" in the upper right-hand list. A screen entitled "ICM Detrital Fate Dialog" will appear. (If not visible, look under the "Eco-Icm Exchange" window.) Double-click on the information to transfer to Ecopath. These entries will be highlighted in red (Figure 8).

2. Click in the "Detrital Fate" box under the "Transfer" heading.

3. Click the "Execute Transfer" bar. A "Transfer Summary Report" will appear. This report can be dismissed.

4. Click the file header and then click the "Save EcoPath eii file" option. Provide a name (such as Test_3) and click the "Save" bar.

5. Activate Ecopath and click the "File" header. Click on the "Import Text (.eii)" option and navigate to the folder where the output from the GUI is stored.

6. Open the .eii file produced by the GUI. The items selected in Step 1 should appear in the Ecopath "Detritus Fate" screen (Figure 9). (Note that the columns are ordered differently in the GUI and Ecopath.)

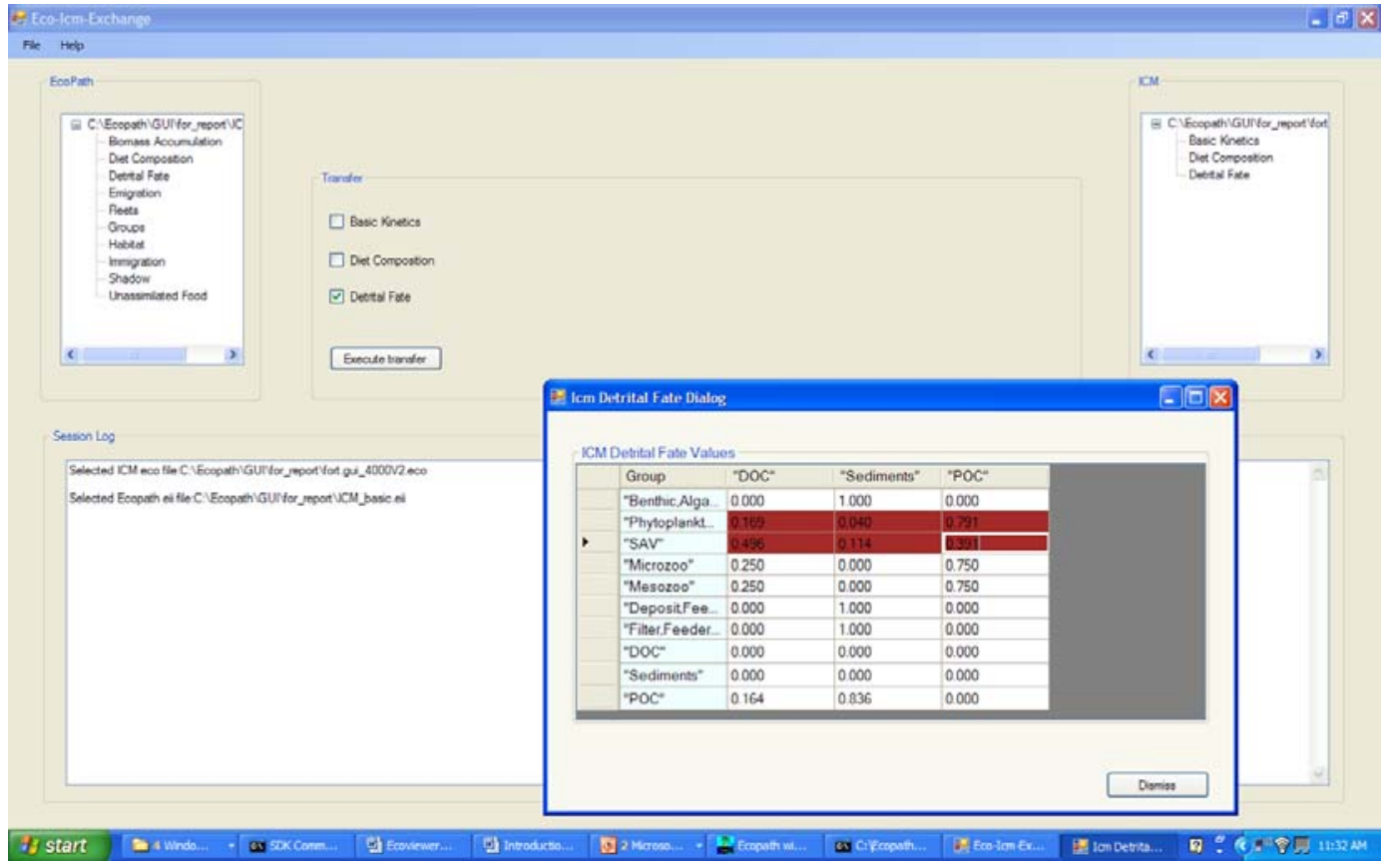

Figure 8. Selecting “Detritus Fate” information to be transferred from ICM to Ecopath. 


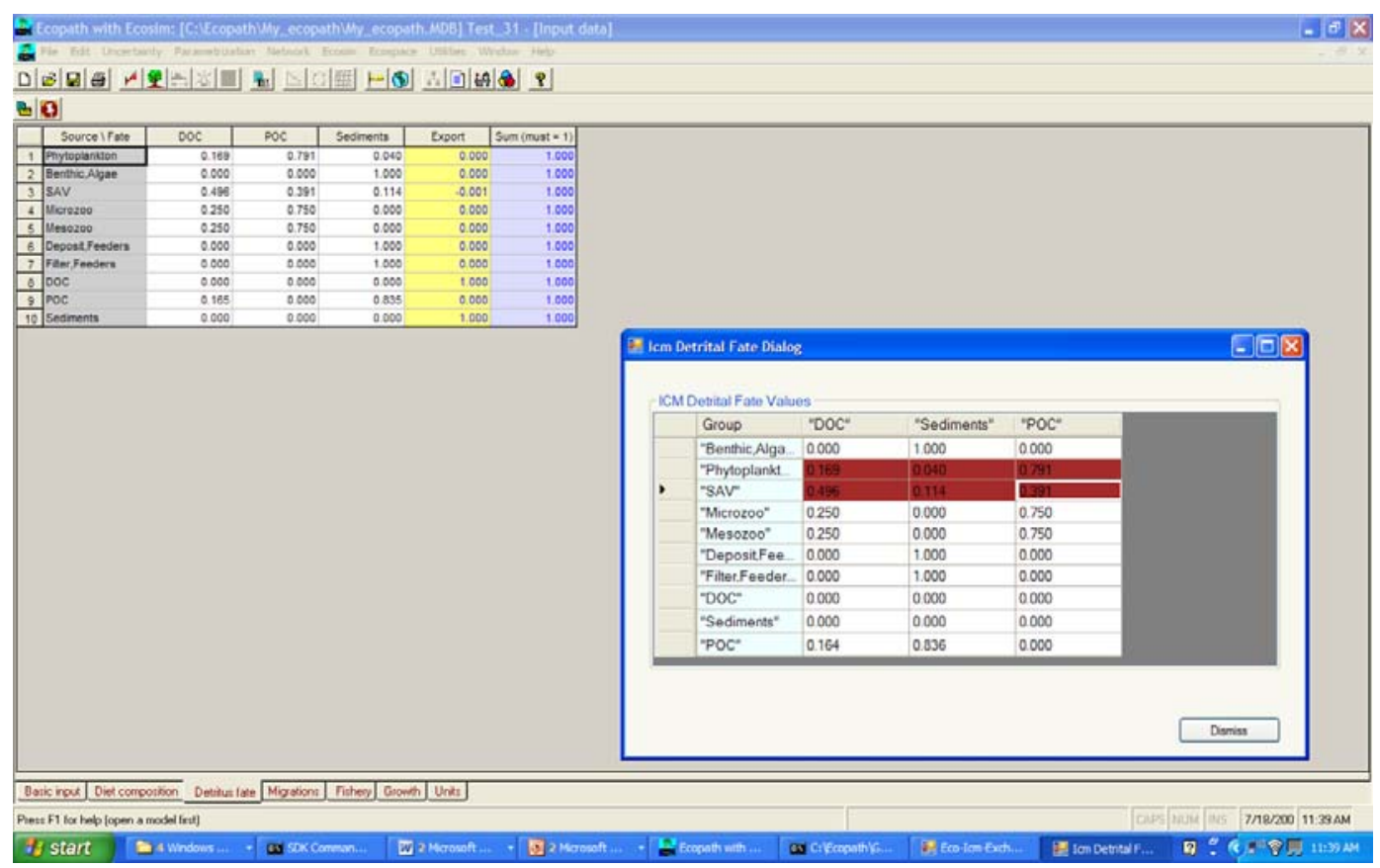

Figure 9. Ecopath after importing "Detritus Fate" information from the "ICM Detritus Fate Dialog."

\section{Important reminder}

Application of the Ecopath model largely amounts to balancing diet composition and other parameters such that a balance is attained and all "Ecotrophic Efficiencies" remain less than unity. If the Ecopath application is balanced prior to importing information from ICM, the application will likely have to be re-balanced after new information is imported. When an .eii file is saved, an "Important Reminder" message appears which cautions the user to check mass balances when returning to Ecopath. Clicking the "OK" bar will dismiss the reminder. 


\section{Linking the Ecopath Model of Chesapeake Bay}

\section{Introduction}

For operational purposes, ICM is linked to an Ecopath model of Chesapeake Bay (Hagy 2002). Transferring information largely follows the procedure outlined in Chapter 2 with a few exceptions necessitated by differences in state variables and units between ICM and Ecopath. ICM represents the summer phytoplankton population in Chesapeake Bay as a single group. Ecopath employs two groups: Picoplankton and Net Phytoplankton. During the transfer process the ICM phytoplankton biomass is split 80 percent Net Phytoplankton and 20 percent Picoplankton. Production-to-biomass ratios and other parameters from the single ICM group are used for both Ecopath groups. ICM employs a single microzooplankton group, while Ecopath has three: Ciliates, Rotifers, and Meroplankton. The biomass of the single ICM group is split equally into the three Ecopath groups. Production-to-biomass ratios and other parameters from the single ICM group are used for all three Ecopath groups. These splits are specified in the .ecm file (kfl_for_hagy.ecm). The ICM biomass unit is $\mathrm{g} \mathrm{C}$ while Ecopath employs $\mathrm{mg} \mathrm{C}$. The units conversion is specified in the GUI as explained below.

\section{Step-by-step instructions}

1. Execute the ICM model and create a KFL file.

2. Start EWE and export an .eii file based on the model of Chesapeake Bay.

3. The names of the .ecm and .eco files are hardwired in the KFL postprocessor. Edit file kfl_cfcs_40oocell.f and ensure the correct files are specified (ecm_input_file = 'hagyV2.ecm', eco_output_file $=$ 'hagyV2.eco')

4. Compile the postprocessor (Figure 2).

5. The postprocessor opens file 'wqm_kfl.opt'. Link the KFL output file to wqm_kfl.opt. (ln -s wqm_kfl.sav_fix wqm_kfl.opt).

6. Execute the postprocessor (./postpro_400o). The postprocessor uses two auxiliary input files. File KFL_postpro_area.npt lists the surface cells in the ICM grid that are to be averaged into a single Ecopath domain. File sbox_col.dat lists the cells that underlie the surface cells 
listed in KFL_postpro_area.npt. The postprocessor creates two output files. File KFL_postpro_area_400o.opt is an ASCII listing of postprocessed information. This material was previously entered into Ecopath by hand. File hagyV2.eco is the information input directly to the GUI.

7. Postprocessing is conducted on the same machine on which ICM is executed. If this machine is not the PC on which Ecopath is operated, the .eco file should be transferred to the PC.

8. Start the GUI by double-clicking on the IcmEcoViewer icon. Go to the "File" heading and open the ICM file (Figure 3). Go to the "File" heading again and open the EcoPath eii file.

\section{Transferring basic kinetics}

Proceed as follows to transfer information to the Ecopath Basic Kinetics screen.

1. Double-click on "Basic Kinetics" in the upper right-hand list (Figure 4). A screen entitled "ICM Basic Kinetics Dialog" will appear. (If not visible, look under the "Eco-Icm Exchange" window.) Double-click on the information to transfer to Ecopath. These entries will be highlighted in red.

2. A box entitled "Biomass Multiplier" is situated in the lower left of the "ICM Basic Kinetics Dialog." Enter 1000 to convert g C to $\mathrm{mg} \mathrm{C}$ and click the "Calculate" button (Figure 10).

3. Click in the "Basic Kinetics" box under the "Transfer" heading.

4. Click the "Execute Transfer" bar. A "Transfer Summary Report" will appear. This report can be dismissed.

5. Click the file header and then click the "Save EcoPath eii file" option. Provide a name (such as Test_1) and click the "Save" bar.

6. Activate Ecopath and click the "File" header. Click on the "Import Text (.eii)" option and navigate to the folder where the output from the GUI is stored.

7. Open the .eii file produced by the GUI. The items selected in Step 1 should appear in the Ecopath "Basic Kinetics" screen (Figure 11). 


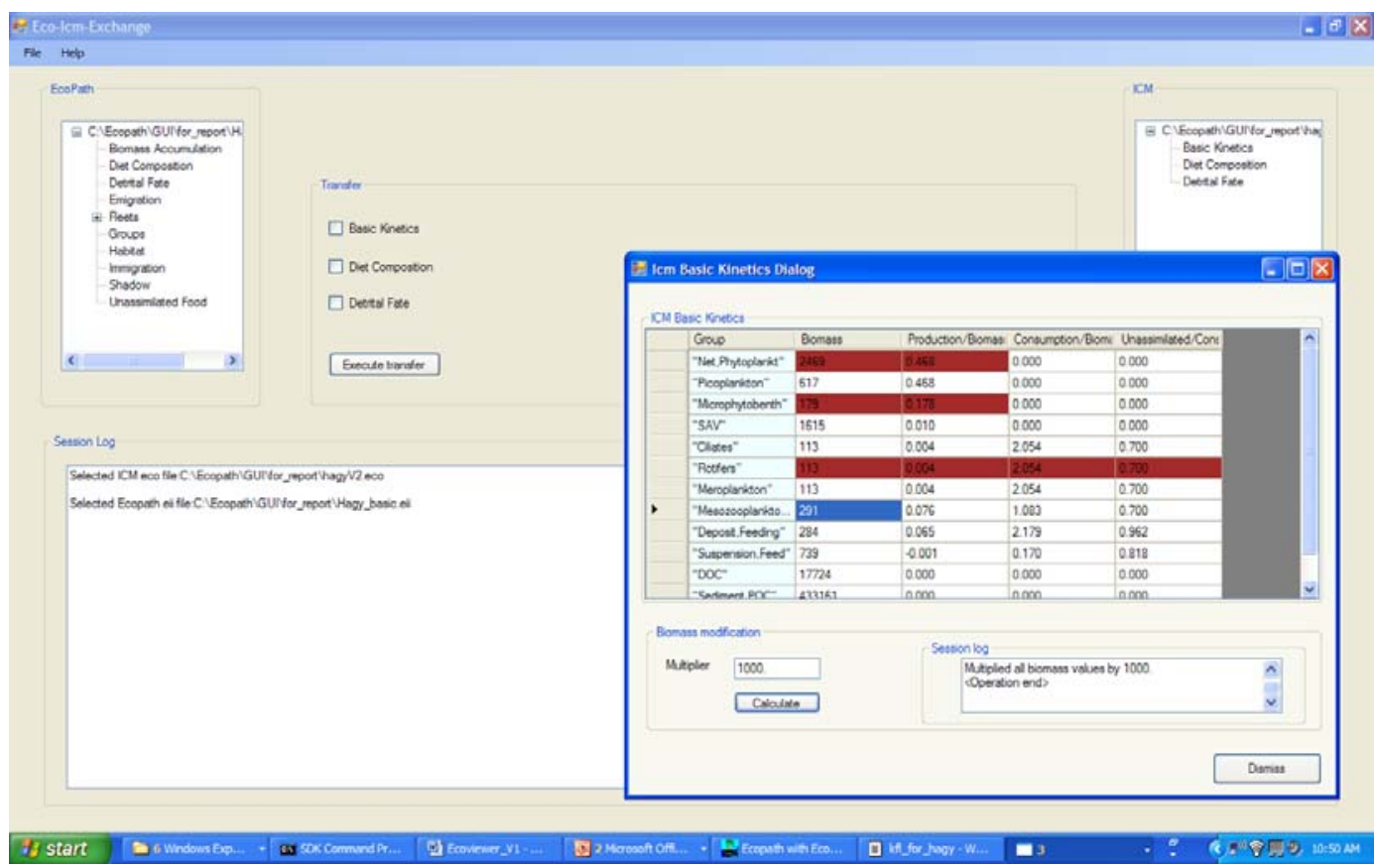

Figure 10. The “ICM Basic Kinetics Dialog” including a biomass conversion.

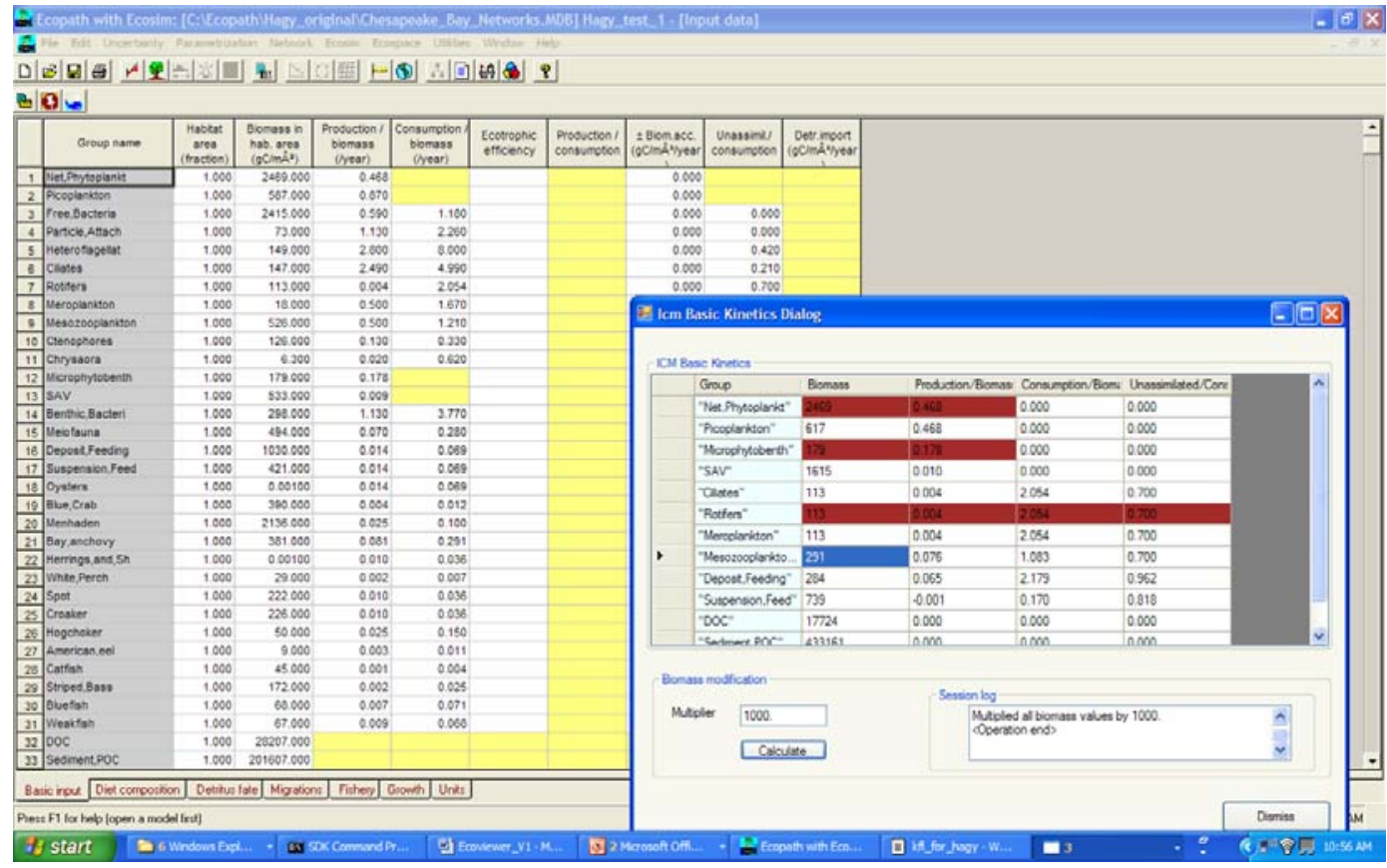

Figure 11. Ecopath model of Chesapeake Bay after importing "Basic Kinetics" information from the "ICM Basic Kinetics Dialog." 


\section{Transferring diet composition}

1. Double-click on "Diet Composition" in the upper right-hand list. A screen entitled "ICM Diet Composition Dialog" will appear. (If not visible, look under the "Eco-Icm Exchange" window.) Double-click on the information to transfer to Ecopath. These entries will be highlighted in red (Figure 12).

2. Click in the "Diet Composition" box under the "Transfer" heading.

3. Click the "Execute Transfer" bar. A "Transfer Summary Report" will appear. This report can be dismissed.

4. Click the file header and then click the "Save EcoPath eii file" option. Provide a name (such as Test_2) and click the "Save" bar.

5. Activate Ecopath and click the "File" header. Click on the "Import Text (.eii)" option and navigate to the folder where the output from the GUI is stored.

6. Open the .eii file produced by the GUI. The items selected in Step 1 should appear in the Ecopath "Diet Composition" screen (Figure 13). (Note that the screens are transposed between the GUI and Ecopath.)

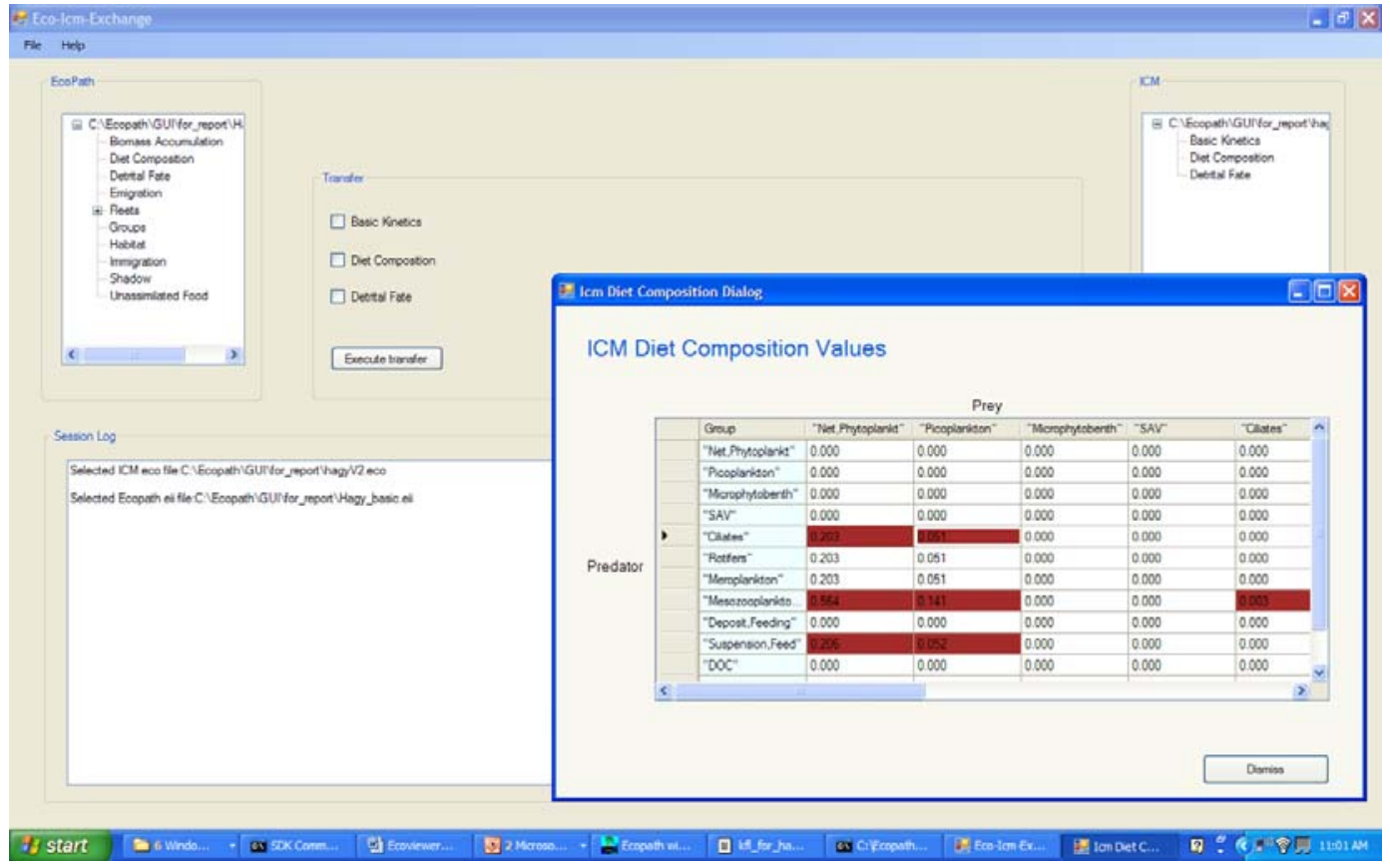

Figure 12. Selecting "Diet Composition" information to be transferred from ICM to the Ecopath model of Chesapeake Bay. 


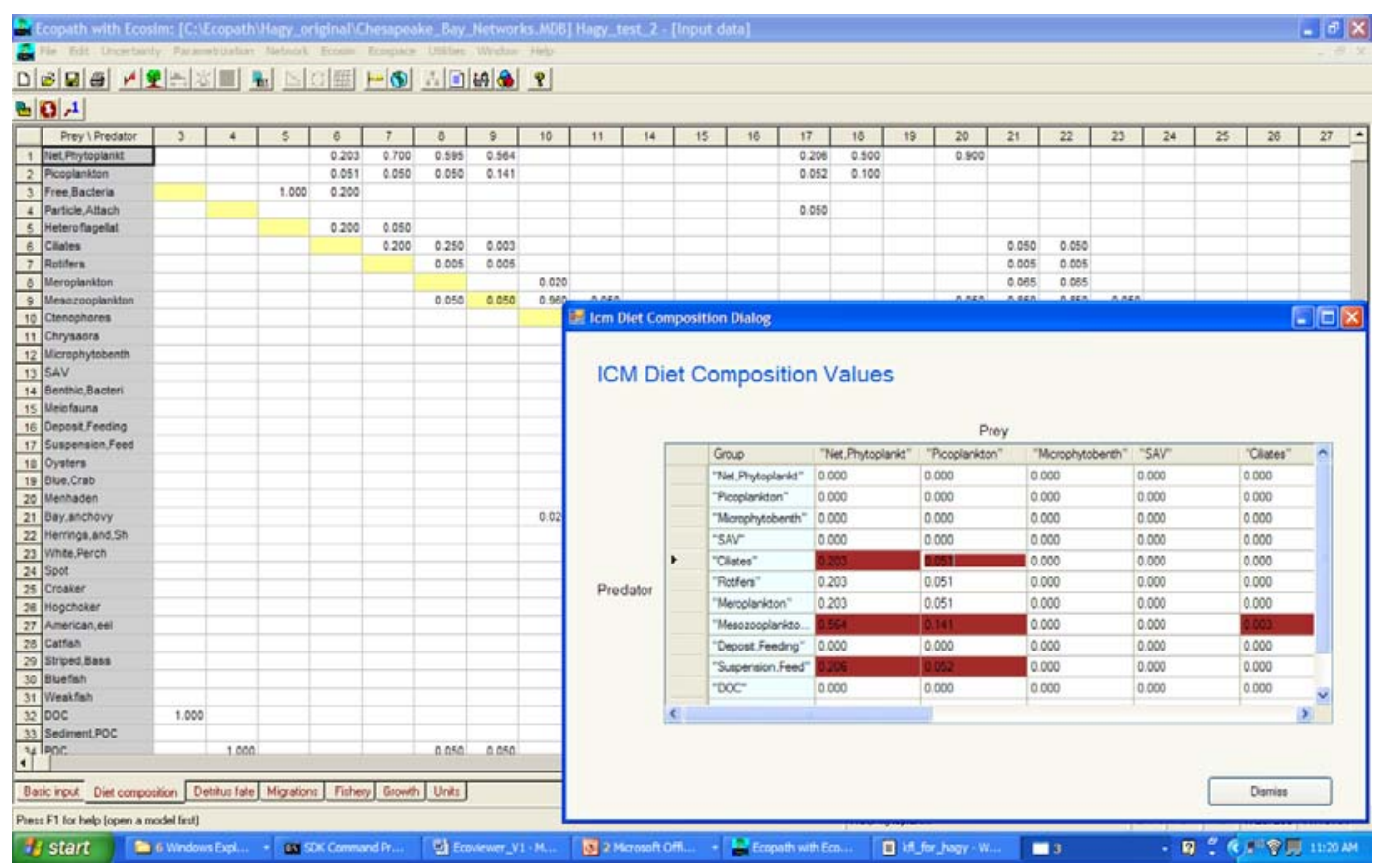

Figure 13. Ecopath model of Chesapeake Bay after importing "Diet Composition" information from the "ICM Diet Composition Dialog."

\section{Transferring detrital fate}

1. Double-click on "Detrital Fate" in the upper right-hand list. A screen entitled "ICM Detrital Fate Dialog" will appear. (If not visible, look under the "Eco-Icm Exchange" window.) Double-click on the information to transfer to Ecopath. These entries will be highlighted in red (Figure 14).

2. Click in the "Detrital Fate" box under the "Transfer" heading.

3. Click the "Execute Transfer" bar. A "Transfer Summary Report" will appear. This report can be dismissed.

4. Click the file header and then click the "Save EcoPath eii file" option. Provide a name (such as Test_3) and click the "Save" bar.

5. Activate Ecopath and click the "File" header. Click on the "Import Text (.eii)" option and navigate to the folder where the output from the GUI is stored.

6. Open the .eii file produced by the GUI. The items selected in Step 1 should appear in the Ecopath "Detritus Fate" screen (Figure 15). (Note that the columns are ordered differently in the GUI and Ecopath.) 


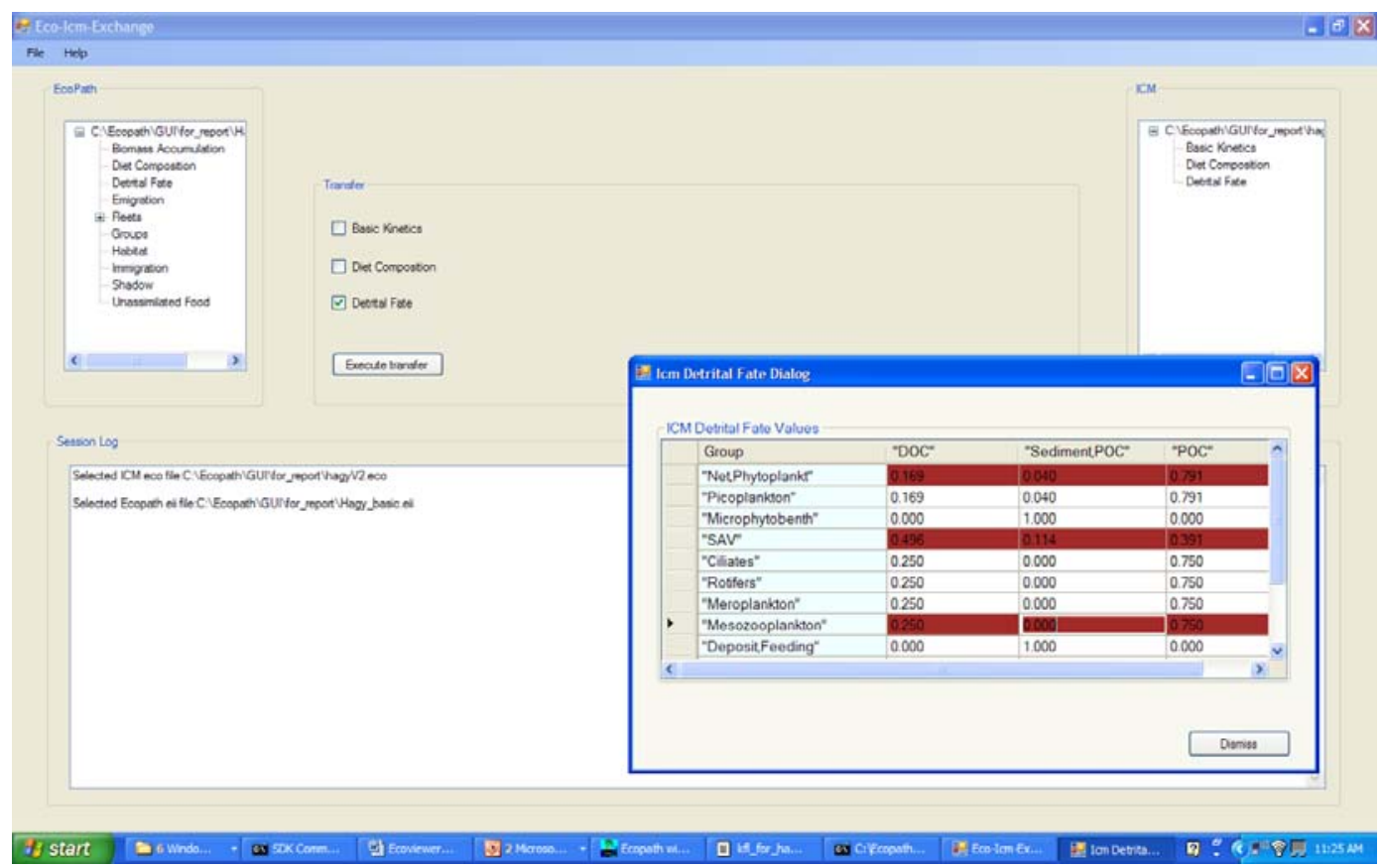

Figure 14. "Detritus Fate" information to be transferred from ICM to Ecopath model of Chesapeake Bay.

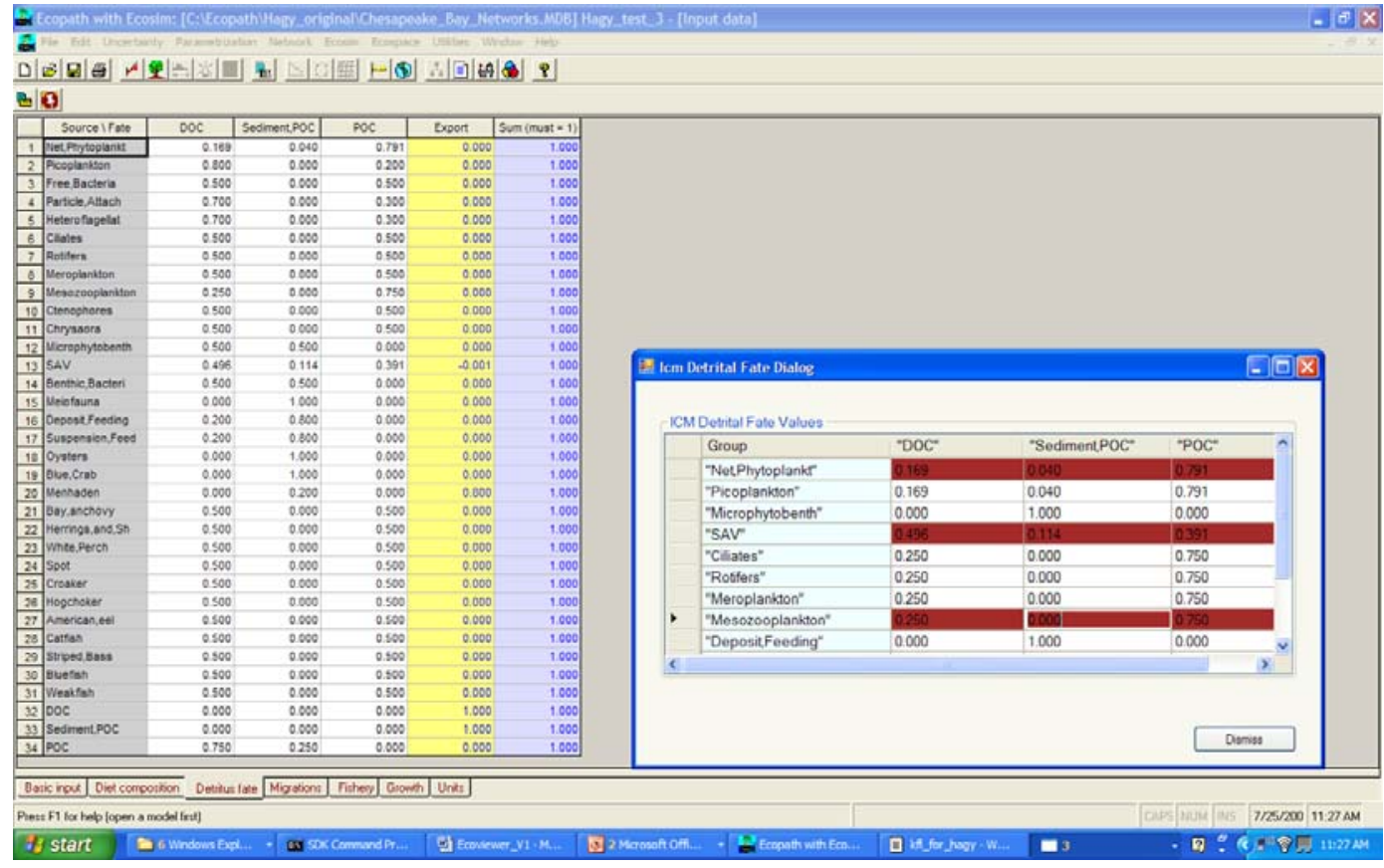

Figure 15. Ecopath model of Chesapeake Bay after importing "Detritus Fate” information from the "ICM Detritus Fate Dialog." 


\section{References}

Cerco, C., and T. Cole. 1994. Three-dimensional eutrophication model of Chesapeake Bay. Technical Report EL-94-4. Vicksburg, MS: U.S. Army Engineer Waterways Experiment Station.

Cerco, C., and M. Meyers. 2000. Tributary refinements to the Chesapeake Bay model. Journal of Environmental Engineering 126(2): 164-174.

Cerco, C., and M. Noel. 2004. The 2002 Chesapeake Bay eutrophication model. EPA 903-R-04-004. Annapolis, MD: Chesapeake Bay Program Office, U.S. Environmental Protection Agency.

Cerco, C., and D. Tillman. 2008. Use of coupled eutrophication and network models for examination of fisheries and eutrophication processes. ERDC/EL TR-08-10. Vicksburg, MS: U.S. Army Engineer Research and Development Center.

Christensen, V., C. Walters, and D. Pauly. 2000. Ecopath with Ecosim: A user's guide. Fisheries Centre, University of British Columbia.

Hagy, J. 2002. Eutrophication, hypoxia and trophic transfer efficiency in Chesapeake Bay. PhD diss., University of Maryland Center for Environmental Science, Horn Point.

Tillman, D., C. Cerco, and M. Noel. 2006. Conceptual processes for linking eutrophication and network models. TN-SWWRP-0905. Vicksburg MS: U.S. Army Engineer Research and Development Center. 


\section{Appendix A: The .ecm File for Ecopath Model of ICM}

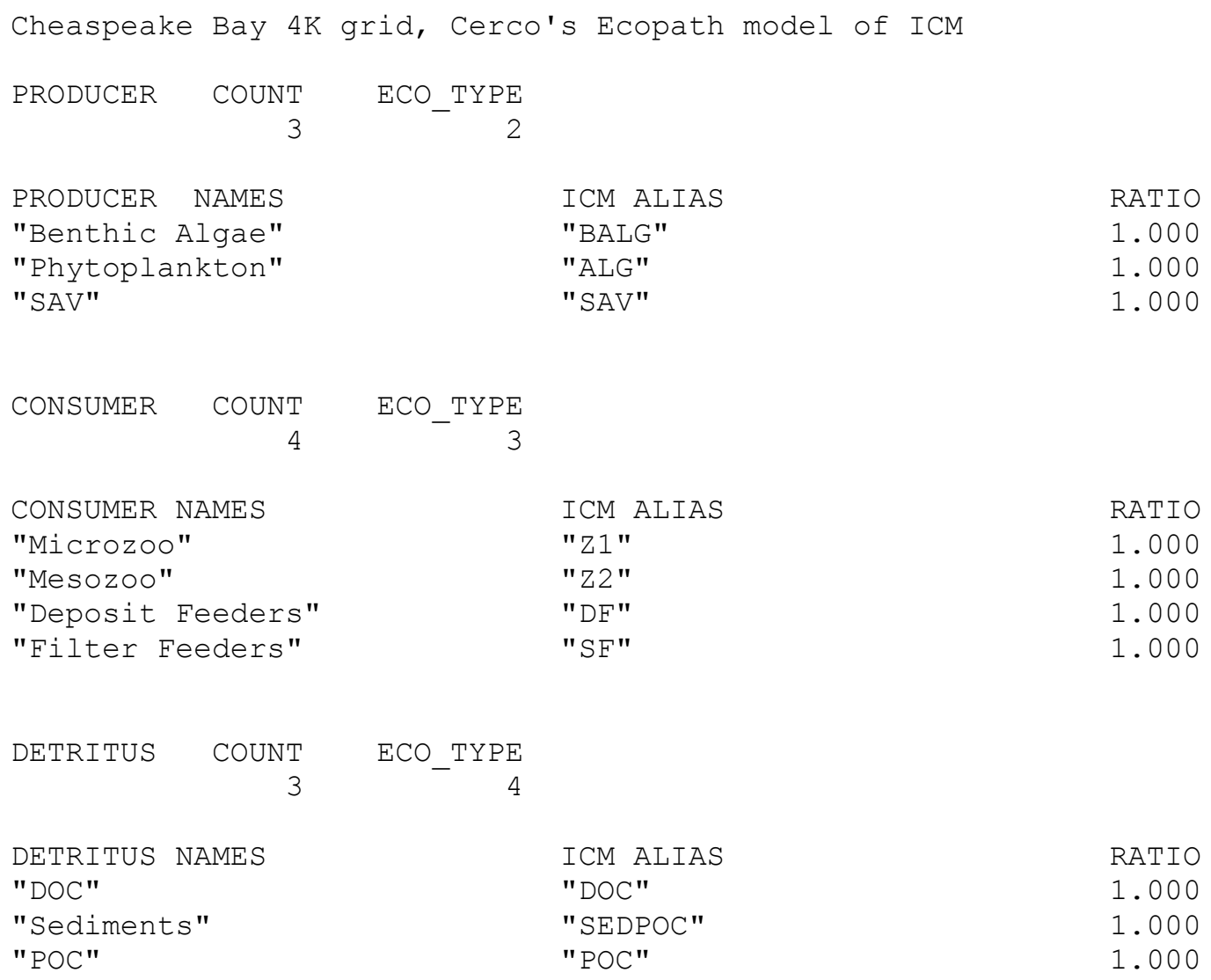




\section{Appendix B: The .ecm File for Ecopath Model of Chesapeake Bay}

\begin{tabular}{|c|c|c|}
\hline $\begin{array}{rr}\text { PRODUCER } & \text { COUNT } \\
& 4\end{array}$ & $\begin{array}{r}\mathrm{ECO} \text { TYPE } \\
2\end{array}$ & \\
\hline $\begin{array}{l}\text { PRODUCER NAMES } \\
\text { "Net, Phytoplankt" } \\
\text { "Picoplankton" } \\
\text { "Microphytobenth" } \\
\text { "SAV" }\end{array}$ & $\begin{array}{l}\text { ICM ALIAS } \\
\text { "ALG" } \\
\text { "ALG" } \\
\text { "BALG" } \\
\text { "SAV" }\end{array}$ & $\begin{array}{l}\text { RATIO } \\
0.8 \\
0.2 \\
1.000 \\
1.000\end{array}$ \\
\hline $\begin{array}{lr}\text { CONSUMER } & \text { COUNT } \\
& 6\end{array}$ & $\begin{array}{r}\mathrm{ECO}{ }_{-}^{\mathrm{TYPE}} \\
3\end{array}$ & \\
\hline $\begin{array}{l}\text { CONSUMER NAMES } \\
\text { "Ciliates" } \\
\text { "Rotifers" } \\
\text { "Meroplankton" } \\
\text { "Mesozooplankton" } \\
\text { "Deposit, Feeding" } \\
\text { "Suspension, Feed" }\end{array}$ & $\begin{array}{l}\text { ICM ALIAS } \\
\text { "Z1" } \\
\text { "Z1" } \\
\text { "Z1" } \\
\text { "Z2" } \\
\text { "DF" } \\
\text { "SF" }\end{array}$ & $\begin{array}{l}\text { RATIO } \\
0.333 \\
0.333 \\
0.333 \\
1.000 \\
1.000 \\
1.000\end{array}$ \\
\hline $\begin{array}{lr}\text { DETRITUS } & \text { COUNT } \\
& 3\end{array}$ & $\begin{array}{r}\mathrm{ECO} \text { TYPE } \\
4\end{array}$ & \\
\hline $\begin{array}{l}\text { DETRITUS NAMES } \\
\text { "DOC" } \\
\text { "Sediment POC" } \\
\text { "POC" }\end{array}$ & $\begin{array}{l}\text { ICM ALIAS } \\
\text { "DOC" } \\
\text { "SEDPOC" } \\
\text { "POC" }\end{array}$ & $\begin{array}{l}\text { RATIO } \\
1.000 \\
1.000 \\
1.000\end{array}$ \\
\hline
\end{tabular}




\section{Appendix C: The KFL Postprocessor}

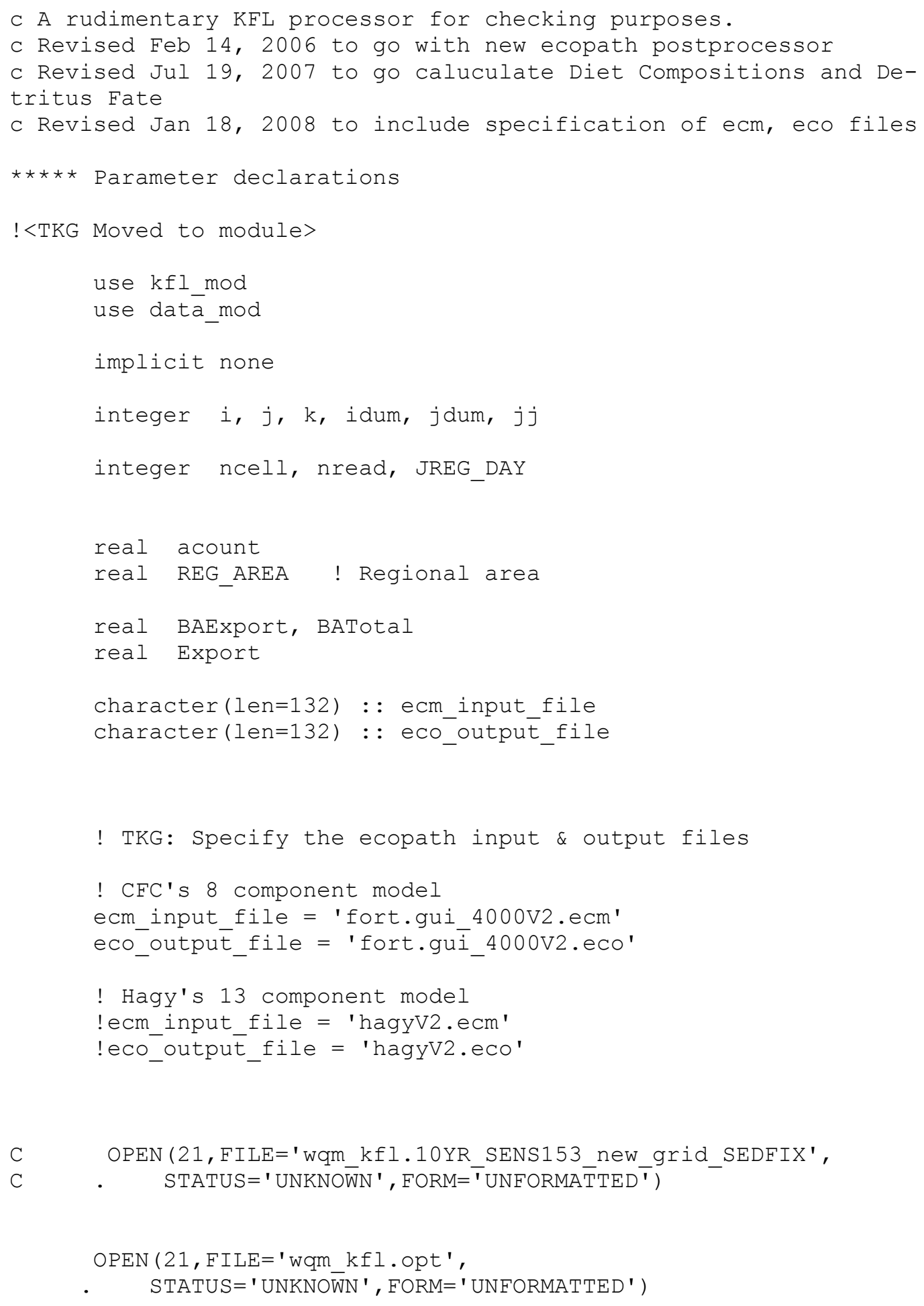




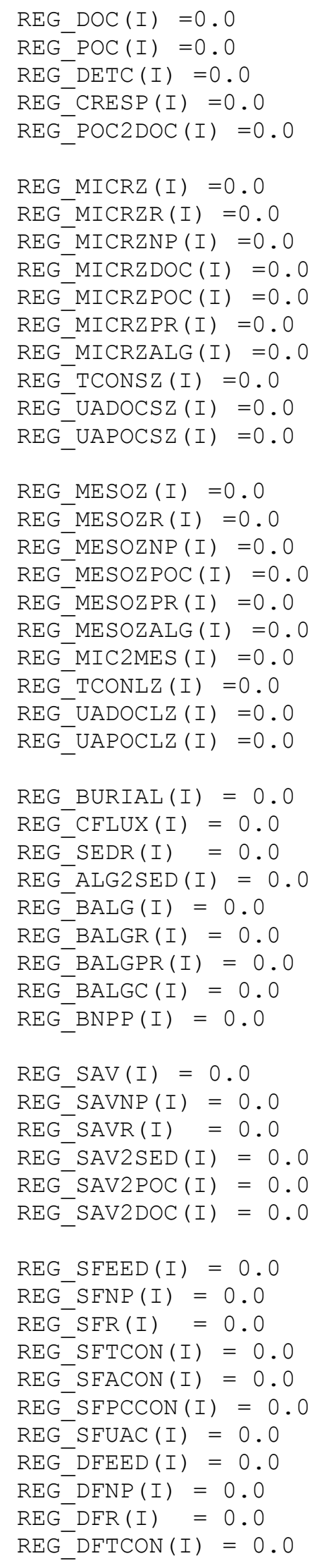




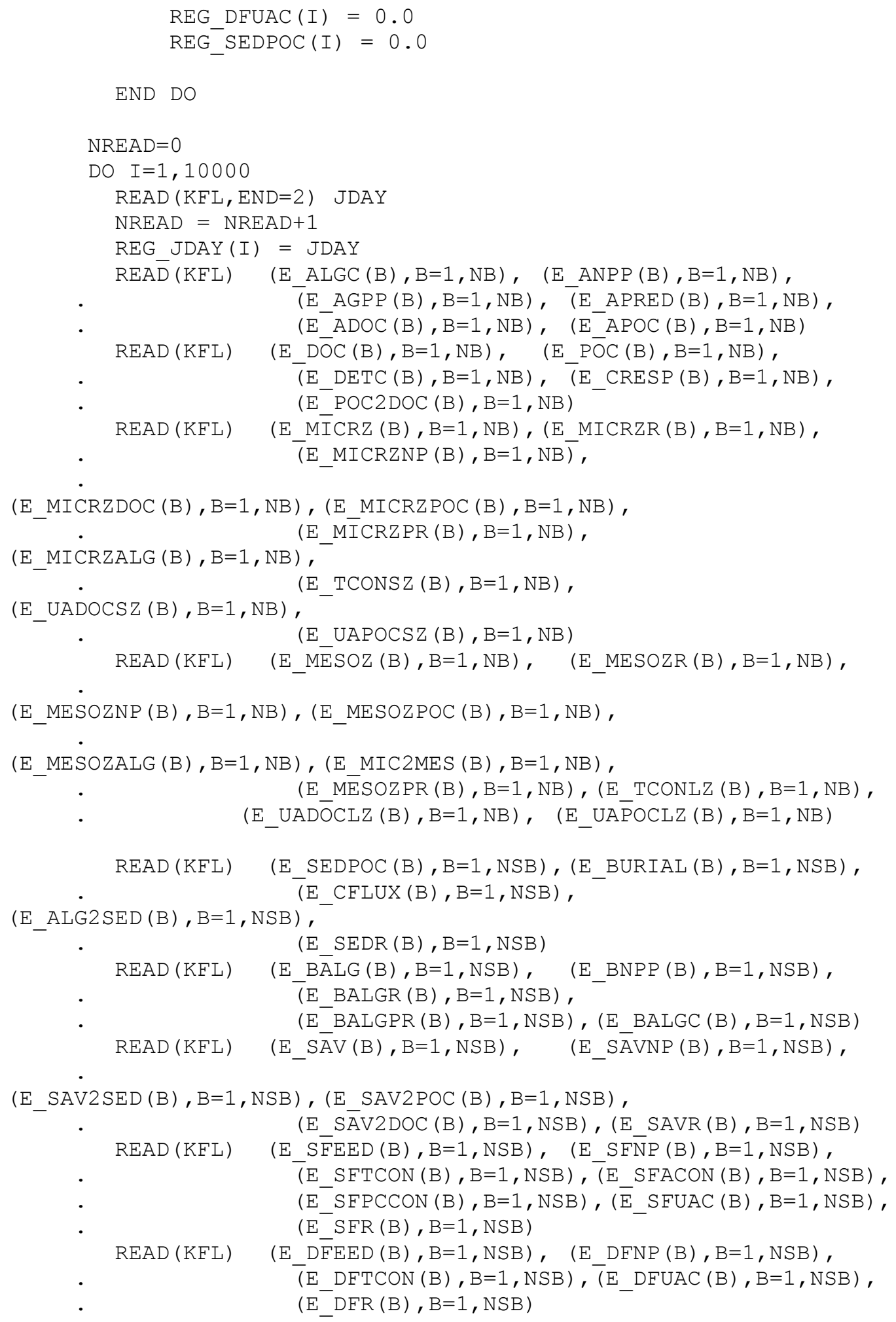

C SUM THESE OVER ALL COLUMNS IN THE REGION

DO JJ $=1$, NCELL

C ZERO OUT COLUMN SUMS 


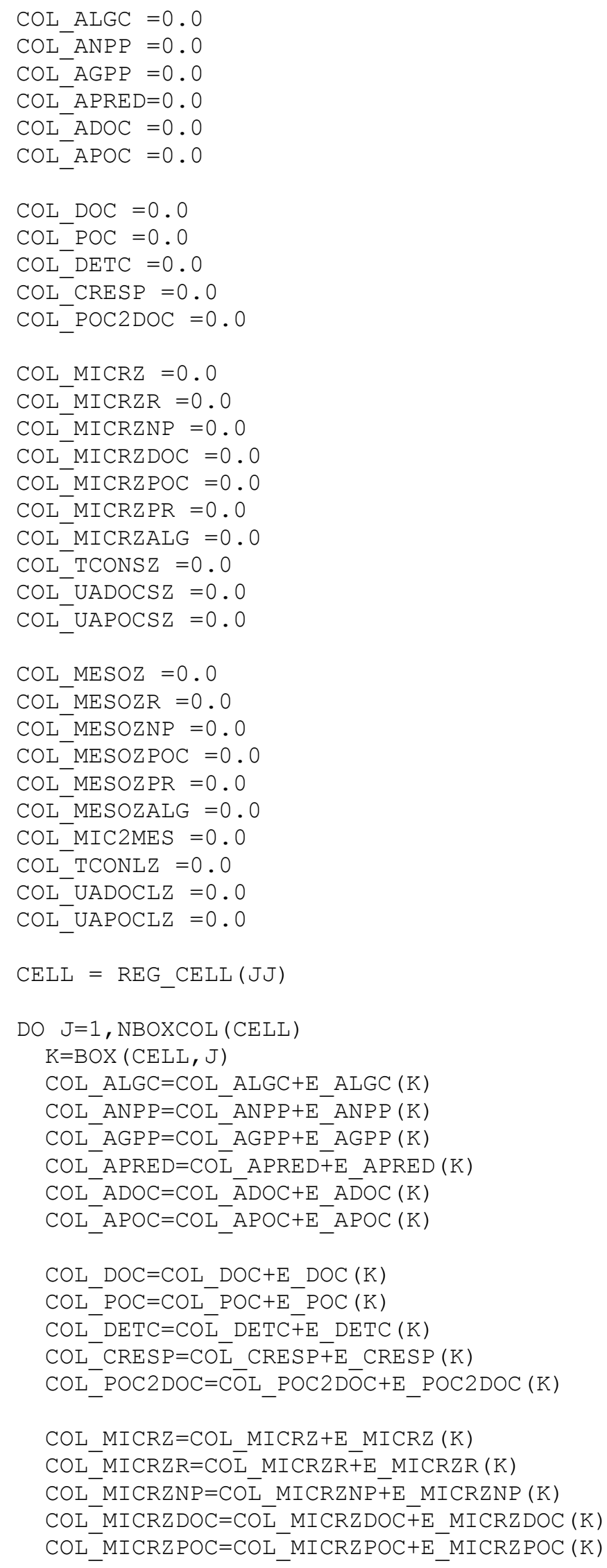


COL_MICRZPR=COL_MICRZPR+E MICRZPR (K)

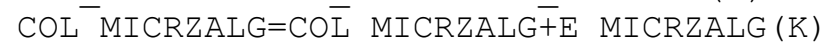

COL_TCONSZ $=$ COL_TCONSZ+E_TCON $\bar{S} Z(K)$

COL_UADOCSZ $=\mathrm{CO} \overline{\mathrm{I}}$ UUADOCSZ$\overline{+} \mathrm{E}$ UAADOCSZ $(\mathrm{K})$

COL_UAPOCSZ $=\mathrm{COL}^{-}{ }_{-}^{-} \mathrm{UAPOCSZ}+\mathrm{E}^{-} \mathrm{UAPOCSZ}(\mathrm{K})$

$\mathrm{COL} \quad \mathrm{MESOZ}=\mathrm{COL} \quad \mathrm{MESOZ}+\mathrm{E} \quad \mathrm{MESOZ}(\mathrm{K})$

$\mathrm{COL}^{-} \mathrm{MESOZR}=\mathrm{CO} \overline{\mathrm{L}} \mathrm{MESOZR} \overline{+} \mathrm{E} \operatorname{MESOZR}(\mathrm{K})$

$\mathrm{COL}{ }^{-} \mathrm{MESOZNP}=\mathrm{CO} \overline{\mathrm{L}} \mathrm{MESOZNP}+\mathrm{E} \_\mathrm{MESOZNP}(\mathrm{K})$

$\mathrm{COL}$ _MESOZPOC $=\mathrm{COL}$ MESOZPOC+E_MESOZPOC $(\mathrm{K})$

COL ${ }^{-} \mathrm{MESOZPR}=\mathrm{COL} \overline{\mathrm{M}} \mathrm{SSOZPR}+\mathrm{E}$ MESOZPR $(\mathrm{K})$

$\mathrm{COL}-\mathrm{MESOZALG}=\mathrm{CO} \overline{\mathrm{L}} \mathrm{MESOZALG}+\mathrm{E}$ MESOZALG (K)

$\mathrm{COL}-\mathrm{MIC} 2 \mathrm{MES}=\mathrm{COL} \overline{\mathrm{MIC}} 2 \mathrm{MES}+\mathrm{E} \operatorname{MIC} 2 \mathrm{MES}(\mathrm{K})$

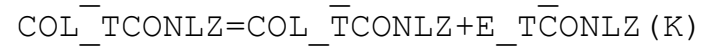

COL_UADOCLZ $=\mathrm{CO}=\mathrm{L}$ UADOCLZ+E_UADOCLZ $(\mathrm{K})$

$\mathrm{COL} \mathrm{UAPOCLZ}=\mathrm{COL} \mathrm{UAPOCLZ}+\mathrm{E}^{-} \mathrm{UAPOCLZ}(\mathrm{K})$ END D $\bar{O}$

C SAVE THE VARIABLES THAT ONLY EXIST AT THE BOTTOM

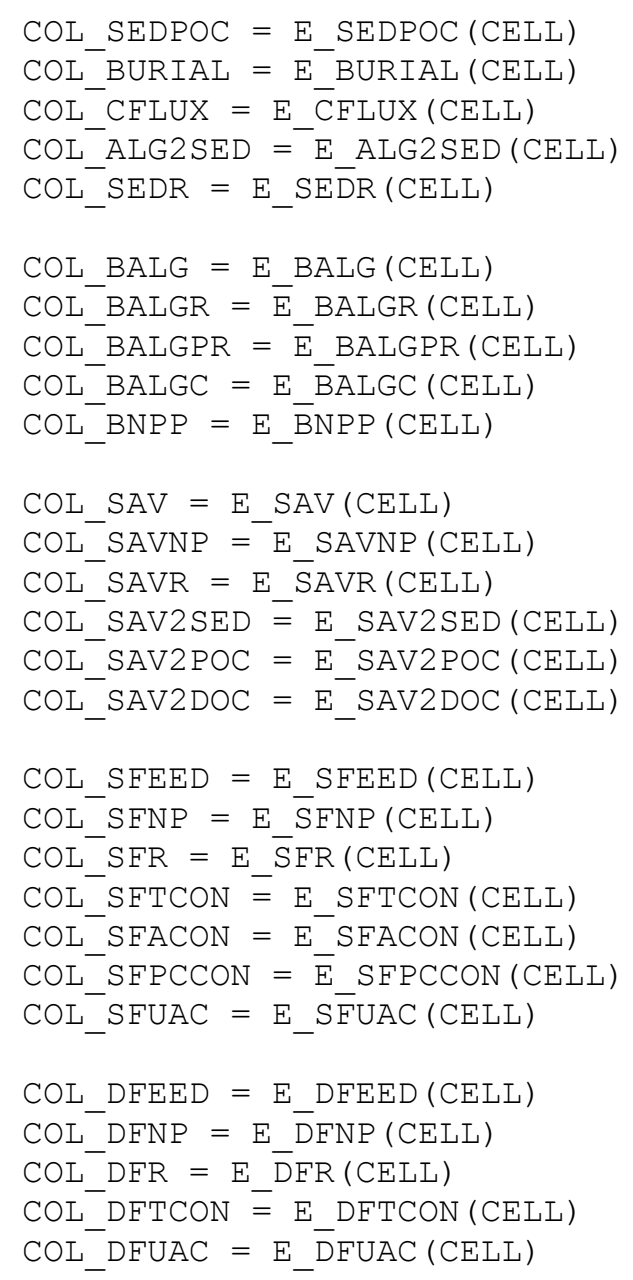

C SUM CELLS OVER REGION

REG_ALGC $(I)=R E G \_A L G C(I)+C O L \_A L G C * S F A(C E L L)$

REG_ANPP $(I)=R E G \_A N P P(I)+C O L \_A N P P * S F A(C E L L)$ 
REG_AGPP (I) $=$ REG AGPP (I) +COL_AGPP*SFA (CELL)

$R E G-\operatorname{APRED}(I)=R E \bar{G} \operatorname{APRED}(I)+C \bar{O} L$ APRED*SEA (CELL)

REG_ADOC (I) $=$ REG_A $\bar{A} D O C(I)+C O L \_A \bar{D} O C * S F A(C E L L)$

REG_APOC (I) $=$ REG_APOC (I) +COL_APOC*SFA (CELL)

REG_DOC (I) $=$ REG_DOC (I) +COL_DOC $*$ SFA (CELL)

$\mathrm{REG}^{-} \mathrm{POC}(\mathrm{I})=\mathrm{REG}^{-} \mathrm{POC}(\mathrm{I})+\mathrm{COL}^{-} \mathrm{POC}^{\star} \mathrm{SFA}(\mathrm{CELL})$

REG ${ }^{-} \operatorname{DETC}(I)=\operatorname{RE} \bar{G} \operatorname{DETC}(I)+C \bar{O} \mathrm{~L} \quad \mathrm{DETC}{ }^{*} \mathrm{SFA}$ (CELL)

$\mathrm{REG}^{-} \mathrm{CRESP}(\mathrm{I})=\mathrm{RE} \overline{\mathrm{G}} \mathrm{CRESP}(\mathrm{I})+\mathrm{CO} \mathrm{O} \_\mathrm{CRESP}{ }^{*} \mathrm{SFA}$ (CELL)

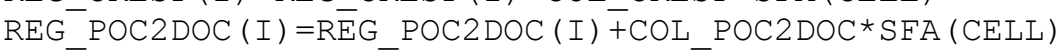

REG MICRZ (I) =REG MICRZ (I) +COL_MICRZ*SFA (CELL)

$\operatorname{REG}{ }^{-} \operatorname{MICRZR}(I)=\operatorname{RE} \bar{G} \operatorname{MICRZR}(I)+C \bar{O} L \quad M I C R Z R * S F A(C E L L)$

REG_MICRZNP (I) $=$ REG_MICRZNP (I ) +CODL_MICRZNP *SFA (CELL)

REG ${ }^{-} \operatorname{MICRZDOC}(\mathrm{I})=\mathrm{RE} \overline{\mathrm{G}} \operatorname{MICRZDOC}(\mathrm{I})+\mathrm{C} \overline{\mathrm{L}} \mathrm{M}$ MICRZDOC SFA (CELL)

REG_MICRZPOC (I) $=$ REG_MICRZPOC (I) +COL_MICRZPOC $*$ SFA (CELL)

REG_MICRZPR (I) =REG_MICRZPR (I) +COL_MI CRZPR *SFA (CELL)

REG ${ }^{-}$MICRZALG (I) $=$RE $\bar{G}$ MICRZALG (I) +CŌL MICRZALG*SFA (CELL)

REG ${ }^{-}$TCONSZ $(I)=R E G ~ T \overline{C O N S Z}$ (I) +COL TCONNSZ *SFA (CELL)

REG_UADOCSZ (I) $=$ REG_UADOCSZ $(I)+C \bar{O} L$ L_UADOCSZ *SFA (CELL)

REG_UAPOCSZ (I) $=\mathrm{REG}_{-}^{-} \mathrm{UAPOCSZ}(\mathrm{I})+\mathrm{COL}{ }_{-}^{-} \mathrm{UAPOCSZ}$ *SFA (CELL)

REG MESOZ (I) $=$ REG MESOZ (I) +COL MESOZ*SFA (CELL)

REG_MESOZR (I) =REG_MESOZR (I) +CŌL_MESOZR*SFA (CELL)

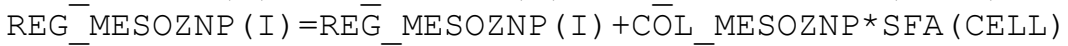

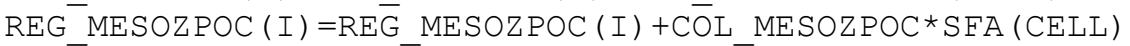

REG_MESOZPR (I ) =REG_MESOZPR (I ) +COL_MESOZPR *SEA (CELL)

REG_MESOZALG (I) $=$ REG $\overline{-}$ MESOZALG (I ) +CŌL_MESOZALG*SFA (CELL)

REG ${ }^{-}$MIC2MES $(I)=R E G \quad \overline{M I C} 2 \mathrm{MES}(I)+C O L$ MIC2MES * SEA (CELL)

REG_TCONLZ (I) =REG_TCONLZ (I) +COL_TCONLZ *SFA (CELL)

REG_UADOCLZ (I) $=\mathrm{RE} \overline{\mathrm{G}}$ UADOCLZ (I) +COOL_UADOCLZ *SFA (CELL)

REG_UAPOCLZ (I) $=\mathrm{REG}_{-}^{-} \mathrm{UAPOCLZ}(\mathrm{I})+\mathrm{COL}{ }_{-}^{-} \mathrm{UAPOCLZ}$ *SFA (CELL)

REG SEDPOC $(I)=\operatorname{REG} \operatorname{SEDPOC}(I)+C O L \quad S E D P O C * S F A(C E L L)$

REG_SEDR $(I)=R E G \_S E D R(I)+C O L \_S E D R * S F A(C E L L)$

REG_BURIAL $(I)=R \bar{E} G$ BURIAL $(I)+C O L$ BURIAL $*$ SFA (CELL)

$\mathrm{REG}^{-} \mathrm{CFLUX}(\mathrm{I})=\mathrm{REG} \overline{\mathrm{C}} \mathrm{FLUX}(\mathrm{I})+\mathrm{COL} C \overline{\mathrm{F}} \mathrm{LUX}{ }^{\star} \mathrm{SFA}$ (CELL)

REG_ALG2SED $(I)=R \bar{E} G \_A L G 2 \operatorname{SED}(I) \overline{+}$ COL_ALG2SED*SFA (CELL)

REG_BALG $(I)=$ REG_BALG (I) +COL_BALG*SFA (CELL)

REG_BALGR $(I)=R E \bar{G}$ BALGR $(I)+C \bar{O} L \_B A L G R * S F A(C E L L)$

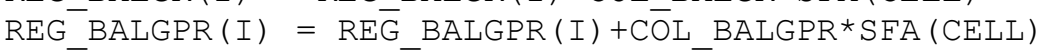

REG_BALGC $(I)=R E G \_\overline{B A L G C}(I)+C O L \_B \bar{A} L G C * S F A(C E L L)$

REG_BNPP $(I)=R E G \_\overline{B N P P}(I)+C O L \_B \bar{N} P P * S F A(C E L L)$

REG_SAV (I) = REG_SAV (I) +COL_SAV*SFA (CELL)

REG_SAVNP $(I)=R \bar{E} G$ SSAVNP $(I) \overline{+}$ COL_SAVNP*SFA (CELL)

REG_SAVR (I) = REG_SAVR (I) +COL_SA $\bar{S} V *$ SFA (CELL)

$\mathrm{REG}^{-} \mathrm{SAV} 2 \mathrm{SED}(\mathrm{I})=\overline{\mathrm{R}} \mathrm{SG} \operatorname{SAV} 2 \mathrm{SED}(\overline{\mathrm{I}})+\mathrm{COL}$ SAV2SED*SFA $(\mathrm{CELL})$

REG SAV2POC (I) $=$ REG SAV2POC $(I)+C O L-S A V 2 P O C * S F A(C E L L)^{-}$

REG_SAV2DOC $(I)=\mathrm{REG}_{-} \mathrm{SAV} 2 \mathrm{DOC}(\mathrm{I})+\mathrm{COL}$-SAV2DOC*SFA $(\mathrm{CELL})$

REG_SFEED $(I)=$ REG_SFEED (I) +COL_SFEED*SFA (CELL)

REG_SFNP $(I)=R E G \_\bar{S} F N P(I)+C O L \_S \bar{F} N P * S F A(C E L L)$

REG_SFR (I) = REG_SFR (I) +COL_SFR*SFA (CELL)

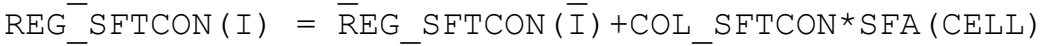

REG_SFACON $(I)=R E G \_S F A C O N(I)+C O L \_S F A C O N * S F A(C E L L)$ 


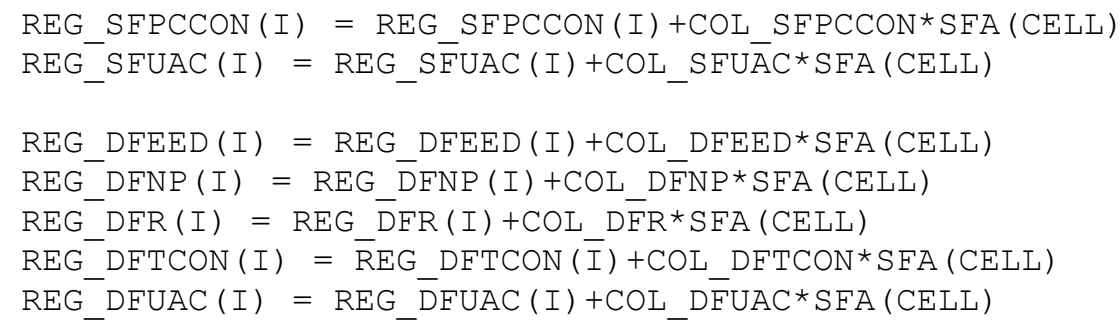

END DO

C DIVIDE REGIONAL SUMS BY SURFACE AREA

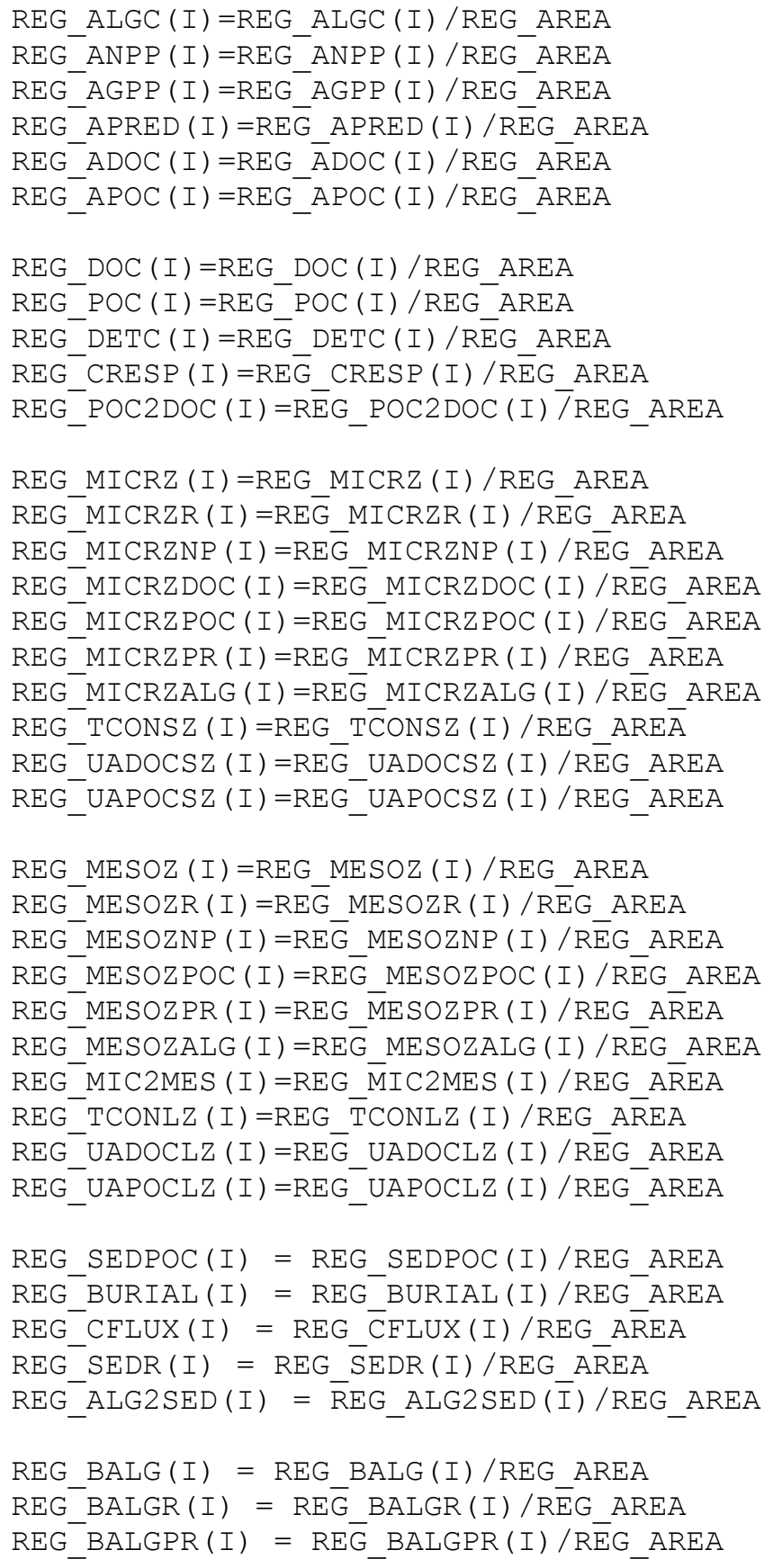




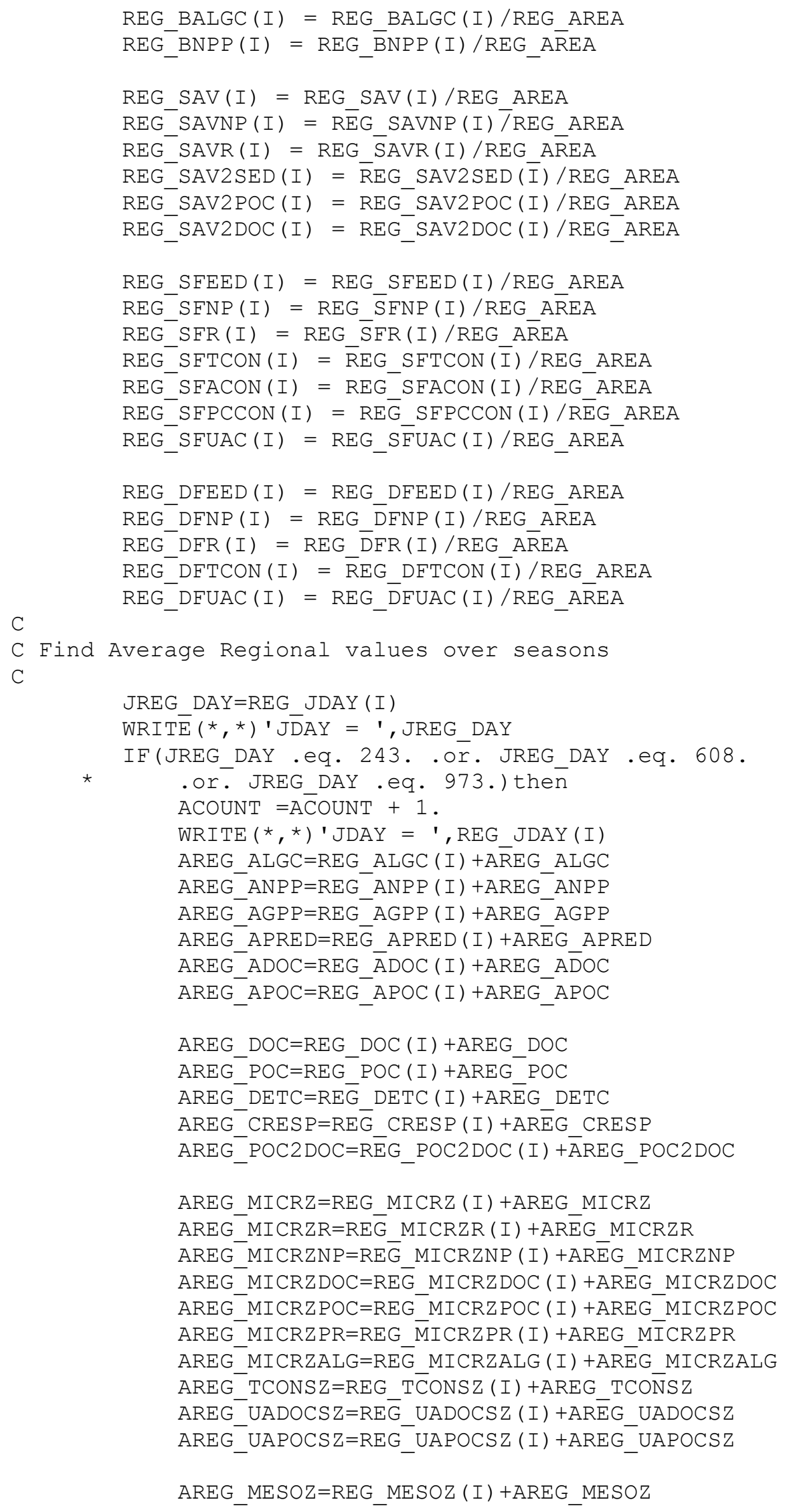


AREG_MESOZR=REG_MESOZR (I) +AREG_MESOZR AREG_MESOZNP=RE $\bar{G}$ MESOZNP (I ) +ARE G MESOZNP AREG_MESOZPOC $=R E \bar{G}$ MESOZPOC (I $)+A R \bar{E} G$ MESOZPOC AREG_MESOZPR=REG_MESOZPR (I ) +AREG_MESOZPR AREG_MESOZALG $=R E \bar{G}$ _MESOZALG (I $)+A R \bar{E} G$ _MESOZALG AREG - MIC2MES $=R E G$ MIC2MES (I ) +AREG MI C2MES AREG ${ }^{-}$TCONLZ=REG TCONLZ (I) +AREG TC $\bar{C} O N L Z$ $A R E G-U A D O C L Z=R E \bar{G}$ UADOCLZ (I ) +ARE $G$ UADOCLZ AREG_UAPOCLZ=REG_UAPOCLZ (I ) +AREG_UAPOCLZ

AREG_SEDPOC $=$ REG_SEDPOC (I $)+$ AREG_SEDPOC AREG ${ }^{-}$BURIAL $=$REG ${ }^{-}$BURIAL $(I)+A R E G$ BURIAL $A R E G{ }^{-} C F L U X=R E G \quad \bar{C} F L U X(I)+A R E G \_C \bar{F} L U X$ AREG ${ }^{-}$SEDR $=$REG SEDR (I) +AREG SEDR

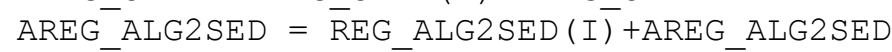

AREG_BALG $=$ REG_BALG $(I)+$ AREG BALG AREG_BALGR $=$ RE $\bar{G}$ BALGR $(I)+A R \bar{E} G$ BALGR AREG ${ }^{-} B A L G P R=R E \bar{G} B A L G P R(I)+A R \bar{E} G$ BALGPR AREG_BALGC $=$ REG_BALGC $(I)+$ AREG_BĀLGC AREG_BNPP $=$ REG_B $\overline{B N P P}(I)+A R E G \_B \bar{N} P P$

AREG SAV = REG SAV(I) +AREG SAV AREG_SAVNP $=$ REEG_SAVNP $(I)+\bar{A} R E G$ SAVNP AREG_SAVR $=$ REG_SAVR $(I)+$ AREG SA $\overline{\text { A } V R ~}$

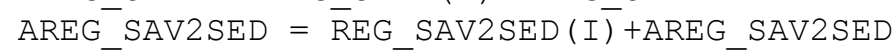
AREG_SAV2POC $=$ REG_SAV2POC (I $)+$ AREG_SAV2POC AREG_SAV2DOC $=$ REG_SAV2DOC (I $)+$ AREG_SAV2DOC 


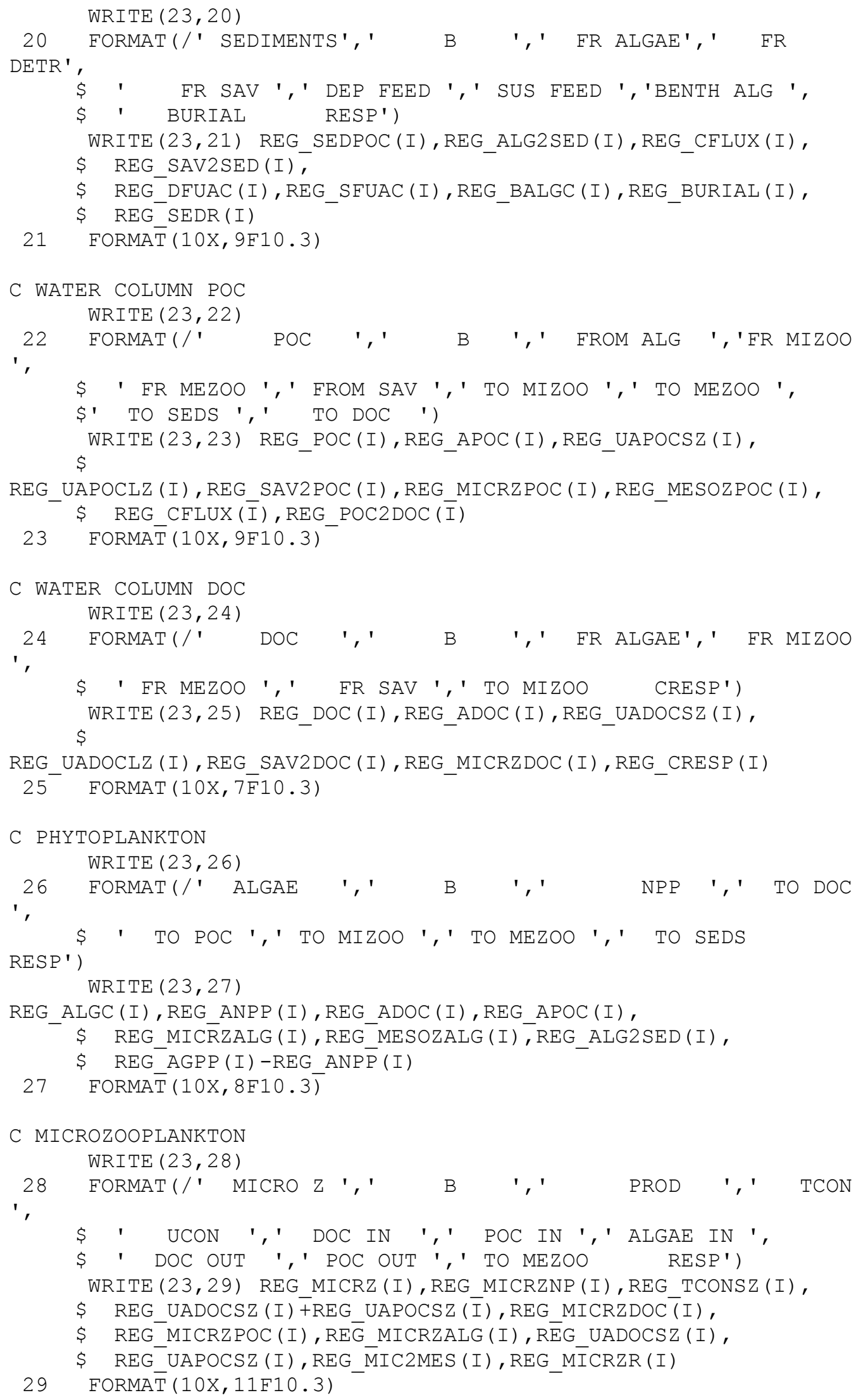




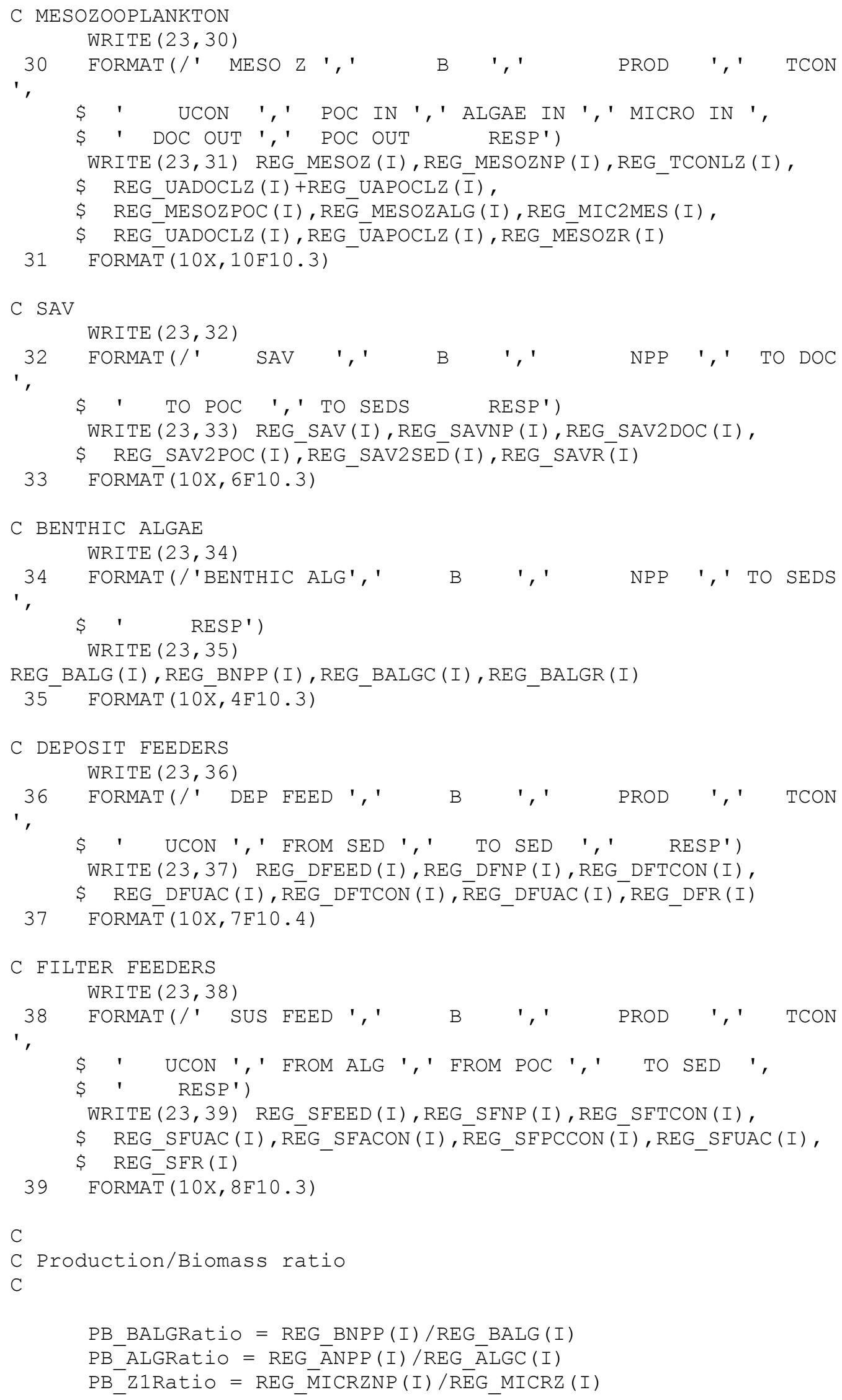




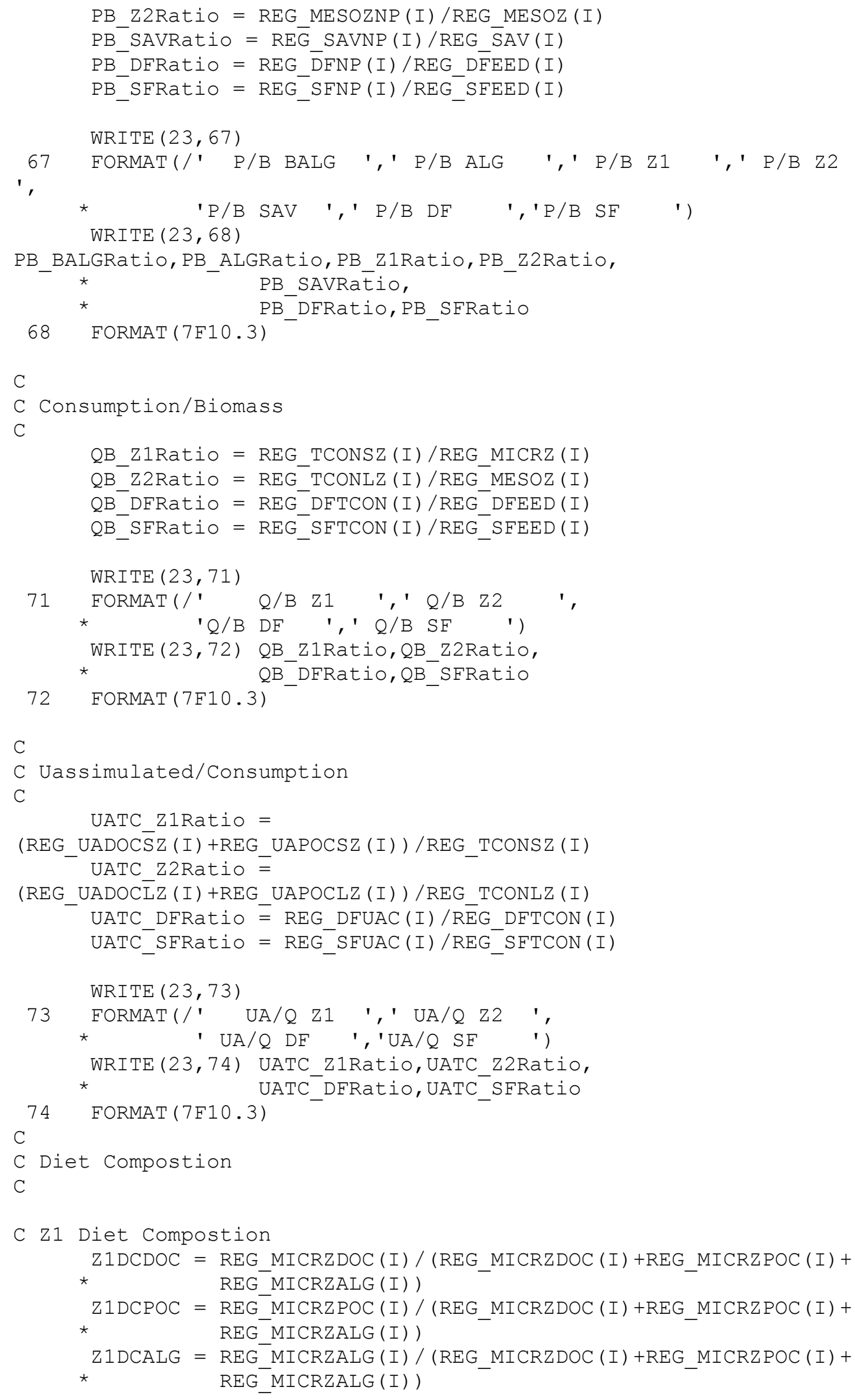




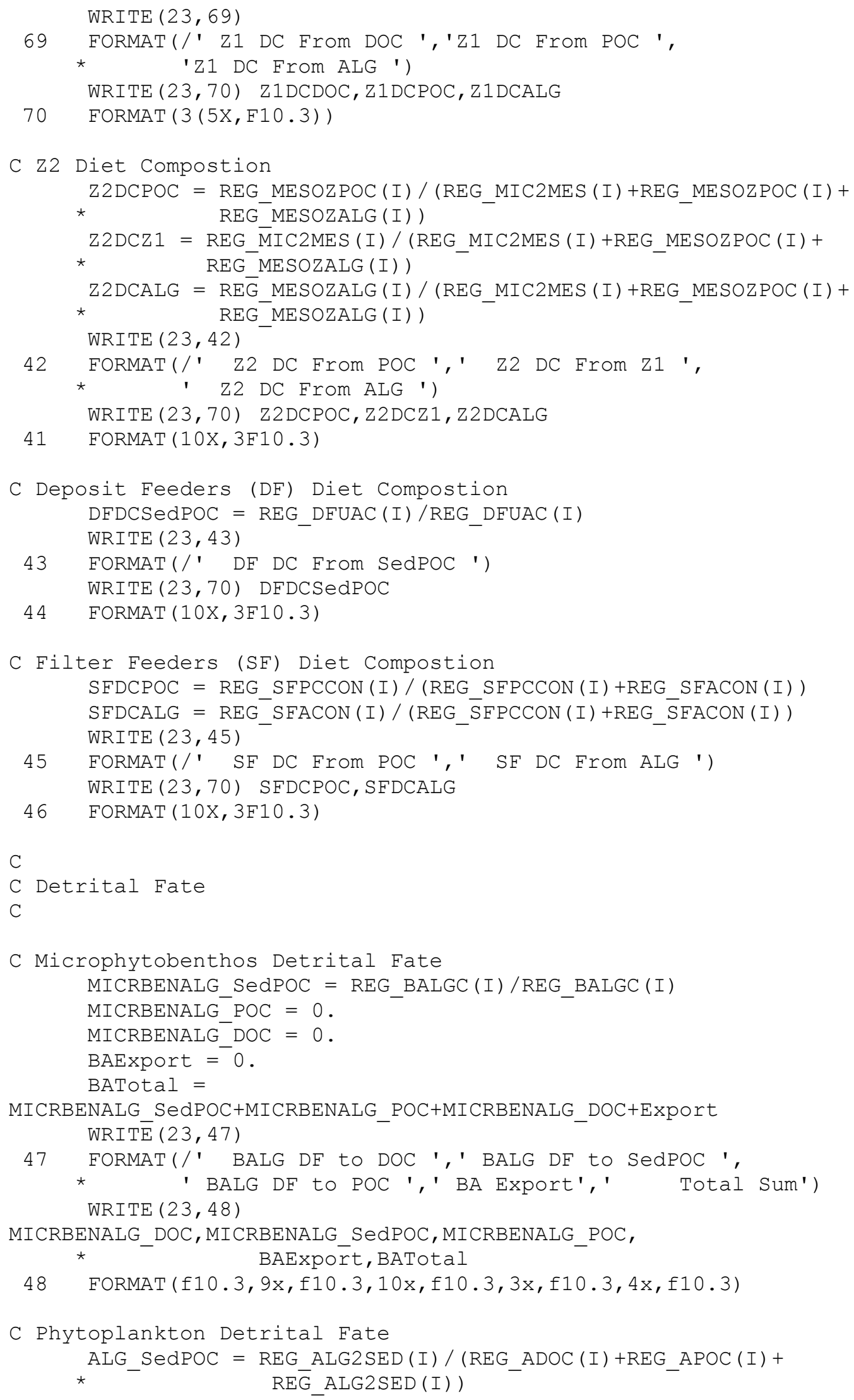




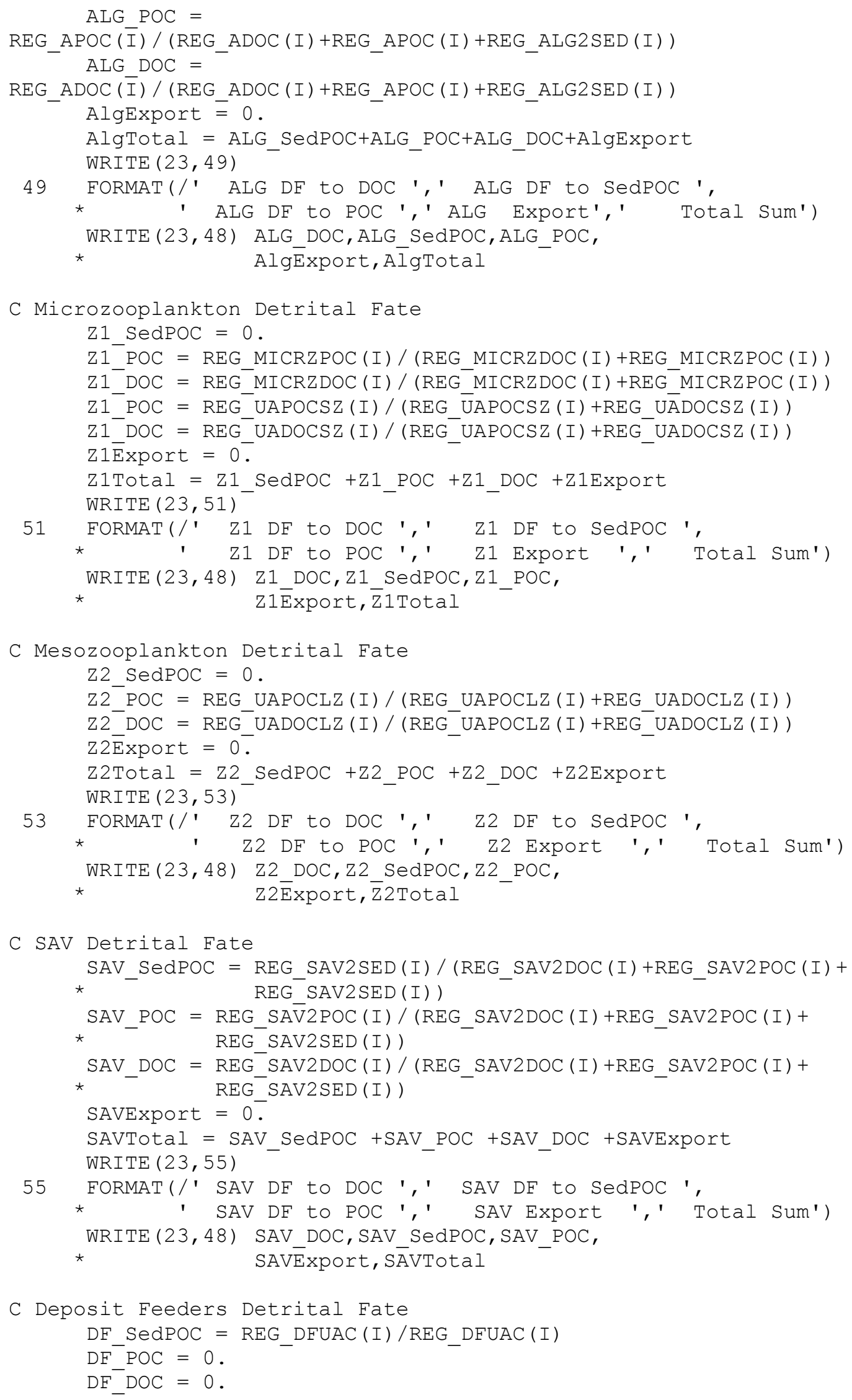




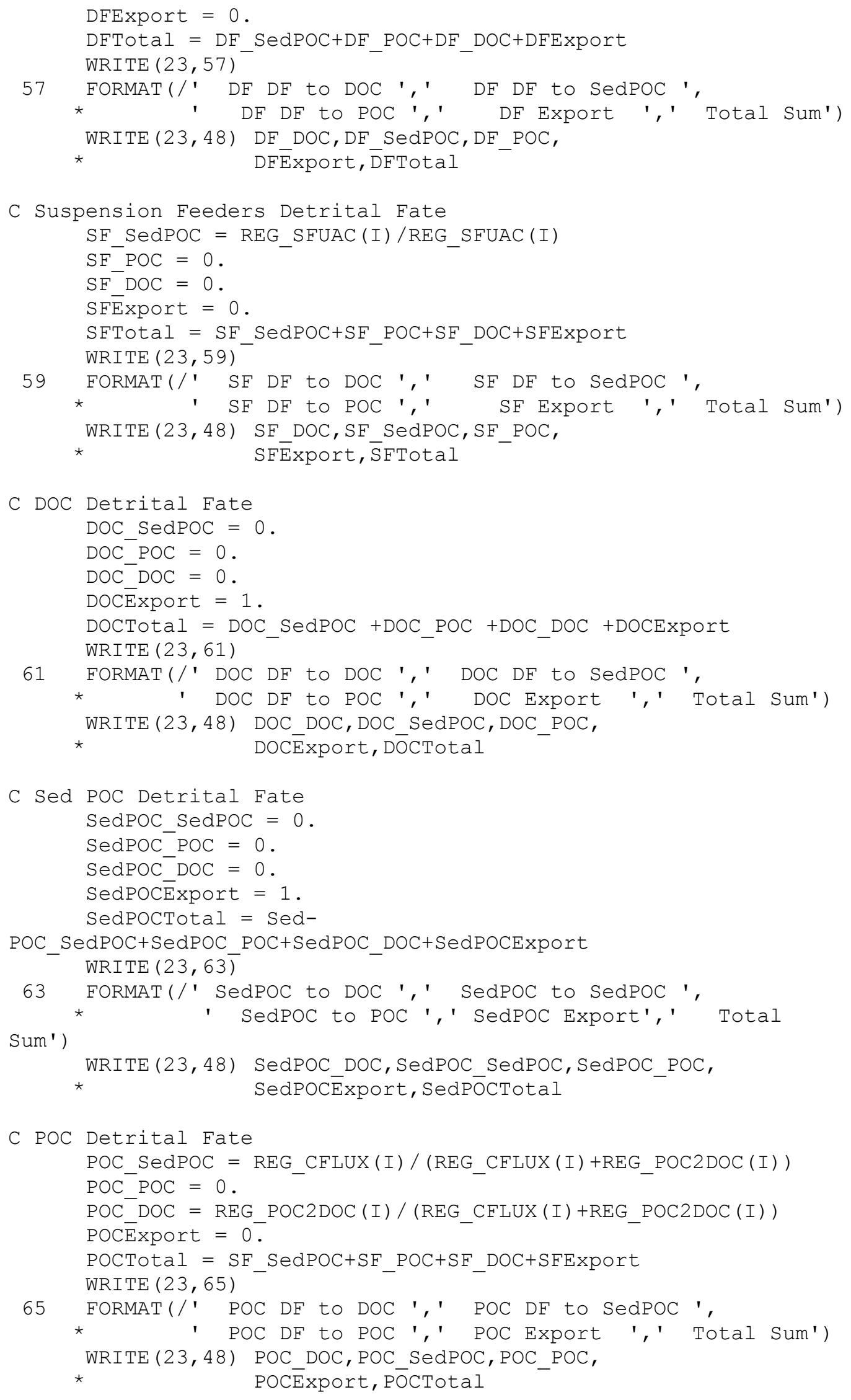




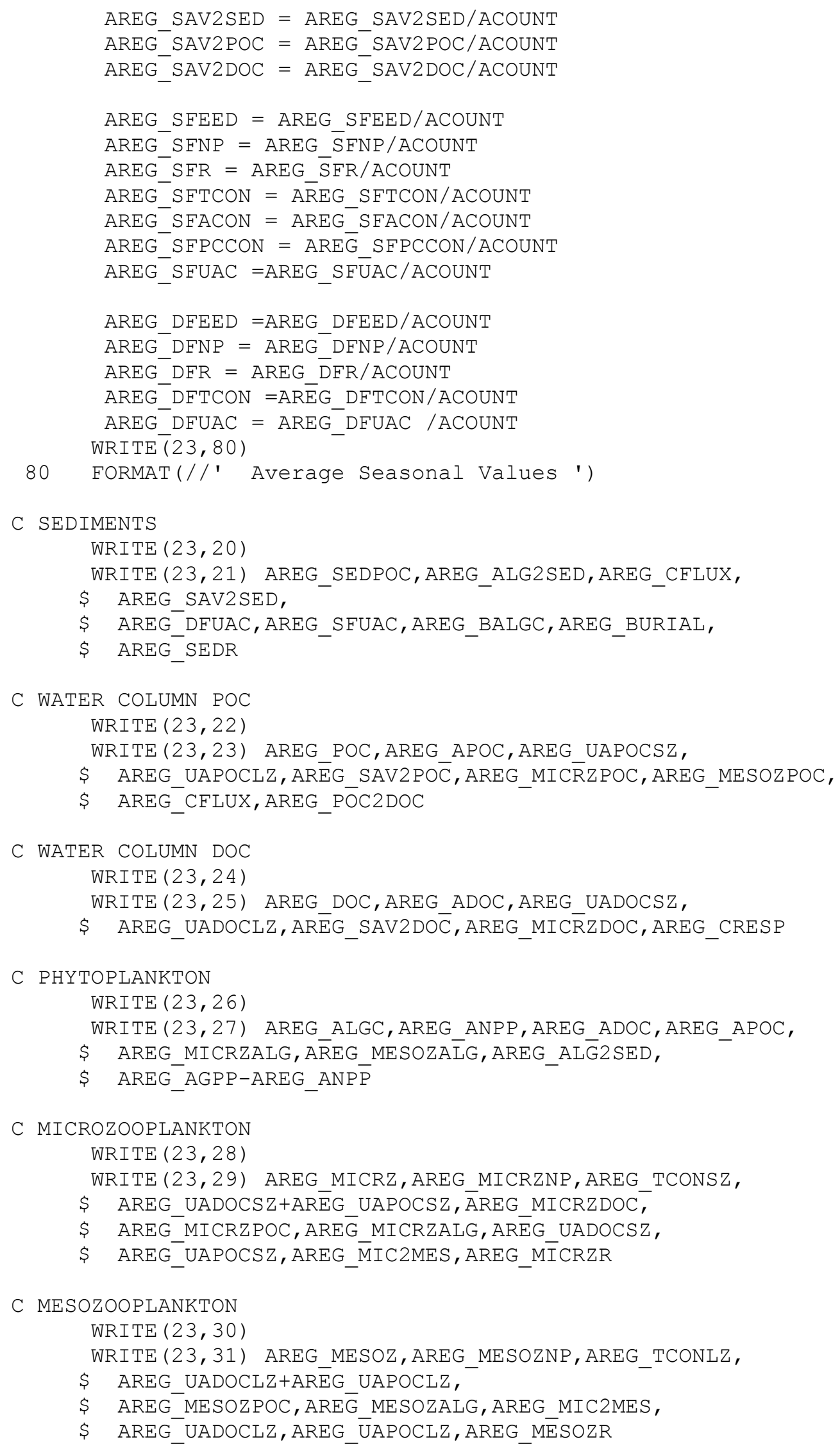




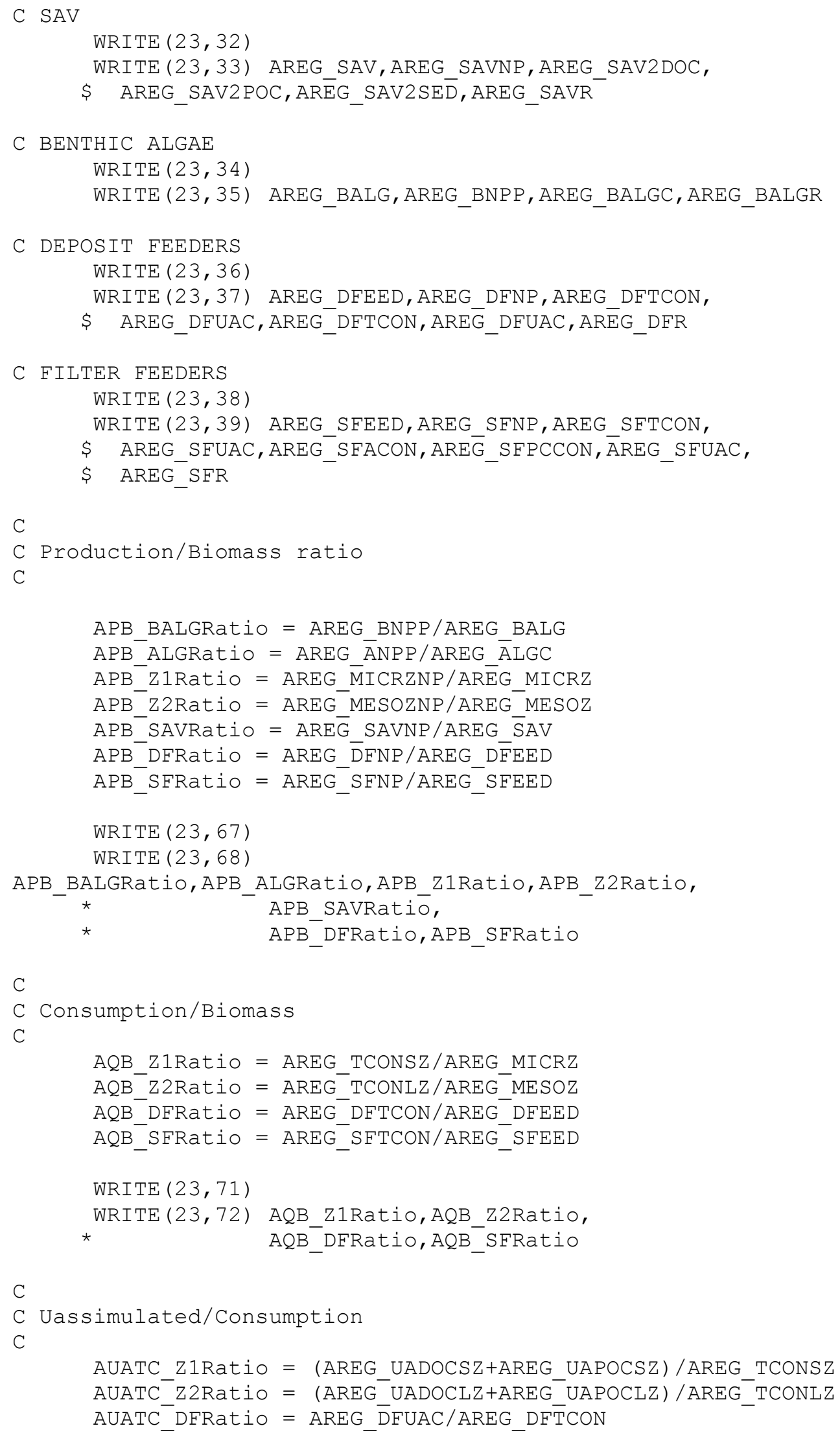




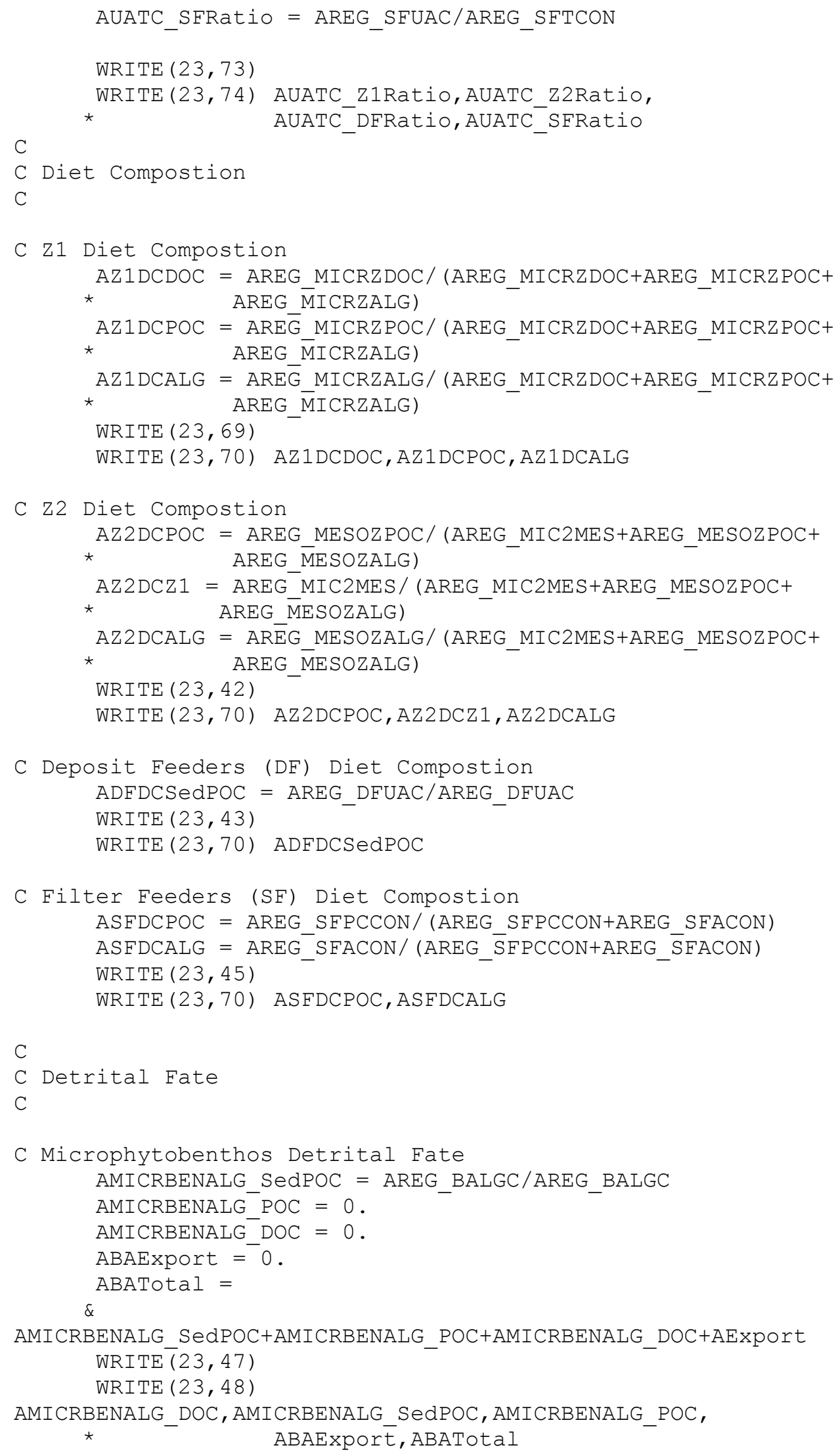


C Phytoplankton Detrital Fate

AALG_SedPOC $=$ AREG_ALG2SED $/\left(A R E G \_A D O C+A R E G \_A P O C+\right.$

* $\quad$ AREG ALG2SED)

AALG_POC $=$ AREG_APOC/ (AREG_ADOC+AREG_APOC+AREG_ALG2SED)

$A A L G{ }^{-} D O C=A R E G_{-}^{-} A D O C /\left(A R E G{ }_{-}^{-} A D O C+A R E G{ }_{-}^{-} A P O C+A R E G{ }_{-}^{-} A L G 2 S E D\right)$

AAlgExport $=0$.

AAlgTotal = AALG SedPOC+AALG POC+AALG DOC+AAlgExport $\operatorname{WRITE}(23,49)$

$\operatorname{WRITE}(23,48)$ AALG_DOC,AALG_SedPOC,AALG_POC,

* AAlgExport, AĀ̄gTotal

C Microzooplankton Detrital Fate

AZ1_SedPOC $=0$.

AZ1_POC $=$ AREG_UAPOCSZ/(AREG_UAPOCSZ+AREG_UADOCSZ)

AZ1_DOC $=$ AREG_UADOCSZ/ (AREG_UAPOCSZ+AREG_UADOCSZ)

AZ1Export $=0$.

AZ1Total = AZ1_SedPOC +AZ1_POC +AZ1_DOC +AZ1Export

WRITE $(23,51)$

$\operatorname{WRITE}(23,48)$ AZ1_DOC,AZ1_SedPOC,AZ1_POC,

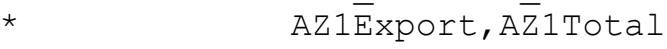

C Mesozooplankton Detrital Fate

AZ2 SedPOC $=0$.

AZ2 ${ }^{-} \mathrm{POC}=$ AREG UAPOCLZ/(AREG UAPOCLZ+AREG UADOCLZ)

AZ2_DOC = AREG_UADOCLZ/ (AREG_UAPOCLZ+AREG_UADOCLZ)

$\mathrm{Az} 2 \overline{\mathrm{Export}}=0$.

Az2Total = AZ2_SedPOC +AZ2_POC +AZ2_DOC +AZ2Export

$\operatorname{WRITE}(23,53)$

WRITE $(23,48)$ AZ2_DOC,AZ2_SedPOC,AZ2_POC,

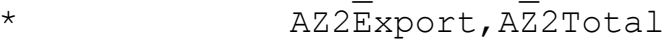

C SAV Detrital Fate

ASAV_SedPOC $=$ AREG_SAV2SED $/($ AREG_SAV2DOC+AREG_SAV2POC+

* AREG SAV2SED)

ASAV_POC $=$ AREG_SAV2POC/(AREG_SAV2DOC+AREG_SAV2POC +

* $\quad$ AREG_SAV2SED)

ASAV_DOC $=$ AREG_SAV2DOC/(AREG_SAV2DOC+AREG_SAV2POC+

* $\quad$ AREG_SAV2SED)

ASAVExport $=0$.

ASAVTotal = ASAV_SedPOC +ASAV_POC +ASAV_DOC +ASAVExport $\operatorname{WRITE}(23,55)$

WRITE $(23,48)$ ASAV_DOC,ASAV_SedPOC,ASAV_POC,

* ASAVExport, ASĀVTotal

C Deposit Feeders Detrital Fate

ADF_SedPOC $=$ AREG_DFUAC/AREG_DFUAC

$\mathrm{ADF} \mathrm{POC}=0$.

$A D F^{-} D O C=0$.

$A D E \bar{E}$ xport $=0$.

ADFTotal = ADF_SedPOC+ADF_POC+ADF_DOC+ADFExport

$\operatorname{WRITE}(23,57)$

$\operatorname{WRITE}(23,48)$ ADF_DOC,ADF_SedPOC,ADF_POC,

* $\quad$ ADFExport, ADETotal

C Suspension Feeders Detrital Fate

ASF_SEdPOC $=$ AREG_SFUAC/AREG_SFUAC

$\mathrm{ASE}_{-} \mathrm{POC}=0$. 


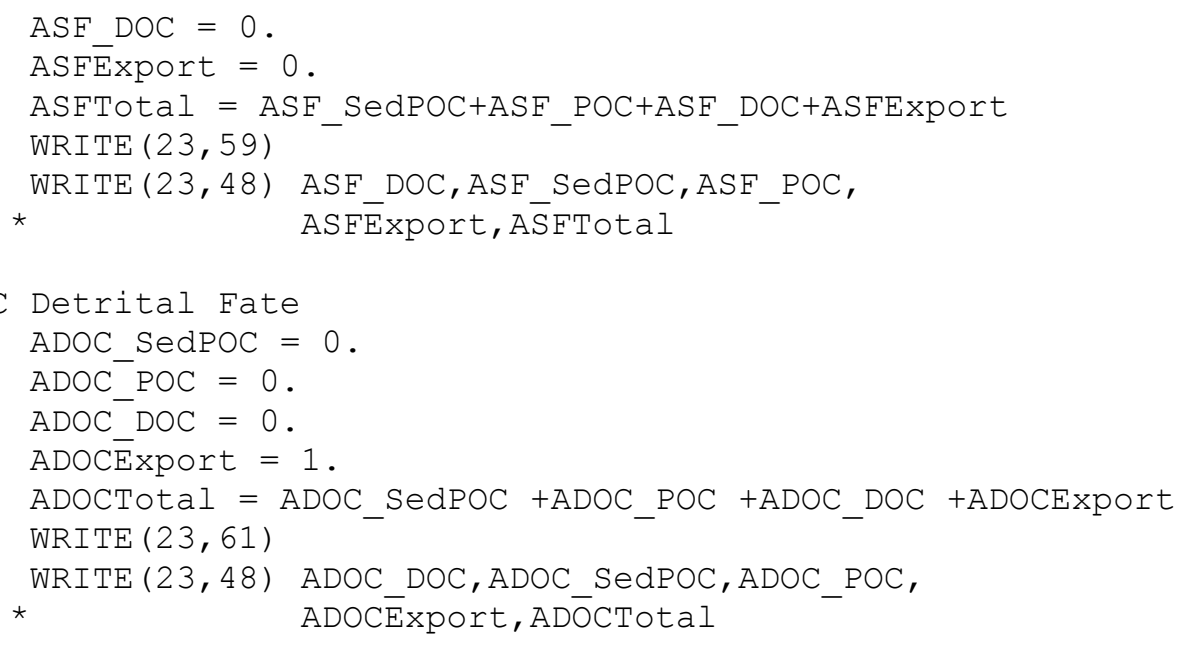




\section{Appendix D: The forEcopathGui.f90 File}

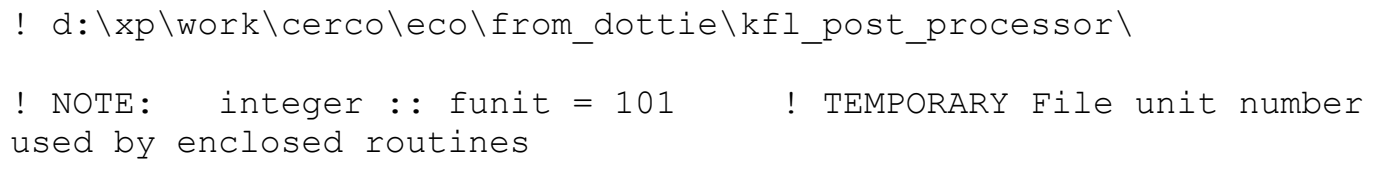




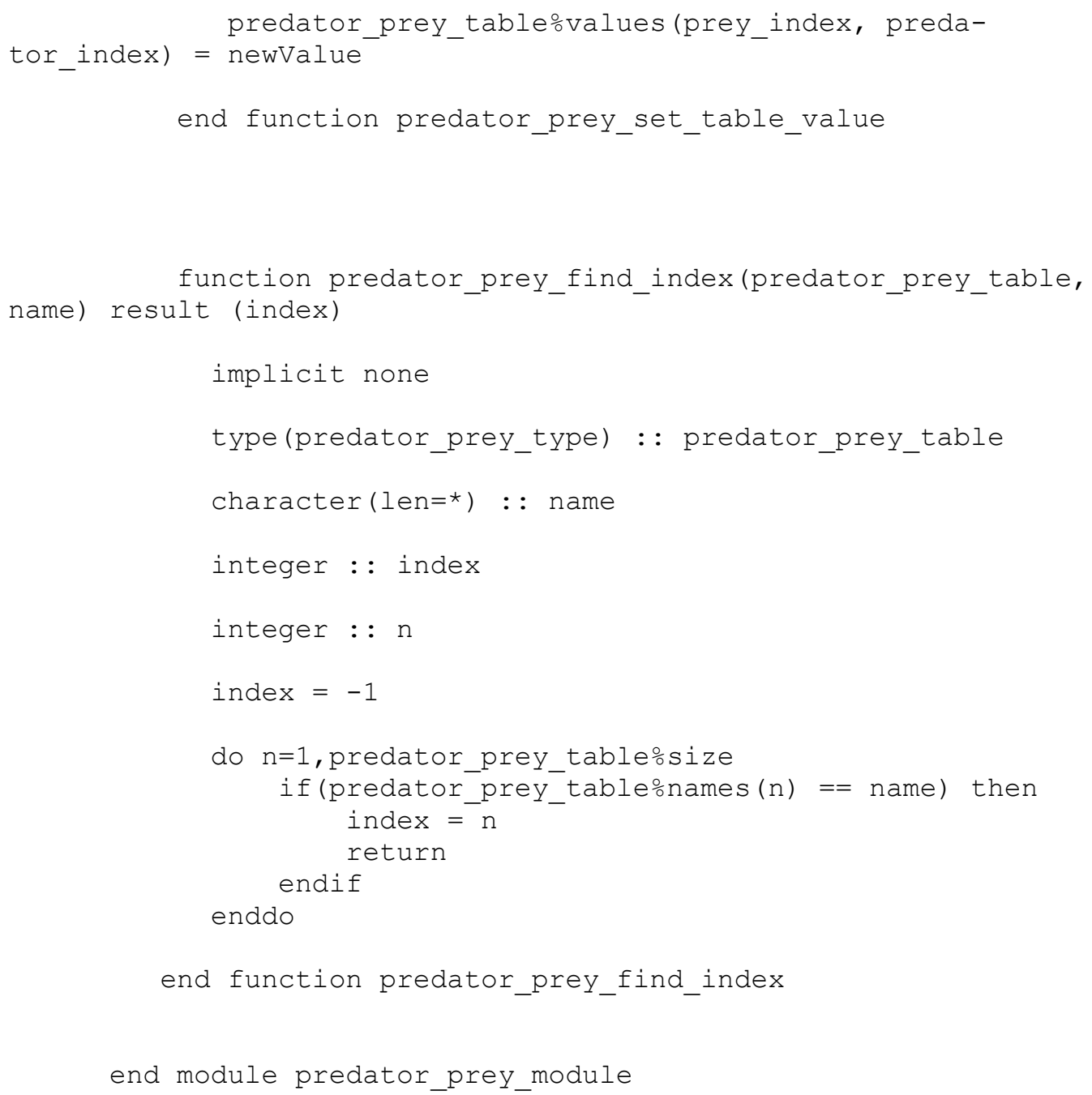




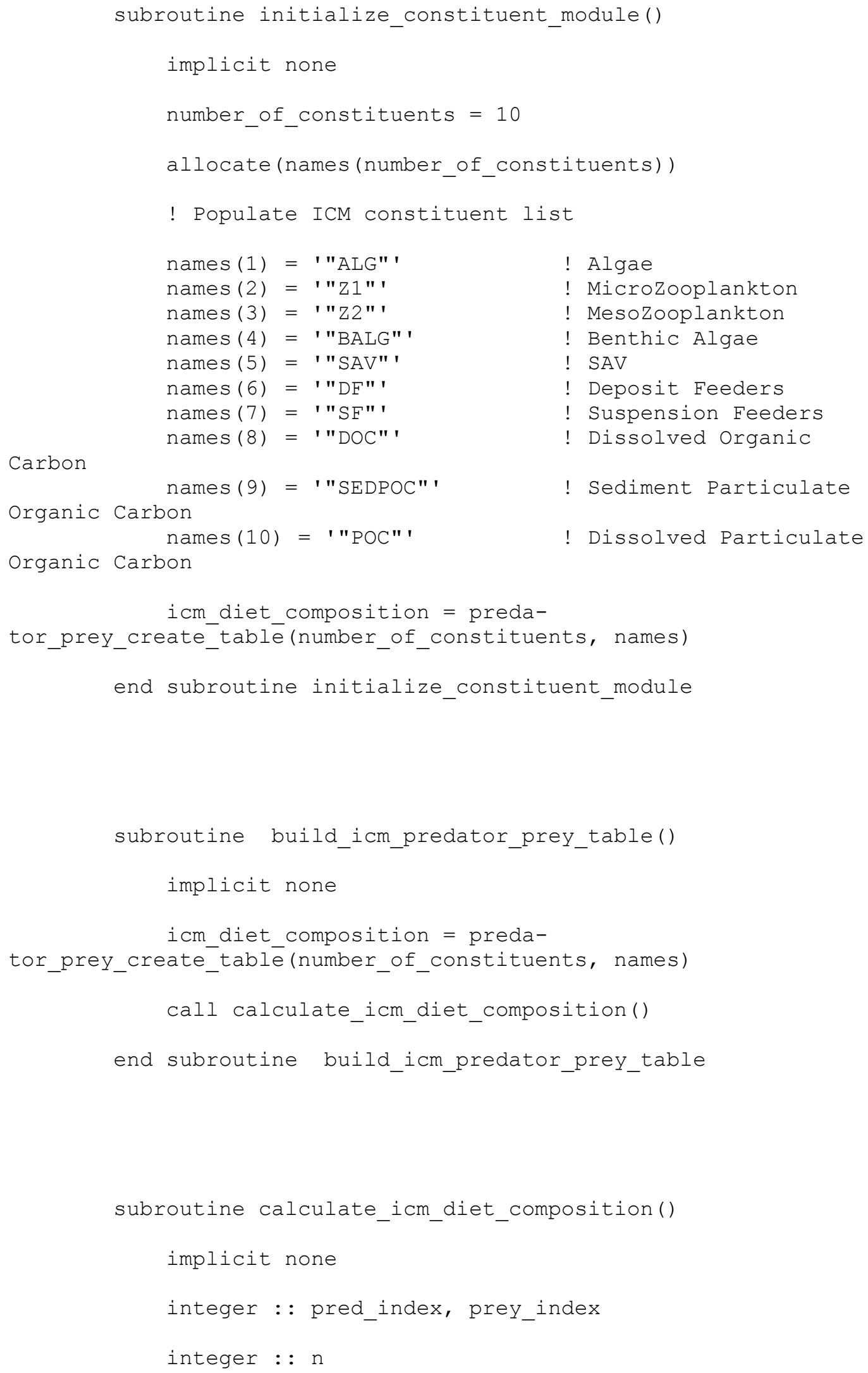




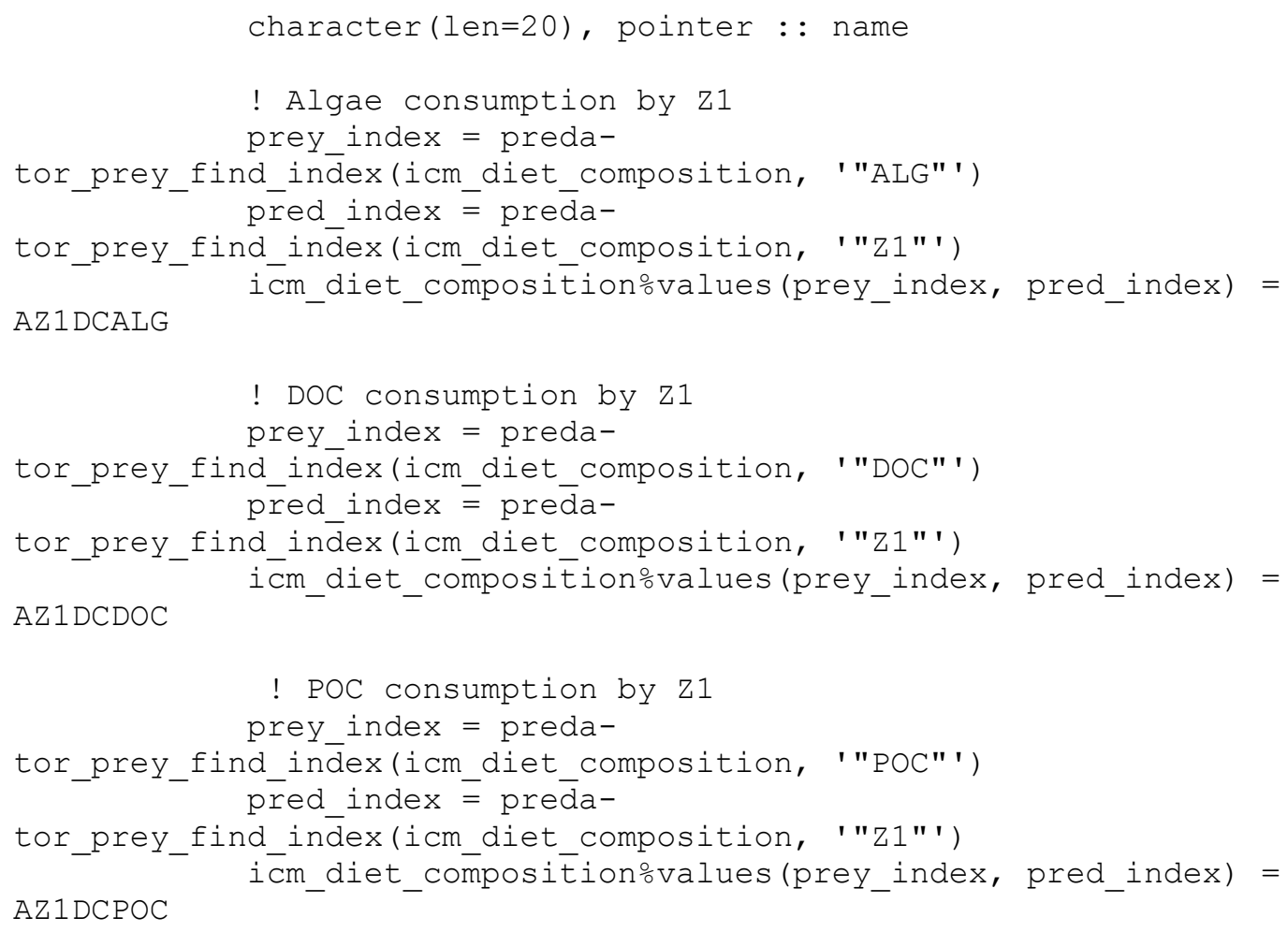




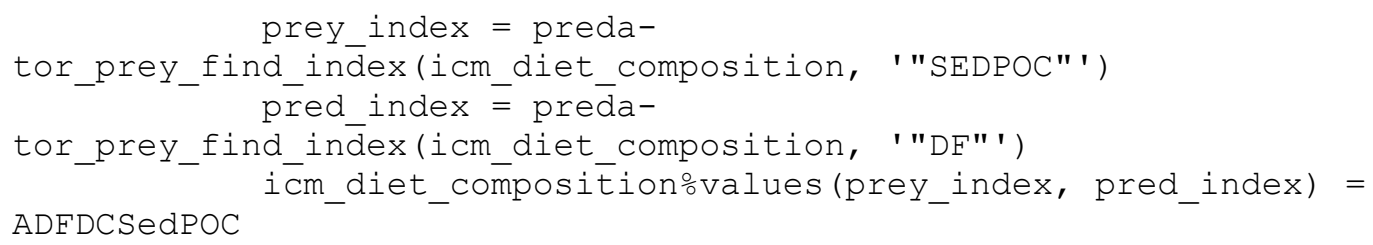




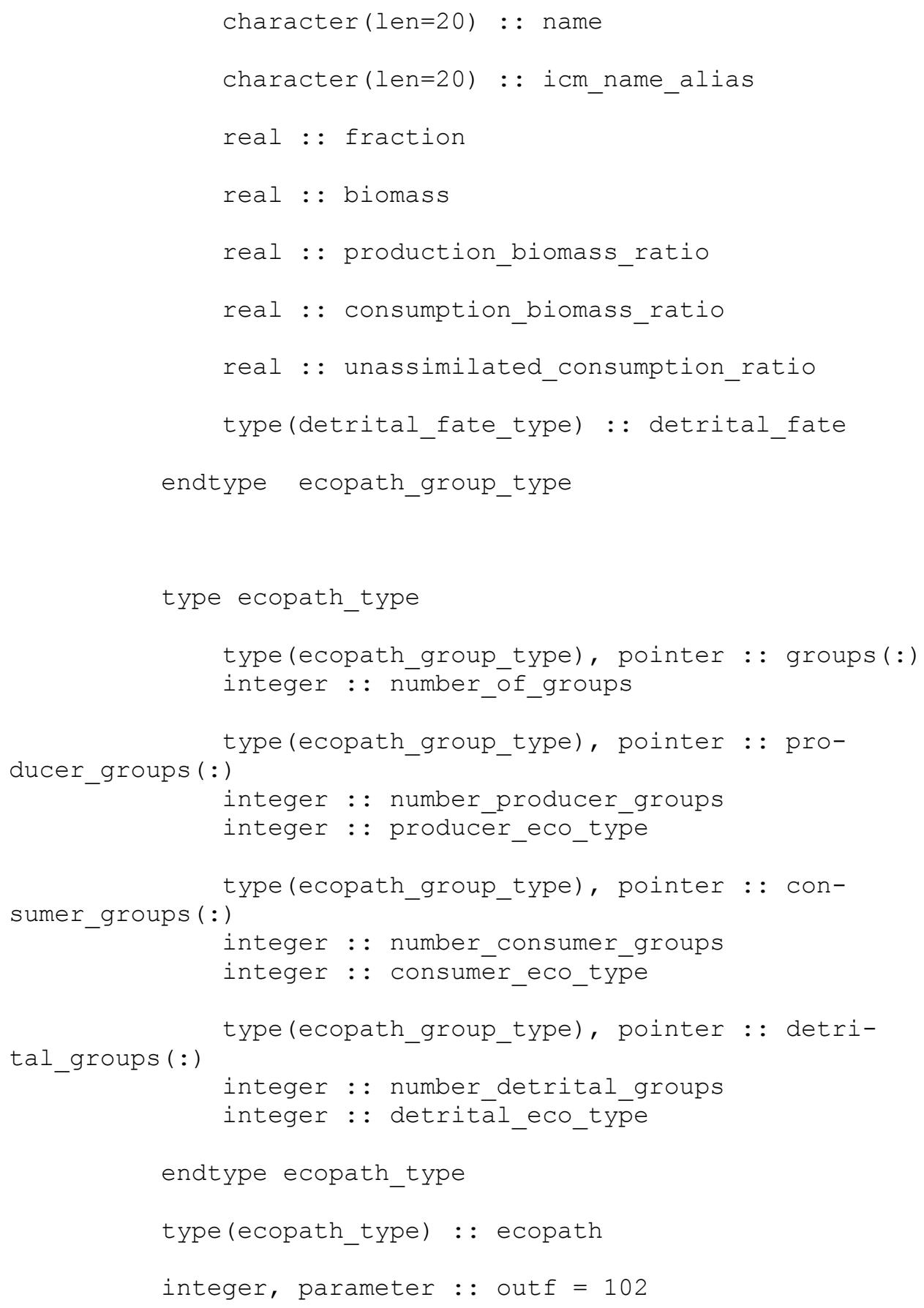




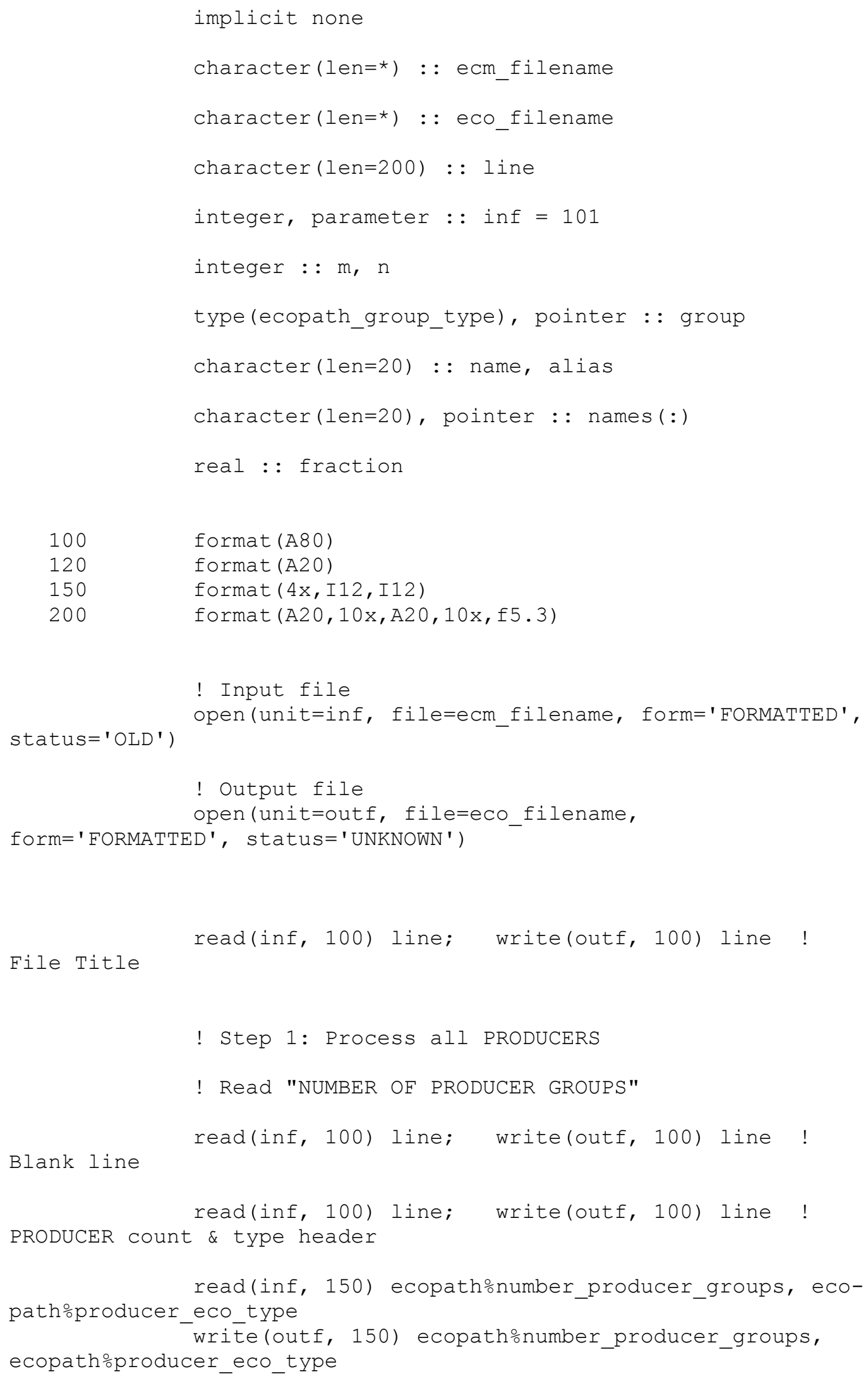


allo-

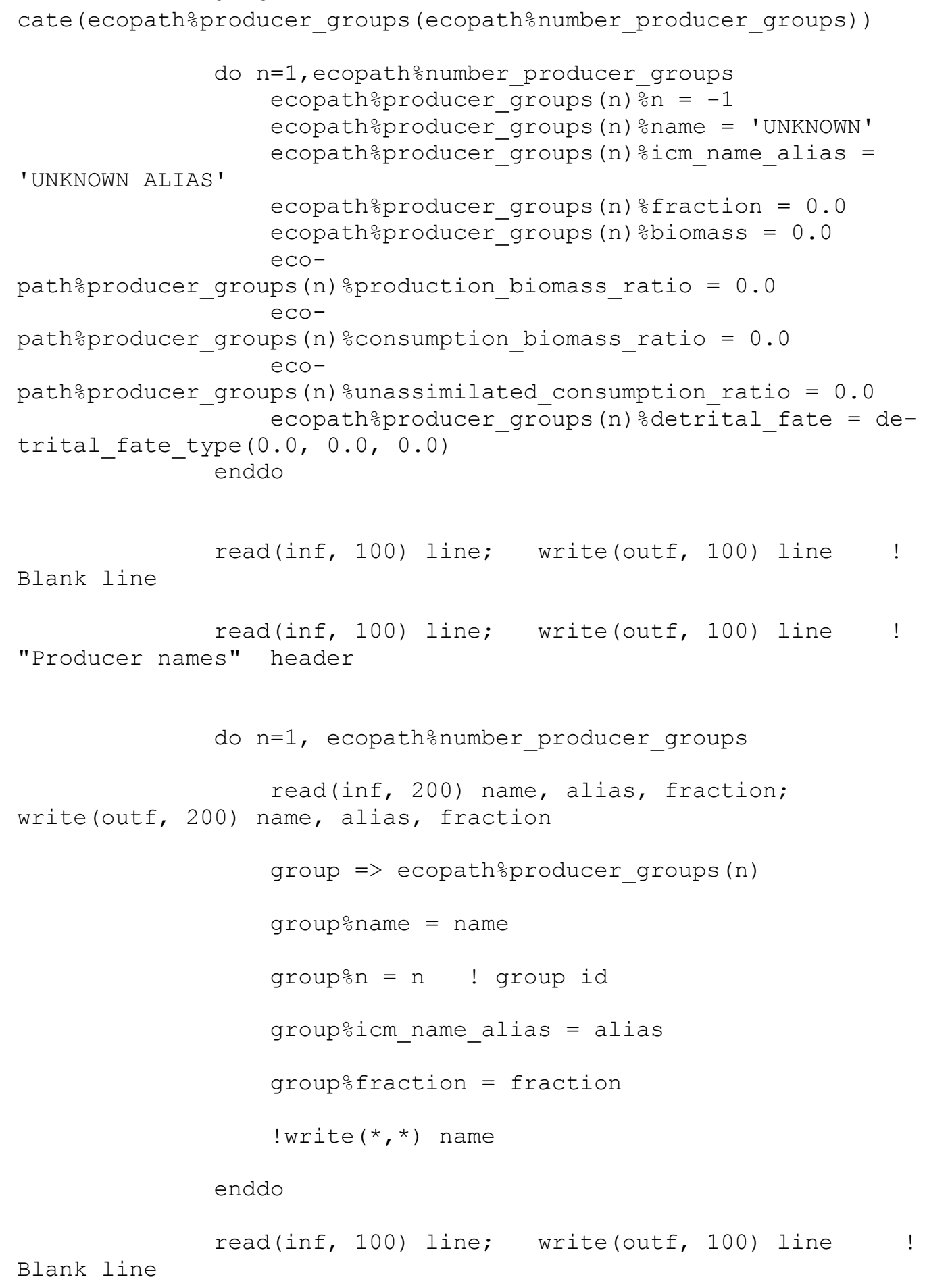


Blank line

! Read "NUMBER OF CONSUMER GROUPS"

read(inf, 100) line; write(outf, 100) line !

read(inf, 100) line; write(outf, 100) line !

CONSUMER count \& type header

read(inf, 150) ecopathonumber_consumer_groups, ecopathoconsumer_eco_type

write(outf, 150) ecopathonumber_consumer_groups, ecopathoconsumer_eco_type

allo-

cate (ecopath\%consumer_groups (ecopathonumber_consumer_groups))

do $n=1$, ecopathonumber_consumer_groups ecopath\%consumer $\bar{g}$ roups $(n) \frac{\circ}{\circ} n=-1$ ecopath\%consumer_groups $(n) \circ$ name $=$ 'UNKNOWN'

' UNKNOWN ALIAS ' ecopath\%consumer_groups $(\mathrm{n})$ \%icm_name_alias $=$ ecopath\%consumer_groups $(n)$ \% fraction $=0.0$ ecopathoconsumer_groups $(\mathrm{n})$ 응omass $=0.0$ eco-

pathoconsumer_groups $(\mathrm{n}) \stackrel{\circ}{\circ}$ production_biomass_ratio $=0.0$ eco-

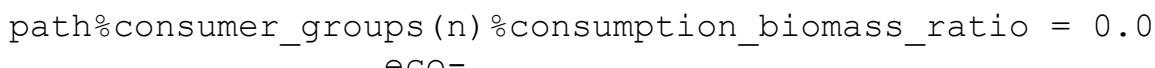
eco-

path\%consumer_groups $(\mathrm{n})$ \%unassimilated_consumption_ratio $=0.0$ trital_fate_type $(0.0,0.0,0.0)$

enddo

Blank line

read(inf, 100) line; write(outf, 100) line !

read(inf, 100) line; write(outf, 100) line !

"CONSUMER names" header

write (outf, 200)

do $n=1$, ecopathonumber_consumer_groups

read(inf, 200) name, alias, fraction;

name, alias, fraction

group $=>$ ecopath\%consumer_groups $(\mathrm{n})$

group $\%$ name $=$ name

group $\%=\mathrm{n} \quad$ ! group id

groupoicm_name_alias = alias

group $\%$ raction = fraction

!write $(*, *)$ name 
Blank line

enddo

read(inf, 100) line; write(outf, 100) line !

Blank line

! Step 3: Process all DETRITUS

! Read "NUMBER OF DETRITAL GROUPS"

read(inf, 100) line; write(outf, 100) line !

read(inf, 100) line; write(outf, 100) line !

DETRITUS count \& type header

pathodetrital_eco_type

read(inf, 150) ecopathonumber_detrital_groups, eco-

writeloutf, 150) ecopathonumber_detrital_groups, ecopathodetrital_eco_type

allo-

cate (ecopathodetrital_groups (ecopath\%number_detrital_groups))

do $n=1$, ecopath\%number_detrital_groups ecopathodetrital groups $(n) \bar{\circ} \frac{\bar{o}}{\mathrm{n}}=-1$ ecopathodetrital_groups $(n)$ \%name = 'UNKNOWN'

' UNKNOWN ALIAS ' ecopathodetrital_groups $(n)$ \%icm_name_alias $=$

ecopathodetrital_groups $(\mathrm{n}) \%$ fraction $=0.0$ ecopath\%detrital_groups $(n)$ \%biomass $=0.0$ eco-

path\%detrital_groups (n) \%production_biomass_ratio $=0.0$ eco-

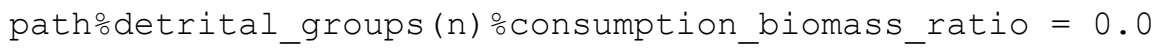
eco-

pathodetrital_groups (n) \%unassimilated_consumption_ratio $=0.0$ trital_fate_type $(0.0,0.0,0.0)$ ecopathodetrital_groups $(n)$ odetrítal_fate $=$ deenddo

Blank line read(inf, 100) line; write(outf, 100) line ! read(inf, 100) line; write(outf, 100) line ! "DETRITUS names" header

do $n=1$, ecopathonumber_detrital_groups read(inf, 200) name, alias, fraction; write(outf, 200) name, alias, fraction 


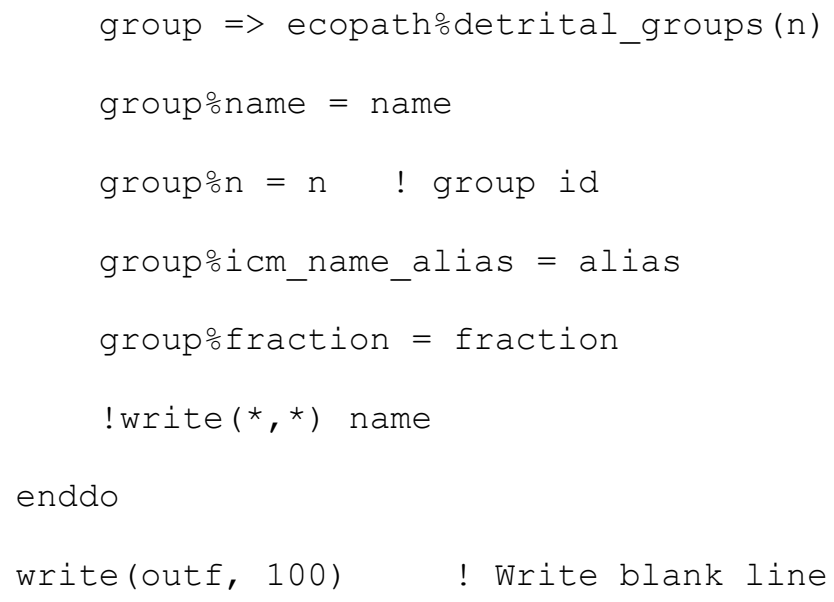


!close (outf);

close (inf);

P R E Y

! L A S T

S T E P

T A B L E

! Build predator-prey table. (Need an array of char variables containing group name)

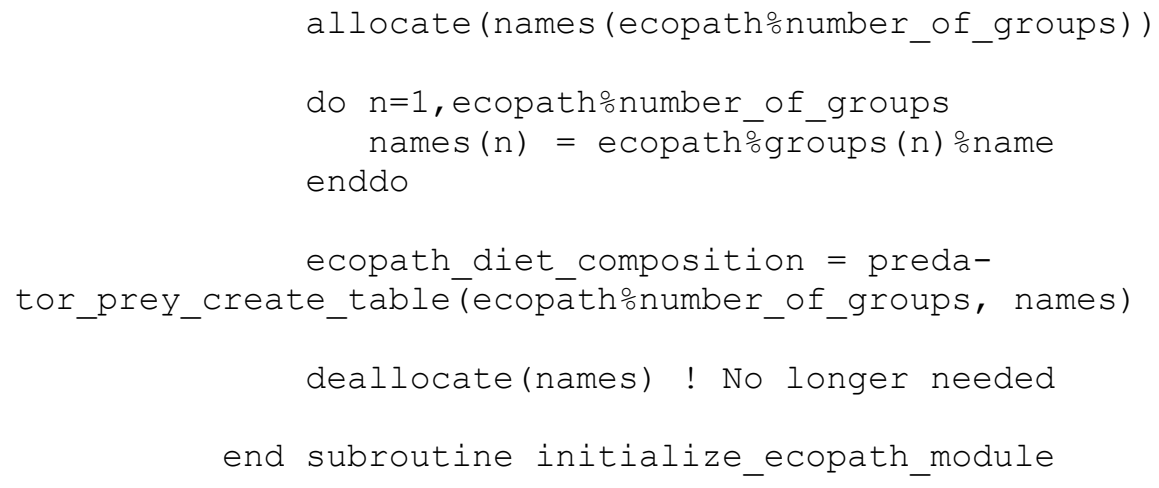




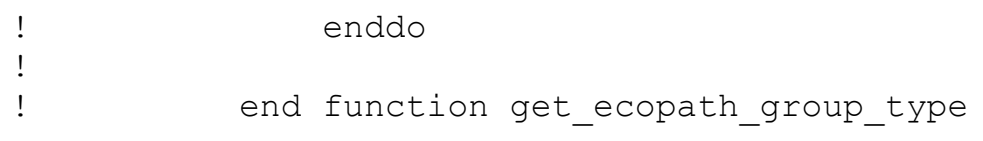

end module ecopath_module

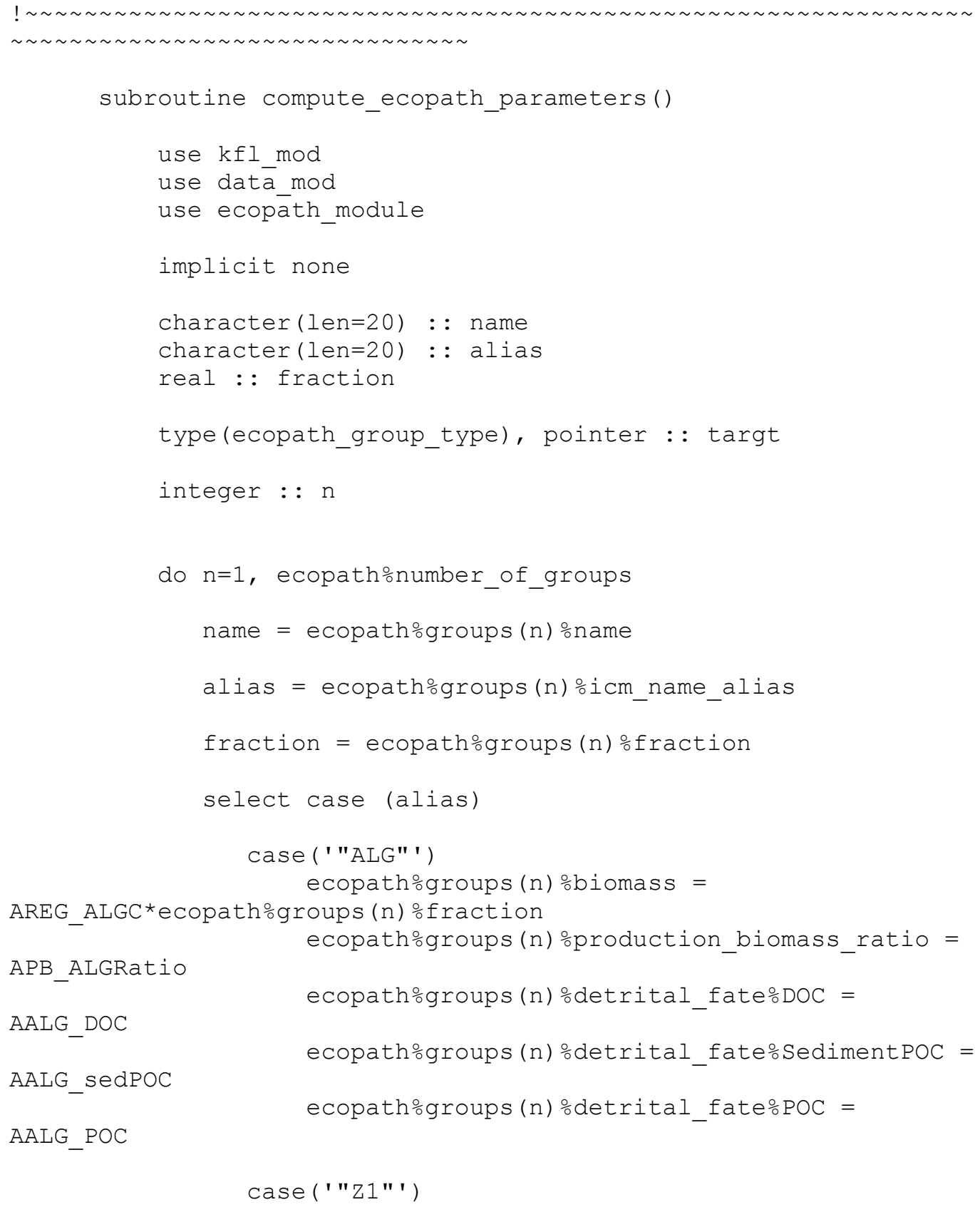




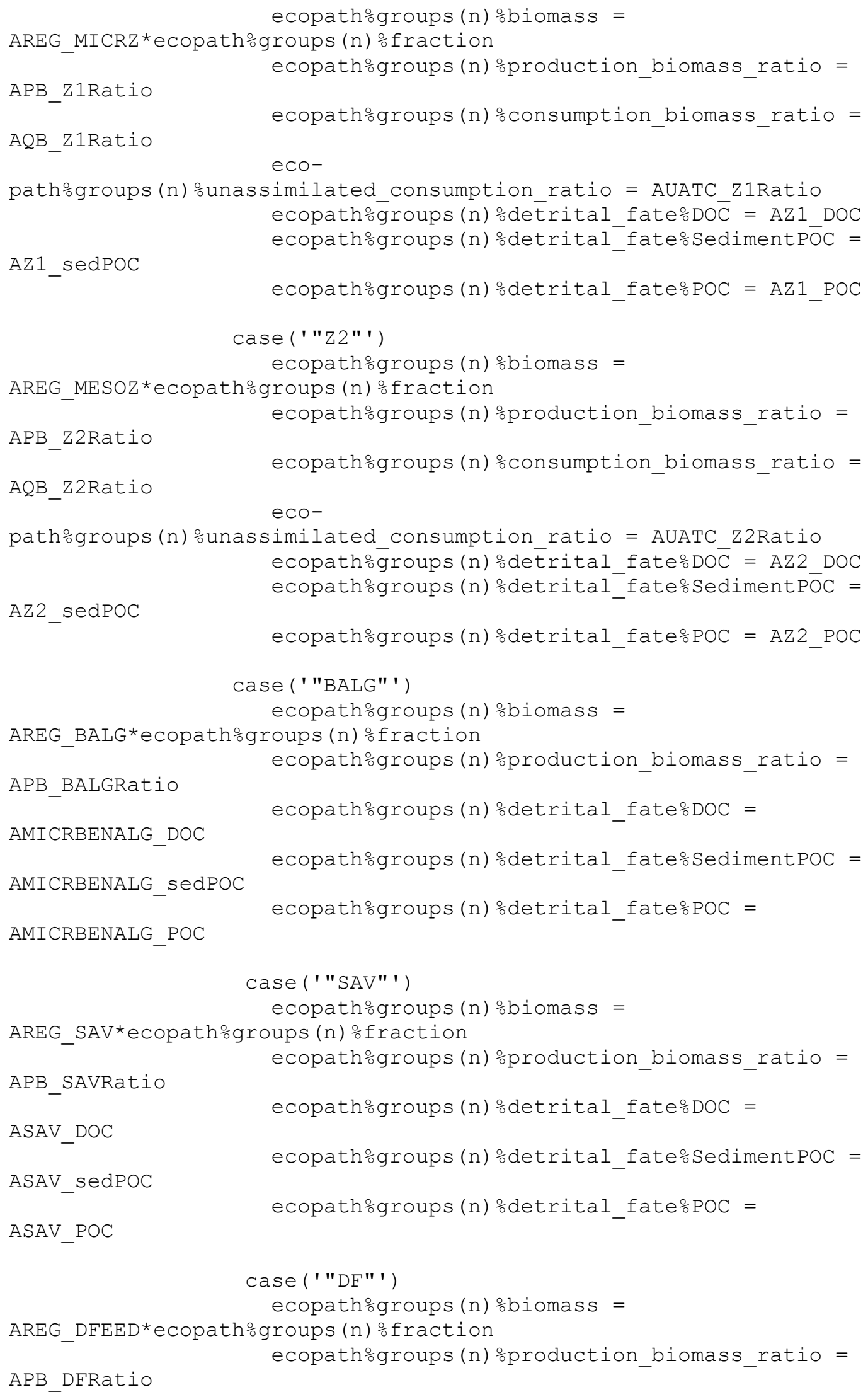




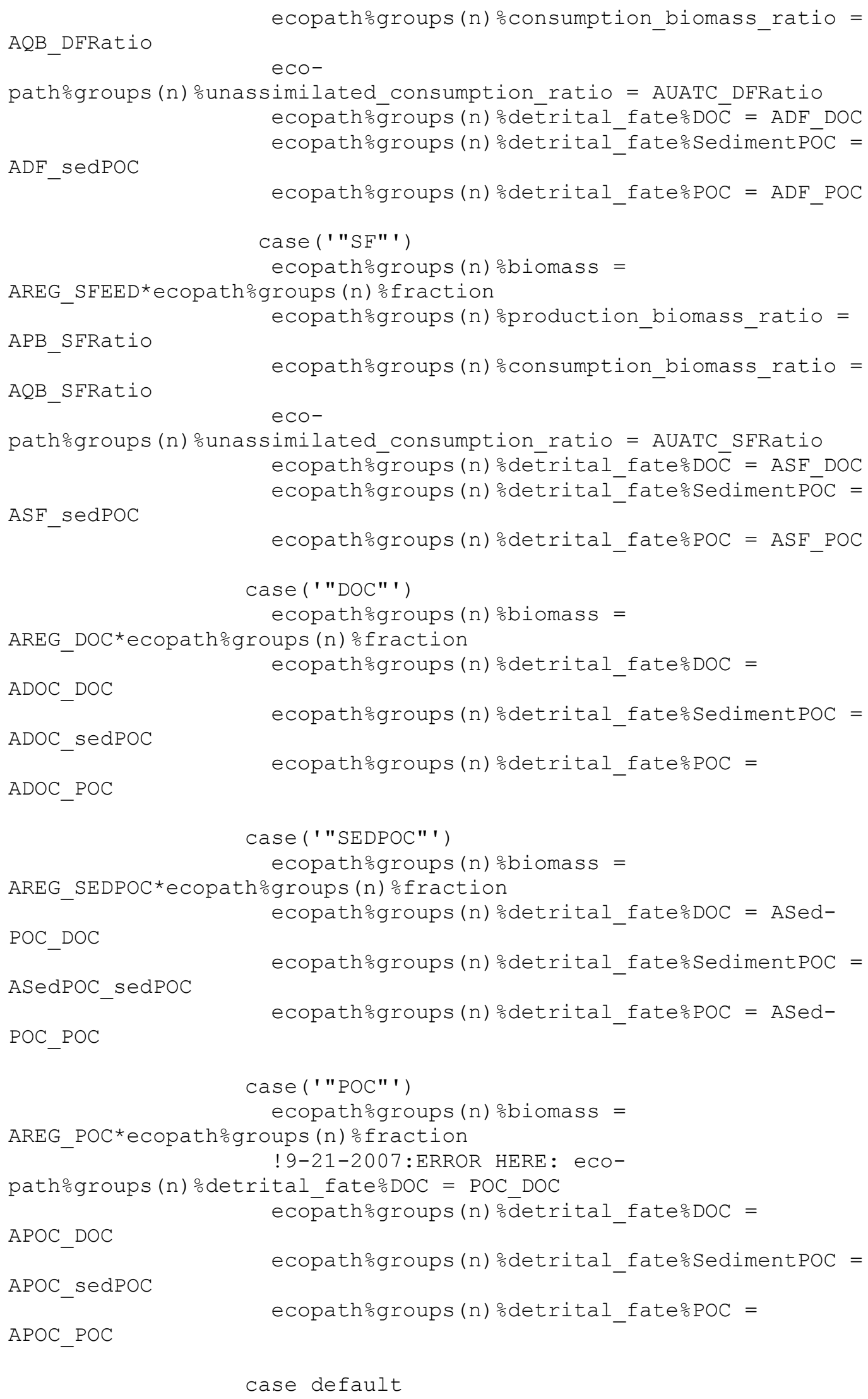




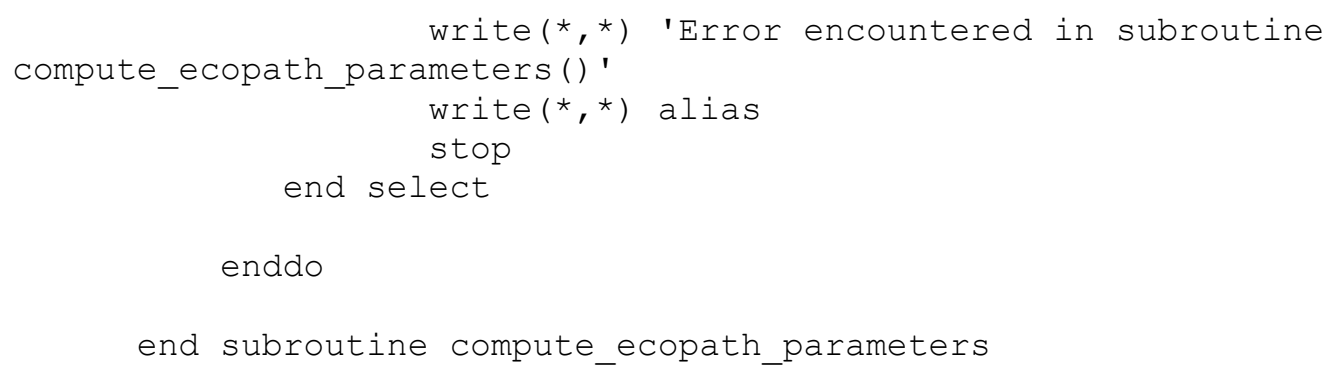




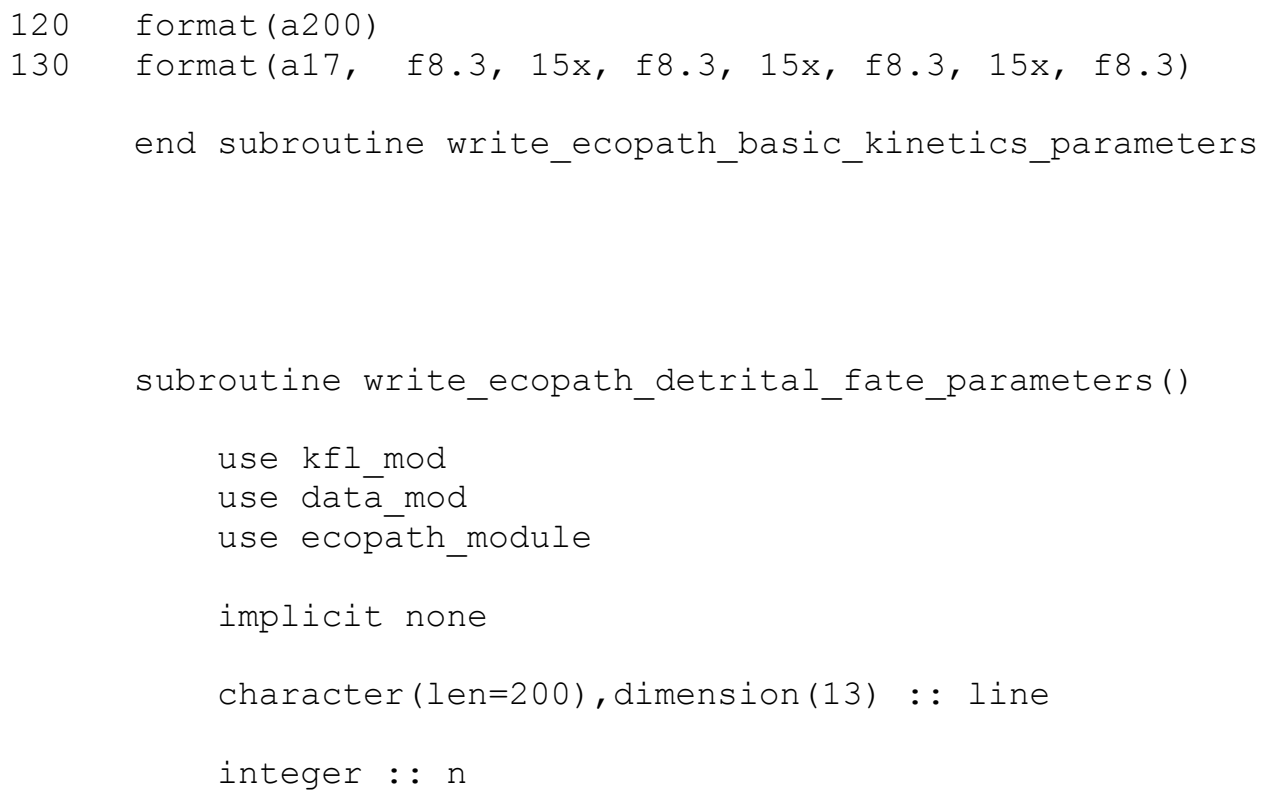




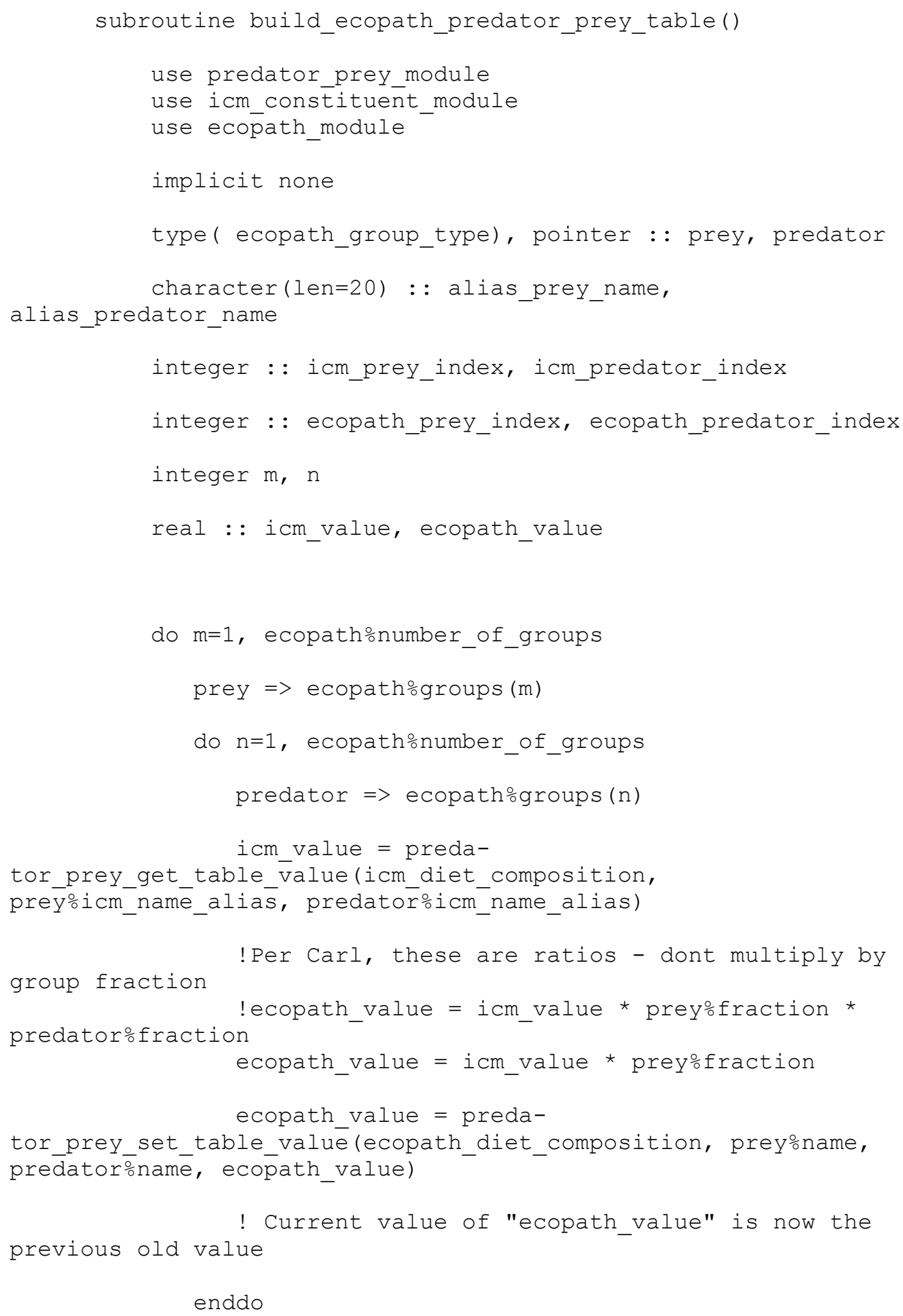




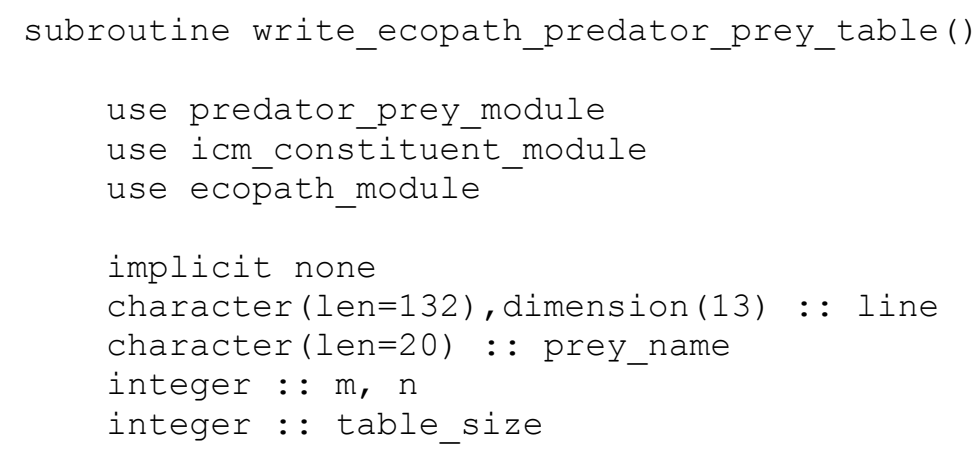




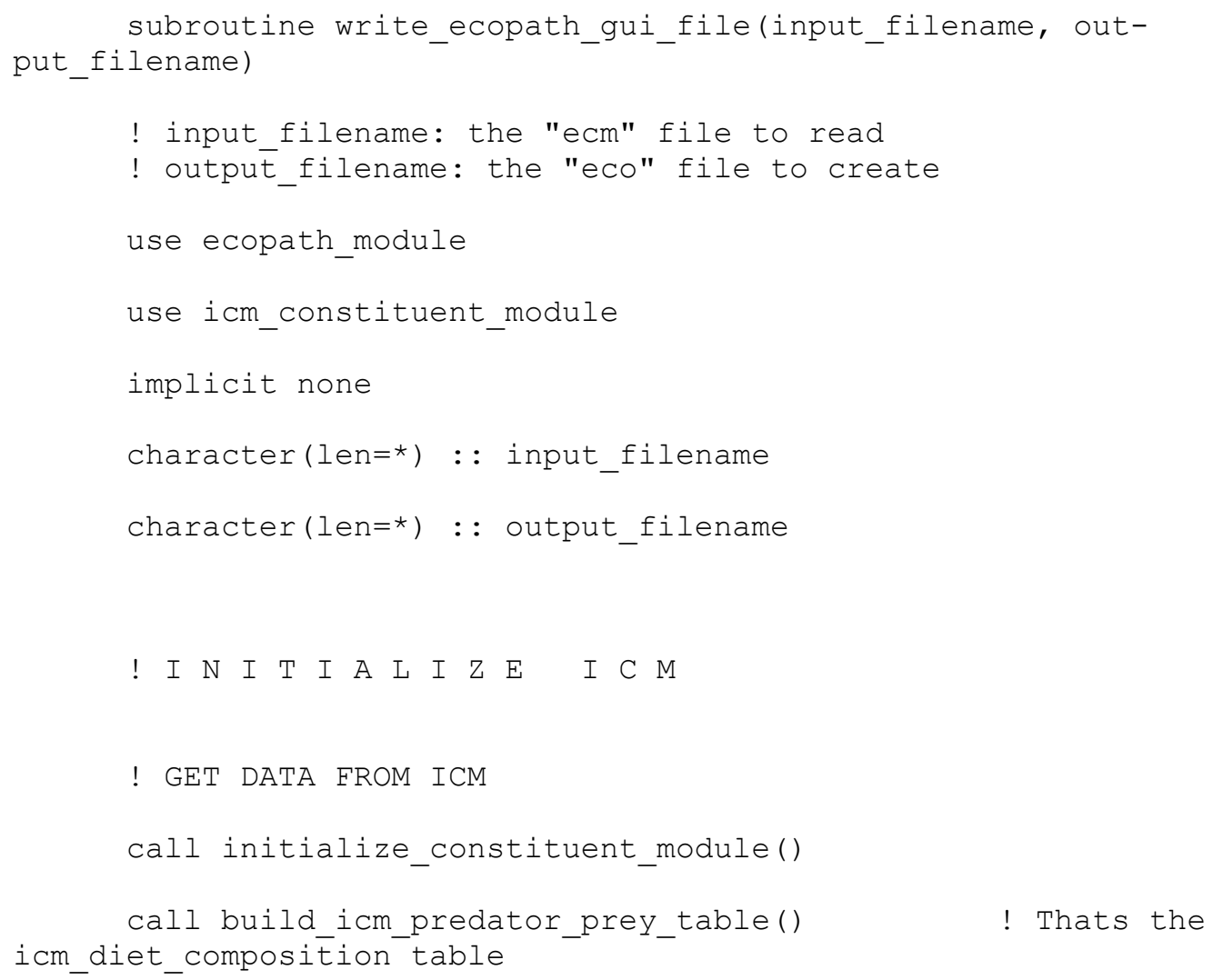




\section{Appendix E: Module File for 4000-Cell KFL Postprocessor}

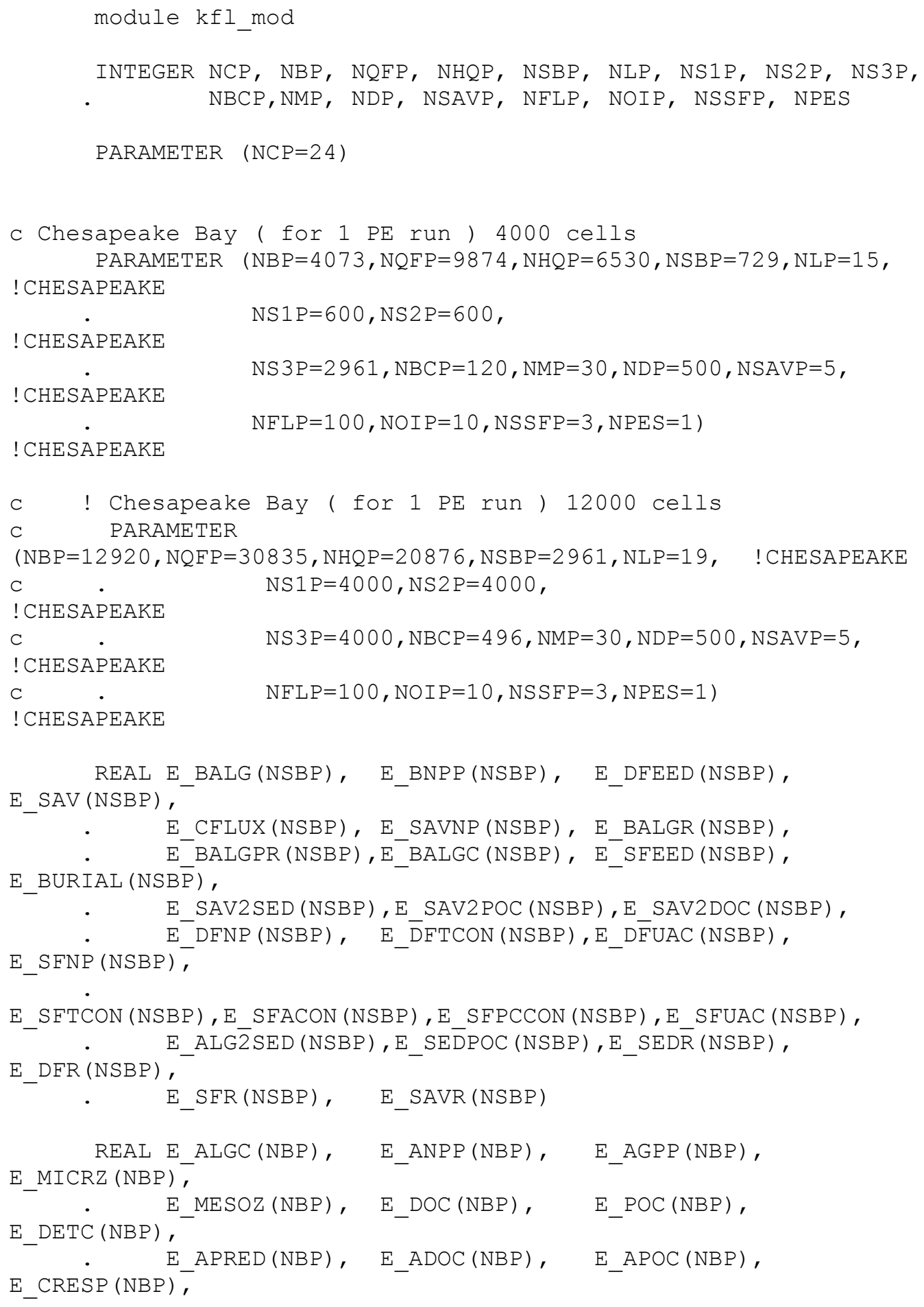




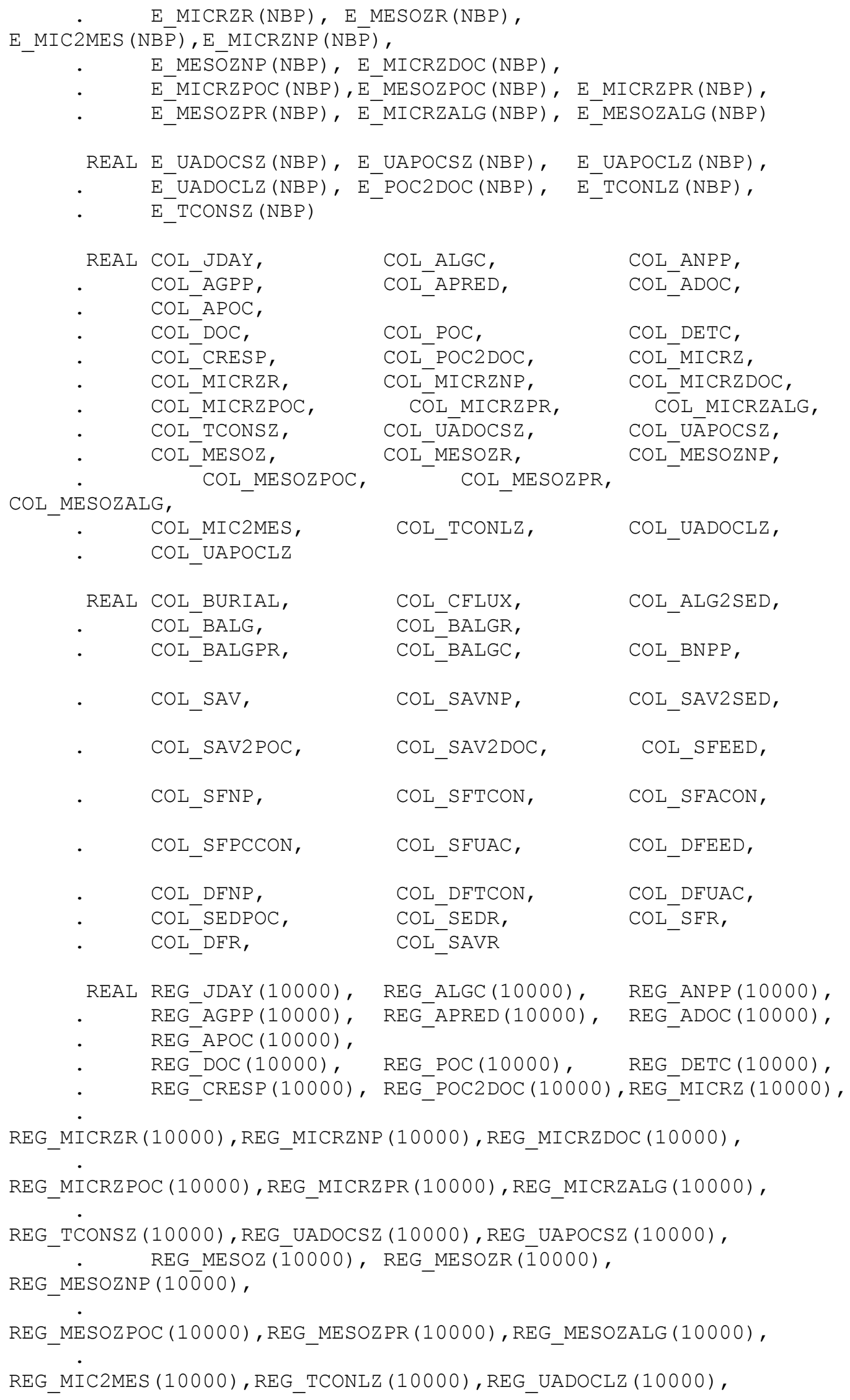




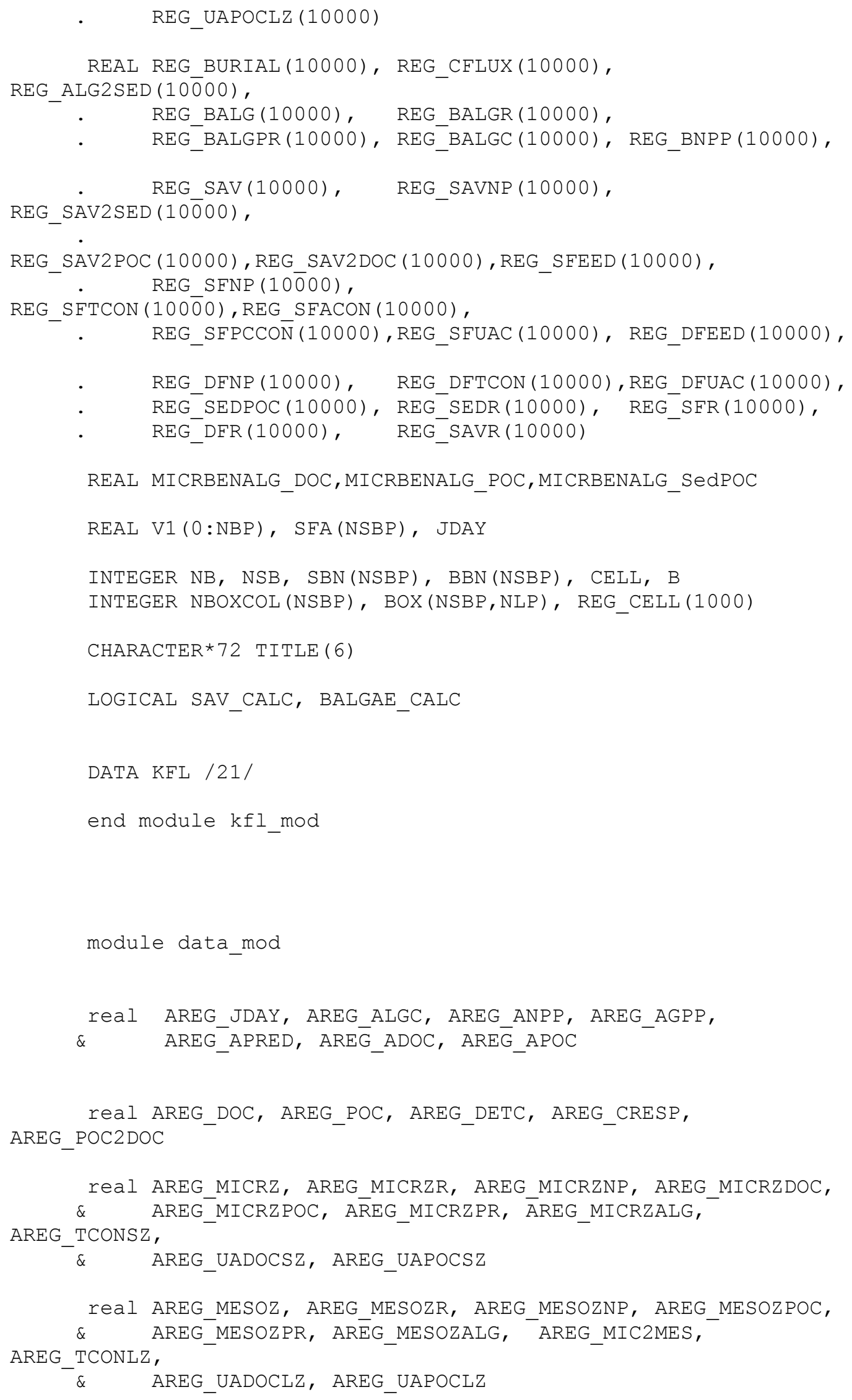




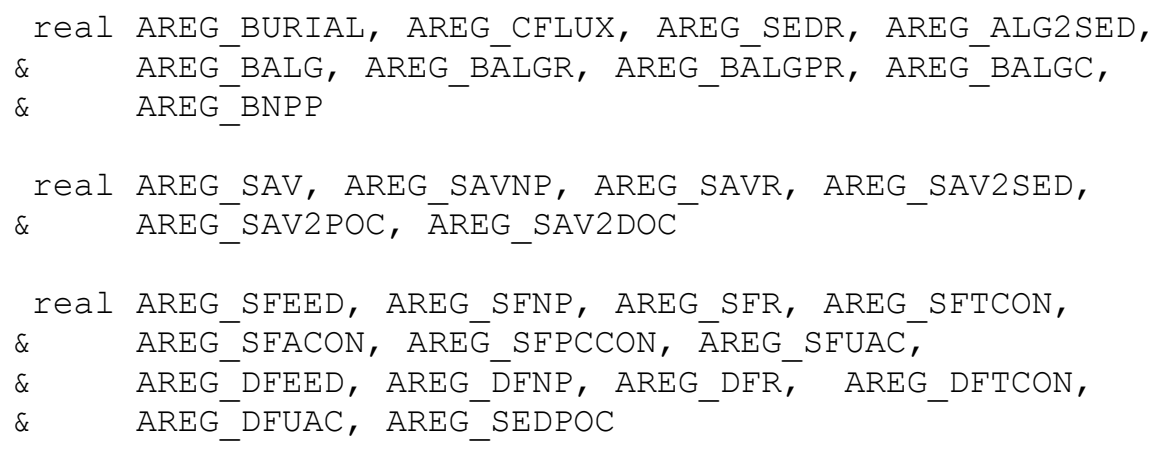




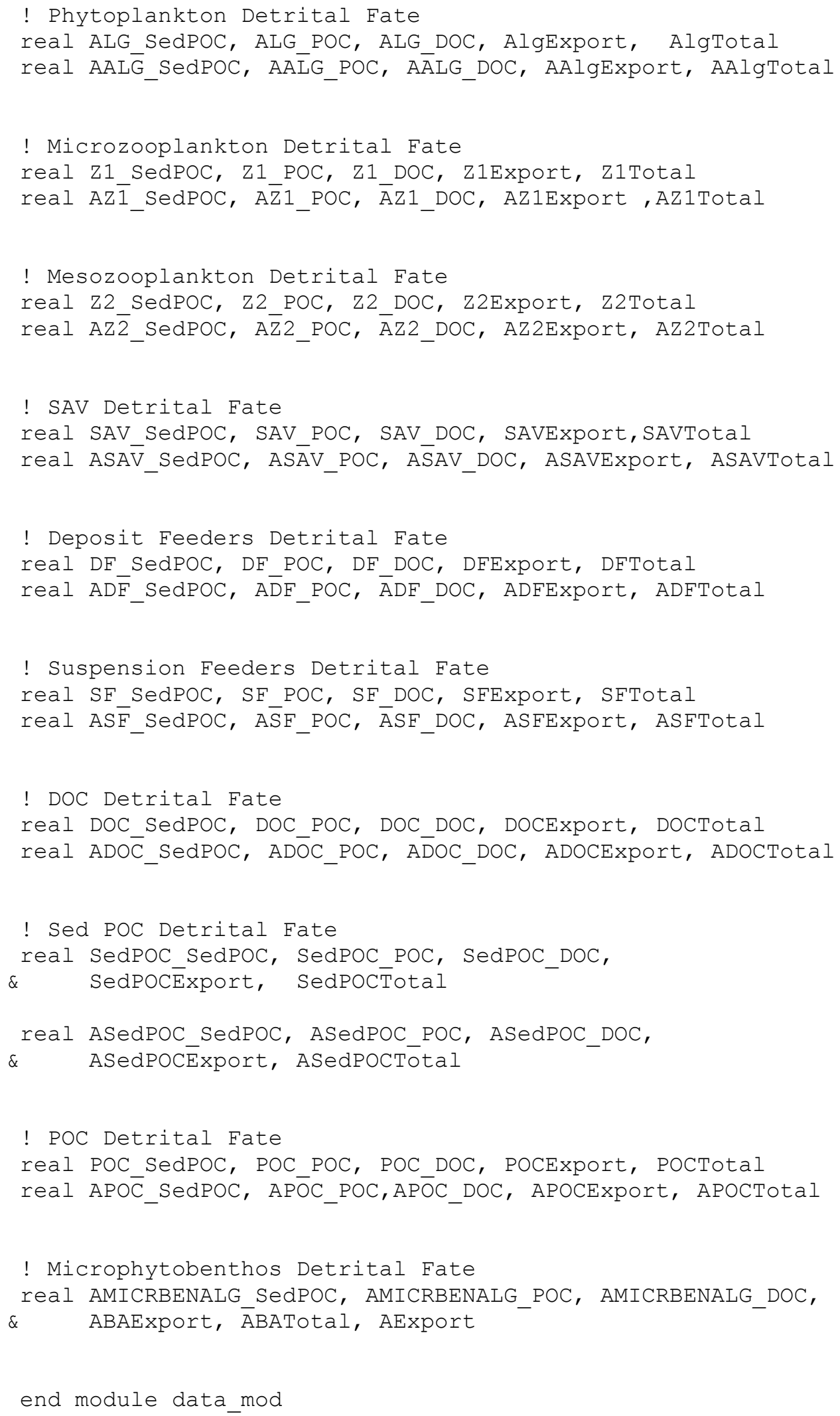




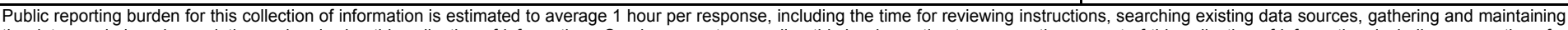

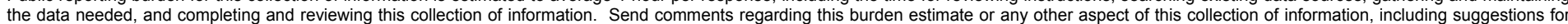

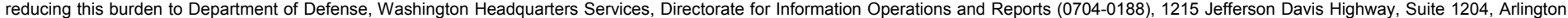

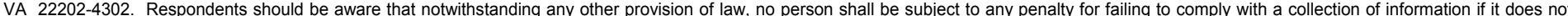
display a currently valid OMB control number. PLEASE DO NOT RETURN YOUR FORM TO THE ABOVE ADDRESS.

\begin{tabular}{l|l|l}
\hline 1. REPORT DATE (DD-MM-YYYY) & 2. REPORT TYPE & 3. DATES COVERED (FrOm - To)
\end{tabular}

August 2009

Final report

\section{TITLE AND SUBTITLE}

User's Guide to Linking the CE-QUAL-ICM and Ecopath Models

5a. CONTRACT NUMBER

User's Guide to Linking the CE-QUAL-ICM and Ecopath Models

5b. GRANT NUMBER

5c. PROGRAM ELEMENT NUMBER

6. AUTHOR(S)

Carl F. Cerco, Dorothy H. Tillman, and Terry K. Gerald

5d. PROJECT NUMBER

5e. TASK NUMBER

5f. WORK UNIT NUMBER

7. PERFORMING ORGANIZATION NAME(S) AND ADDRESS(ES)

8. PERFORMING ORGANIZATION REPORT NUMBER

U.S. Army Engineer Research and Development Center

ERDC/EL SR-09-1

Environmental Laboratory

3909 Halls Ferry Road

Vicksburg, MS 39180-6199

9. SPONSORING / MONITORING AGENCY NAME(S) AND ADDRESS(ES)

10. SPONSOR/MONITOR'S ACRONYM(S)

U.S. Army Corps of Engineers

Washington, DC 20314-1000

11. SPONSOR/MONITOR'S REPORT NUMBER(S)

\section{DISTRIBUTION / AVAILABILITY STATEMENT}

Approved for public release; distribution is unlimited.

\section{SUPPLEMENTARY NOTES}

\section{ABSTRACT}

The present report is one of a series that documents research relating the coupling of spatially and temporally detailed eutrophication models with ecosystem models that lack spatial and temporal resolution. Specifically, the Corps of Engineers Integrated Compartment Water Quality Model (CE-QUAL-ICM) is coupled to the Ecopath with Ecosim (EWE) fisheries model. Previous reports in this series introduced the concepts necessary for communication between the two models and detailed the linkage. The previous linkage relied on a "human interface" between the two models. That is, information from CE-QUAL-ICM was printed and entered into the EWE input screen by hand. This process has been replaced by a graphical user interface (GUI), which is documented herein.

\section{SUBJECT TERMS}

CE-QUAL-ICM

Chesapeake Bay

16. SECURITY CLASSIFICATION OF:

\begin{tabular}{|l|l|l|}
\hline $\begin{array}{l}\text { a. REPORT } \\
\text { UNCLASSIFIED }\end{array}$ & $\begin{array}{c}\text { b. ABSTRACT } \\
\text { UNCLASSIFIED }\end{array}$ & $\begin{array}{c}\text { c. THIS PAGE } \\
\text { UNCLASSIFIED }\end{array}$ \\
\hline
\end{tabular}

Ecosystem models Eutrophication models

17. LIMITATION
OF ABSTRACT

EWE fisheries model

\begin{tabular}{c|l|}
$\begin{array}{l}\text { 18. NUMBER } \\
\text { OF PAGES }\end{array}$ & $\begin{array}{l}\text { 19a. NAME OF RESPONSIBLE } \\
\text { PERSON }\end{array}$ \\
\cline { 2 - 2 } 73 & $\begin{array}{l}\text { 19b. TELEPHONE NUMBER (include } \\
\text { area code) }\end{array}$ \\
\hline
\end{tabular}

